\title{
Auditory evoked potential audiometry in fish
}

\author{
Friedrich Ladich • Richard R. Fay
}

Received: 8 September 2012/ Accepted: 8 December 2012/Published online: 18 January 2013

(C) The Author(s) 2013. This article is published with open access at Springerlink.com

\begin{abstract}
A recent survey lists more than 100 papers utilizing the auditory evoked potential (AEP) recording technique for studying hearing in fishes. More than $95 \%$ of these AEP-studies were published after Kenyon et al. introduced a non-invasive electrophysiological approach in 1998 allowing rapid evaluation of hearing and repeated testing of animals. First, our review compares AEP hearing thresholds to behaviorally gained thresholds. Second, baseline hearing abilities are described and compared in 111 fish species out of 51 families. Following this, studies investigating the functional significance of various accessory hearing structures (Weberian ossicles, swim bladder, otic bladders) by eliminating these morphological structures in various ways are dealt with. Furthermore, studies on the ontogenetic development of hearing are summarized. The AEP-technique was frequently used to study the effects of high sound/ noise levels on hearing in particular by measuring the temporary threshold shifts after exposure to various noise types (white noise, pure tones and anthropogenic
\end{abstract}

F. Ladich $(\bowtie)$

Department of Behavioural Biology, University of

Vienna, Althanstrasse 14, 1090 Vienna, Austria

e-mail: friedrich.ladich@univie.ac.at

R. R. Fay

Marine Laboratory, Woods Hole, MA 02543, USA

R. R. Fay

179 Woods Hole Rd., Falmouth, MA 02540, USA noises). In addition, the hearing thresholds were determined in the presence of noise (white, ambient, ship noise) in several studies, a phenomenon termed masking. Various ecological (e.g., temperature, cave dwelling), genetic (e.g., albinism), methodical (e.g., ototoxic drugs, threshold criteria, speaker choice) and behavioral (e.g., dominance, reproductive status) factors potentially influencing hearing were investigated. Finally, the technique was successfully utilized to study acoustic communication by comparing hearing curves with sound spectra either under quiet conditions or in the presence of noise, by analyzing the temporal resolution ability of the auditory system and the detection of temporal, spectral and amplitude characteristics of conspecific vocalizations.

Keywords AEP · Hearing - Sound pressure level · Particle acceleration levels · Thresholds · Noise . Ontogeny $\cdot$ Communication

\section{Introduction}

In the modern era, interest in the questions of hearing by fishes began in 1903 (Parker 1903) and reached a peak in its first phase with the work of von Frisch (1938) and his students (e.g., von Frisch and Stetter 1932; von Frisch and Dijkgraaf 1935). The interest stemmed primarily from the questions of how the ears of fishes, lacking a basilar membrane, functioned in hearing, sound source localization, and in frequency 
analysis. Interest peaked again in the 1960s and 1970s (e.g., Tavolga and Wodinsky 1963; Enger 1966; Fay 1969; Popper 1970; Chapman and Johnstone 1974; Hawkins and Johnstone 1978). At that time, most investigators used behavior or conditioning techniques combined with psychophysical paradigms as the ideal way to investigate the sense of hearing in animals (reviewed in Fay 1988). In more recent years, behavioral techniques have declined in popularity due, for example, to the time required to determine a complete audiogram, the interest in rapid measures applicable to studies of temporary threshold shift, and in longitudinal studies on development. For these and other reasons, electrophysiological methods have become more popular than behavioral studies.

Invasive electrophysiological methods have included recording of auditory end organs (microphonic potentials), eighth nerve fibers, and neurons within the auditory brainstem and higher centers in auditory pathway (e.g., Furukawa and Ishii 1967; Fay and Popper 1974; Sand 1974; Fay and Ream 1986; Edds-Walton and Fay 2009). Invasive surgery generally precludes using an individual animal repeatedly. Non-invasive recordings of auditory evoked potentials [auditory evoked potentials (AEP) or auditory brainstem response (ABR)] in fish were first suggested by Bullock (1981) and Corwin (1981). Corwin et al. (1982) showed in two elasmobranchs and several bony fishes that AEPs can be recorded using cutaneous electrodes non-invasively attached to the head. In 1998 Kenyon et al. described a technical approach which allowed the measurement of complete audiograms within a short time period $(4 \mathrm{~h})$ based on the recording of AEPs from the skull surface. They demonstrated that the AEP-technique resulted in audiograms similar in shape to audiograms gained by behavioral methods in the goldfish Carassius auratus and the oscar Astronotus ocellatus.

Approximately 100 papers on more than 100 species have been published using the method inspired by Kenyon et al. (1998) on AEP. These papers range in focus from simple descriptions of auditory response to studies investigating the development of hearing, effects of noise on hearing, and the determination of peripheral sound conduction pathways and other fundamental hearing mechanisms in fishes. There is considerable diversity in auditory structures and functions among the more than 30,000 extant fish species. The new literature on AEP in fishes has helped to reveal some of the dimensions of this diversity by greatly expanding the number of species investigated.

The aim of our review is to present and compare results of these many recent experiments, and to help evaluate the use of AEP techniques to investigate auditory function in fishes.

\section{Behavioral and electrophysiological measures of hearing function}

Hearing is generally defined as the act of perceiving sound, a sensory function that involves the entire organism's behavior. This behavioral "act of perceiving" can only be measured using behavioral methods. We believe that behavioral studies of hearing have a face validity that AEP measures lack and that AEP audiograms, while popular and increasingly used, require comparison with behavioral audiograms wherever possible to help establish their validity as a possible description of a species characteristic (see "Behavioral and AEP thresholds in the goldfish Carassius auratus, Behavioral and AEP thresholds for other fish species" sections). Although behavioral and AEP audiograms are independent measures of auditory thresholds, we compare here the two measures to investigate the hypothesis that behavioral thresholds can be estimated from AEP measures.

Various behavioral techniques have been used in conjunction with psychophysical methods, including classical (Pavlovian) conditioning (e.g., Fay and MacKinnon 1969), operant conditioning (e.g., Yan and Popper 1991), and instrumental avoidance conditioning (e.g., Tavolga and Wodinsky 1963).

Electrophysiological measurements in hearing focus on a subset (sensory and neural) of the many functional elements that normally determine behavior, and as such comprise an incomplete description of hearing. But how "incomplete" is the definition of hearing using these methods? What can we know about hearing, and what can't we know using electrophysiological methods? It is certain that a physiological response is not equivalent to "an act of perceiving" sound. However, it seems likely that a physiological response from the auditory brainstem or whole auditory pathway (inner ear up to the midbrain or forebrain) could stand in for, or predict, hearing under some circumstances, such measuring the Auditory Brainstem Response (ABR) in the screening for 
brainstem abnormalities and consequent hearing impairment in newborn infants (Starr et al. 1977).

There are two fundamental aspects of the description of an organism's hearing capacities: the detectable range of frequencies (bandwidth), and absolute sensitivity (the lowest detectable stimulus level). We assume that electrophysiological methods can be used to reasonably estimate the frequency range of hearing (what sound frequencies produce detectable responses?). This is based on our belief that significant responses from some early elements of the auditory nervous system strongly imply that they could be used by the brain to signal the presence of a sound and produce a hearing sensation. This is not certain, but it is reasonable to believe.

The question of sensitivity, or the meanings of behavioral hearing thresholds versus those of electrophysiological thresholds, is much more problematic. Both behavioral and electrophysiological thresholds are properly defined statistically in terms of probabilities. However, there is no present theory of how these two very different types of thresholds relate to one another. Psychophysical thresholds have been studied for over 100 years, and the various complex factors that determine the statistical nature of the thresholds are relatively well understood (e.g., Green and Swets 1966). Electrophysiological thresholds have often been defined as a voltage response that is discernable with respect to the various sources of noise in the voltage waveform or spectrum, primarily by visual inspection. These measures can be objective and quantitative in every sense, but it is unknown (and perhaps unknowable) what the analytic relationship is between a given voltage recorded from the brainstem and a behavioral detection threshold. Therefore, the correspondence or correlation between these two independent quantities is the only means by which the electrophysiological thresholds can be evaluated as estimates of hearing thresholds measured behaviorally. One major purpose of this review is to determine what these correspondences (and variabilities) are, when both measures are available for a given species. However, we are well aware that this relationship may be species specific and dependent on many factors such as electrical and acoustic noise levels, electrode locations on the skull, and the acoustic characteristics of the test environment.

While electrophysiological and psychophysical thresholds are independent measures of auditory thresholds or auditory response, non-invasive electrophysiological measures have utility, both in within-species or individuals and in between-species investigations of hearing function. They are far more rapid and easier to accomplish compared with behavioral measures, and yet make sequential measurements on then same individuals possible. So, for example, they are ideal for use in experiments involving surgical manipulations of accessory hearing structures (e.g., swim bladders, Weberian ossicles), or in longitudinal studies of hearing development where the equality of behavioral and electrophysiological thresholds need not be assumed. In a limited way, they are also useful for between-species comparisons of sound thresholds and relative descriptions of the frequency range of auditory response (i.e., that one species has a wider hearing bandwidth or different best frequency of response than another). For these and other reasons, AEP audiometry in fishes has been popular in the literature since 1998, and has lead to renewed interest in the questions of hearing by fishes. As long as it is recognized that electrophysiological and behavioral methods do not necessarily lead to the same results, and that they are not ultimately equivalent or interchangeable descriptions of the auditory response, AEP studies on fishes should continue to grow in popularity and continue to answer fundamental questions about hearing in fishes. One of the goals of this review is to illustrate and evaluate how the AEP studies since 1998 have contributed to this rapidly growing field.

In summarizing this field of research, we note that it is presently controversial whether fishes having swim bladders without an obvious connection between the swim bladder and ears (otophysic connections) detect sound pressure or can only respond to acoustic particle motion. In most cases, critical experiments to confirm pressure sensitivity have not been done in fishes without special otophysic adaptations, and it is a matter of opinion whether or not the mere presence of a swim bladder confers sound pressure sensitivity (see Popper and Fay 2011). The Atlantic cod Gadus morhua (Chapman and Hawkins 1973) and the European eel Anguilla anguilla (Jerko et al. 1989) have been shown to be sound pressure sensitive at frequencies above about $100 \mathrm{~Hz}$, but an otophysic connection has not been observed in these species. The Atlantic salmon Salmo salar (Hawkins and Johnstone 1978) and the dusky damselfish Stegastes adustus (formerly Eupomacentrus dorsopunicans) (Myrberg and Spires 1980) 
have been shown to be pressure-sensitive at the higher frequencies, but sensitive to particle acceleration at the lowest frequencies. The majority of species, however, have not been analyzed in this respect. For most species, other than the otophysi and others having a confirmed otophysic connection, auditory thresholds should be measured in terms of particle motion (either displacement, velocity, or acceleration) and sound pressure in order to help determine what acoustic quantity is most appropriate.

In typical experimental lab tanks, the ratio between sound pressure and particle motion amplitudes (impedance) is likely to be different from normal habitats (particle motion will be higher than in the species' normal habitat). Because the relationship between sound pressure and particle motion in typical test tanks cannot be predicted in most cases sound pressure and particle acceleration levels should be measured at the same time. It is possible and likely that many unspecialized fishes detect particle acceleration in their natural habitat, not sound pressure, and audiometric data measured in sound pressure terms may not be appropriate.

Behavioral and AEP thresholds in the goldfish

\section{Carassius auratus}

Among the more than 30,000 extant fish species, the goldfish has become by far the most popular species for studying hearing physiology. The goldfish adapts easily to various holding conditions and is therefore chosen very often by physiologists. It belongs to the otophysines a series of primarily freshwater fishes comprising the orders Cypriniformes (carps and minnows), Siluriformes (catfishes), Characiformes (characins) and Gymnotiformes (South American knifefishes) which possesses well developed hearing and sensitivity to sound pressure due to their Weberian apparatus that mechanically connects the swim bladder and inner ears (e.g., Weber 1820; Popper and Fay 1973, 1993).

In this paper, we first compare hearing curves gained using behavioral techniques and electrophysiological techniques separately. Secondly, we compare the results of both techniques. This should help to determine if and to what degree audiograms differ using both approaches. Possibly, some 'factor' might be identified which would help to predict behavioral hearing thresholds (and bandwidths) from electrophysiological thresholds. Comparisons among other species (see below) for which these data exist could tell us whether or not this hypothetical 'factor' is universal among fish, or is species-specific. The baseline hearing abilities of goldfish have been investigated by numerous investigators applying different behavioral (Enger 1966; Fay 1969; Jacobs and Tavolga 1967; Offutt 1968; Popper 1971; Weiss 1966) or electrophysiological (e.g., Amoser and Ladich 2003; Cordova and Braun 2007) techniques in different labs.

The behavioral audiograms in Fig. 1a are quite diverse in threshold and bandwidth. Thresholds differ by as much as $60 \mathrm{~dB}$ at some frequencies. Best frequency of hearing is between 0.35 and $1.5 \mathrm{kHz}$, and thresholds at the best frequency varies between 52 and $80 \mathrm{~dB}$ re: $1 \mu \mathrm{Pa}$. The conditioning and acoustic methods employed in these studies are also very diverse. Weiss (1966) used instrumental avoidance conditioning with two opposing sound projectors (Navy, J9) operating into a small plexiglas tank operating in a push-pull manner. This was done to create "a uniform sound field" and is unusual among all other studies on goldfish. It was criticised by Harris (comment in Weiss 1967) as possibly producing an "almost perfect near field." Enger (1966) used "conditioned snapping for food" with an open top trough as a tank with a loudspeaker in air and a Navy J9 projector underwater, and got two different audiograms that only significantly differed from one another below about $1 \mathrm{kHz}$. Both Enger and Weiss believed that the lateral line system determined thresholds at the lower frequencies (below $200 \mathrm{~Hz}$ for Weiss 1966 and below $1 \mathrm{kHz}$ for Enger 1966). Fay (1969) used classical respiratory conditioning with a loudspeaker in air operating into a cylindrical water tank through a closed air cavity above the water tank. Popper (1971) and Jacobs and Tavolga (1967) used instrumental avoidance conditioning with a loudspeaker in air, and Offutt (1968) used classical heart-rate conditioning with a Navy J9 projector. The various experiments on goldfish were all done at nominal "room temperature." They may have used different strains of goldfish, but this was not noted or known by the investigators other than that Enger obtained goldfish in Norway and all the rest obtained them in the USA. Every study attempted to reduce ambient noise, but only in some cases were they reported. All studies used similar psychophysical methods (method of limits, and the staircase procedure). Therefore, the methodologies 
used in these studies varied considerably, but there is no particular correlation between the methods used and the resulting audiograms that we can make sense of, and thus no justifiable rationale for deciding which audiogram may be more valid.

The many AEP audiograms (Fig. 1b) are generally comparable in bandwidth and sensitivity with the behavioral audiograms but show somewhat less variation. The methods employed for the AEP audiograms are similarly diverse. Investigators used different speakers (air speakers above or beside subjects, vs. underwater speakers below or in front of subjects),
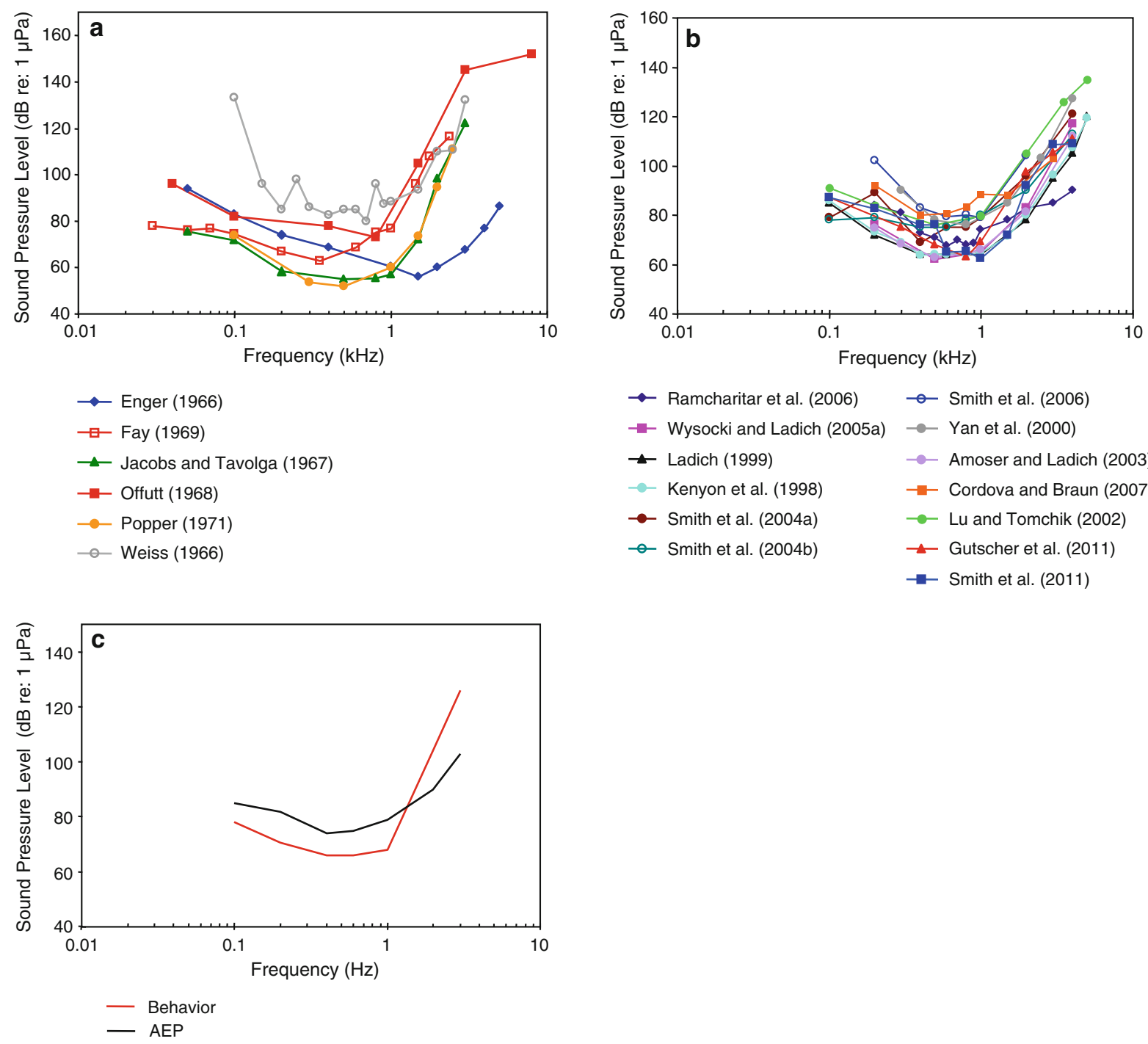

fish positions (immediately below the water surface vs. $5-30 \mathrm{~cm}$ below the surface), different water temperatures, fish sizes, degrees of immobilization, different threshold criteria (visual comparison of AEP waveforms, waveform correlation coefficients, analysis of AEP spectra), different stimuli, different numbers of responses averaged (200-2,000), and perhaps different background noise levels. Best frequency varies from 0.3 to $0.8 \mathrm{kHz}$, and thresholds at best frequency vary between 63 and $84 \mathrm{~dB}$.

The medians of all behavioral and all AEP data sets were calculated and shown in Fig. 1c. They reveal that

Fig. 1 Comparisons of behavioral a and AEP $\mathbf{b}$ audiograms for goldfish (Carassius auratus). c Summaries derived from the median values of both behavioral and AEP data sets 
median AEP thresholds are about $10 \mathrm{~dB}$ above behavioral thresholds up to $1 \mathrm{kHz}$, but are generally lower than behavioral thresholds above this frequency. This effect can partly be explained by the fact that it is difficult with the AEP technique to create short tone bursts at lower frequencies with good precision in the frequency domain. Short tone bursts with a greater rapidity of onset results in a greater efficacy at generating AEPs at higher frequencies (Silman and Silverman 1991; Kenyon et al. 1998).

It is also important to note that the signals used in AEP studies are short (about $20 \mathrm{~ms}$ in duration) while many of the behavioral studies used long duration signals (several seconds). Detection thresholds in behavioural studies have been shown to be higher when signal duration decreases in goldfish (Fay and Coombs 1983) and in Atlantic cod (Hawkins 1981), but in a study by Popper (1972a), no effect of signal duration was observed. So, signal duration may have contributed to the $10 \mathrm{~dB}$ differences observed between AEP and behavioral audiograms at frequencies below $1 \mathrm{kHz}$ in goldfish. The lower AEP thresholds at higher frequencies contradict this assumption and cannot be explained by differences in stimuli length but by the greater rapidity of the stimulus onset.

Note that this effect of duration can be explained, at least in part, by central brain processing (Fay 1985) that may not be reflected in AEP measures.

Behavioral and AEP thresholds for other fish species

There are only a few additional species which have been investigated in behavior and electrophysiology, and therefore our comparison is limited. These additional species are the little skate, Raja erinaceus (Casper et al. 2003), the common carp Cyprinus carpio (Popper 1972b; Köhler 1973; Amoser and Ladich 2005; Kojima et al. 2005), the oyster toadfish Opsanus tau (Fish and Offutt 1972; Yan et al. 2000), the European perch Perca fluviatilis (Wolff 1967; Amoser and Ladich 2005), the red sea bream Pagrus major (Kojima et al. 2010) and the oscar (Yan and Popper 1992; Kenyon et al. 1998).

\section{Little skate Raja erinacea}

All elasmobranchs are sensitive to the impinging particle acceleration (and not sound pressure), because

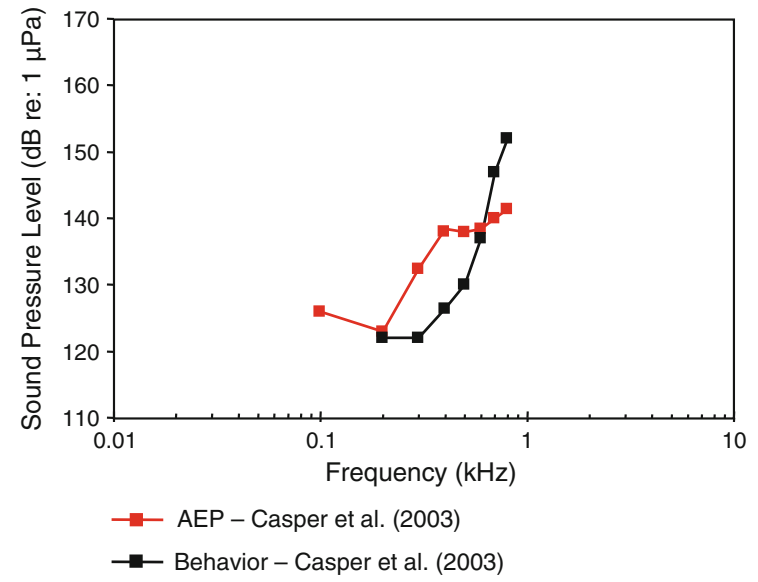

Fig. 2 Audiograms for the little skate Raja erinacea determined behaviorally and using AEP measures. After Casper et al. (2003)

they lack a swim bladder, the structure that gives fish the capacity to detect sound pressure. For the little skate (family Rajidae) the audiograms are roughly similar, but with the AEP audiogram giving higher thresholds below and lower thresholds above $0.6 \mathrm{kHz}$ than the behavioral audiogram (Casper et al. 2003). The skate's frequency of best hearing is between 0.1 (AEP) and $0.2 \mathrm{kHz}$ (behavior) (Fig. 2).

\section{Common carp Cyprinus carpio}

For the common carp (family Cyprinidae), a species closely related to the goldfish, there is comparable variation threshold at best frequency among the behavioral and AEP data (Fig. 3). There is an excellent correspondence between behavioral thresholds of Popper (1972b) and the AEP thresholds of Amoser and Ladich (2005).

The two behavioral threshold estimates differ by as much as $20 \mathrm{~dB}$ at some frequencies, although the frequency of best hearing roughly agrees (between 0.5 and $1 \mathrm{kHz}$ ). The two AEP threshold estimates differ by about $25 \mathrm{~dB}$ at some frequencies, and the frequency of lowest thresholds vary somewhat between 0.5 and $0.8 \mathrm{kHz}$. Thus, for the carp, AEP thresholds by Amoser and Ladich (2005) are reasonable estimates of the behavioral thresholds.

Ideally, for comparative purposes behavioral and AEP-thresholds should be determined under the same acoustical conditions in the same lab. So far this was only done in the investigation by Kojima et al. (2005) in 


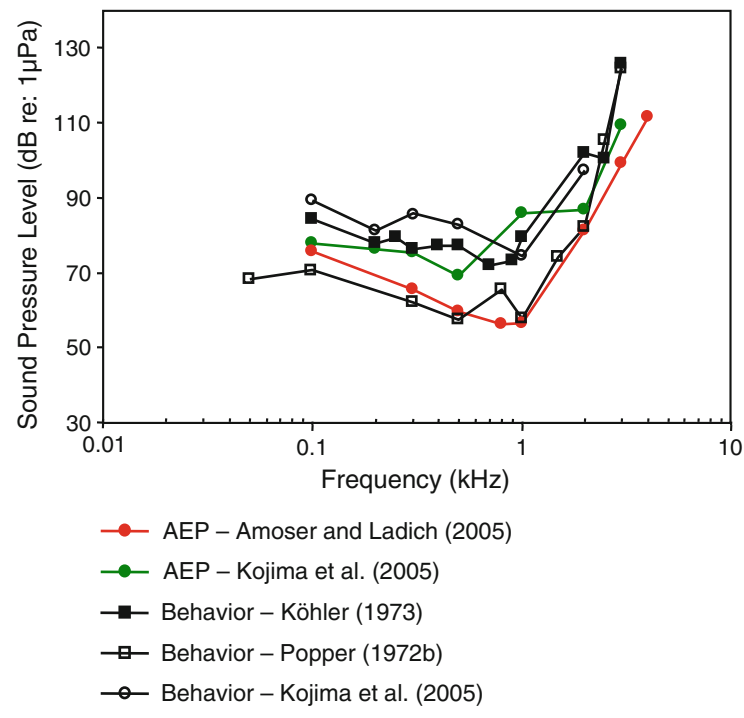

Fig. 3 Behavioral and AEP thresholds for the carp Cyprinus carpio. Köhler (1973) investigated Japanese carps, commonly known as kois. All other studies used common carps. After Köhler (1973), Popper (1972b), Amoser and Ladich (2005) and Kojima et al. (2005)

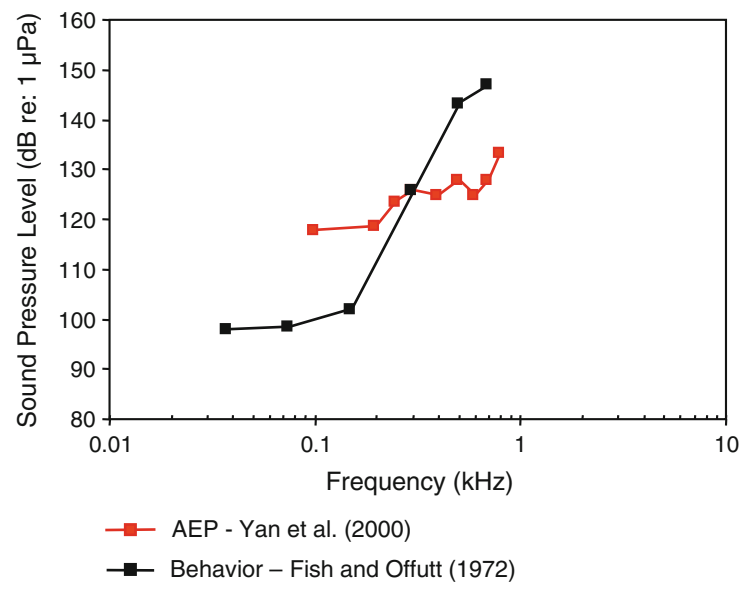

Fig. 4 Behavioral (Fish and Offutt 1972) and AEP (Yan et al. 2000) audiogram for the oyster toadfish Opsanus tau

the carp. They used a heart rate (electrocardiogram, ECG) conditioning procedure including electric shocks to measure behavioral thresholds. In general differences between methodical approaches were small (Fig. 3). Interestingly, Kojima et al. (2005) got lower thresholds when using the AEP-techniques (except at $1 \mathrm{kHz}$ ) as compared to the behavioral (ECG) technique. This is in contrast to the comparison in goldfish using medians of all hearing curves (Fig. 1c).

\section{Oyster toadfish Opsanus tau}

The oyster toadfish (family Batrachoididae) is a popular species for physiological studies, primarily of its directional hearing (e.g., Fay and Edds-Walton 1997). Figure 4 presents the behavioral (Fish and Offutt 1972) and AEP (Yan et al. 2000) audiogram estimates for the oyster toadfish. The correspondence between these curves is only general in that both indicate a very low-frequency response in which thresholds rise above $0.1 \mathrm{kHz}$. The AEP thresholds are about $20 \mathrm{~dB}$ higher at $0.1 \mathrm{kHz}$, but decline only gradually toward $0.8 \mathrm{kHz}$, and are about $15 \mathrm{~dB}$ below the behavioral thresholds at $0.8 \mathrm{kHz}$. Clearly, the AEP thresholds are below behavioral thresholds at the higher frequencies. For a comparison with other toadfish see the AEP audiogram of Lusitanian toadfish Halobatrachus didactylus (Fig. 17; Vasconcelos et al. 2007).

We note here that toadfish and many other species are unlike the goldfish and carp shown above in that they lack any peripheral specializations (even though they may have a swim bladder) that enhance hearing by sound pressure detection; toadfish are thought to detect sound through the otolith organ's direct response to acoustic particle acceleration and not to sound pressure (e.g., Popper and Fay 2011), as is the case for elasmobranchs (see Fig. 2 above), and some other species.

\section{European perch Perca fluviatilus}

The European perch (family Percidae) is also not specialized for sound pressure hearing and is likely sensitive to particle acceleration. The behavioral audiogram by Wolff (1967) is unusual in that it shows a very narrowly tuned response at about $0.1 \mathrm{kHz}$ (Fig. 5). The AEP audiogram for the European perch (Amoser and Ladich 2005) is more usual for unspecialized species than the behavioral audiogram.

\section{Red sea bream Pagrus major}

Auditory sensitivity has been measured in the red sea bream (family Sparidae) by Kojima et al. (2010) utilizing a cardiac conditioning technique and an underwater speaker in the far field (7.7 $\mathrm{m}$ away from the animal), and using the AEP technique in a small 


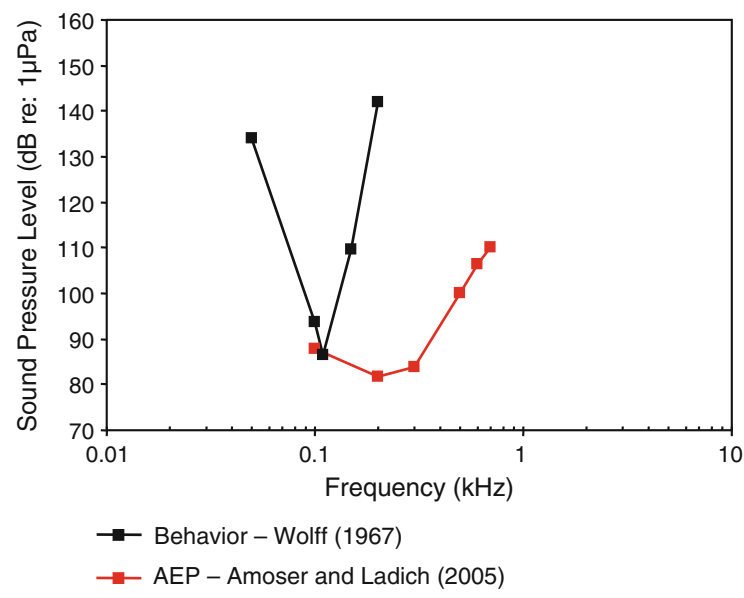

Fig. 5 Audiograms for the European perch Perca fluviatilis determined using behavioral (Wolff 1967) and AEP paradigms (Amoser and Ladich 2005)

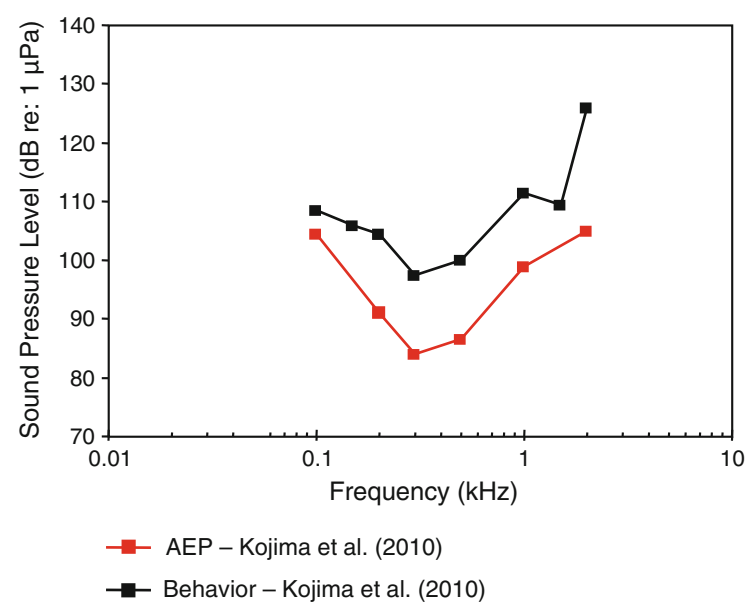

Fig. 6 Audiograms for the Red sea bream Pagrus major determined using behavioral (heart rate conditioning) and AEP techniques. After Kojima et al. (2010)

tub using an air speaker. Both threshold curves were similar in shape with AEP showing lower thresholds (Fig. 6). Authors argue that the far field cardiac conditioning thresholds are pressure thresholds whereas the AEP thresholds were pressure and particle acceleration thresholds. This might explain partly why AEP thresholds are lower at $200-500 \mathrm{~Hz}$. It seems unusual that the AEP gives lower thresholds at all frequencies (See "Behavioral and AEP thresholds in the goldfish Carassius auratus" section and Fig. 1c on the goldfish) but agrees with a similar observation of Kojima et al. (2005) in carps (Fig. 3).

\section{Oscar Astronotus ocellatus}

The oscar (family Cichlidae) is not specialized for sound pressure hearing, and thus is probably more properly described with respect to acoustic particle acceleration. Nevertheless, there is one behavioral (Yan and Popper 1992) and one AEP (Kenyon et al. 1998) sound pressure audiogram (Fig. 7). The AEP thresholds are well below behavioral thresholds, as is also the case for carps (Fig. 3) and red sea bream (Fig. 6). The behavioral study is the only example among hearing studies in fish to use operant conditioning for food reward. Oscars were trained to peck a paddle for food reward upon hearing a sound. The thresholds are unusually high, even for unspecialized fish. Yan and Popper (1992) mentioned that it was quite difficult to condition oscars to learn this response. Both estimates are similar in indicating that the oscar is a very low-frequency animal with relatively high thresholds and a frequency of best response at or below $0.1 \mathrm{kHz}$.

\section{Summary and Conclusions about the relation between behavioral and AEP measures of hearing}

Both behavioral and AEP measures of hearing exist for only seven fish species, even through about 60 species have been studied behaviorally, and approximately 100 species have been investigated using AEP measures. By far, the goldfish has been the most studied species. Behavioral and AEP audiograms for the goldfish show

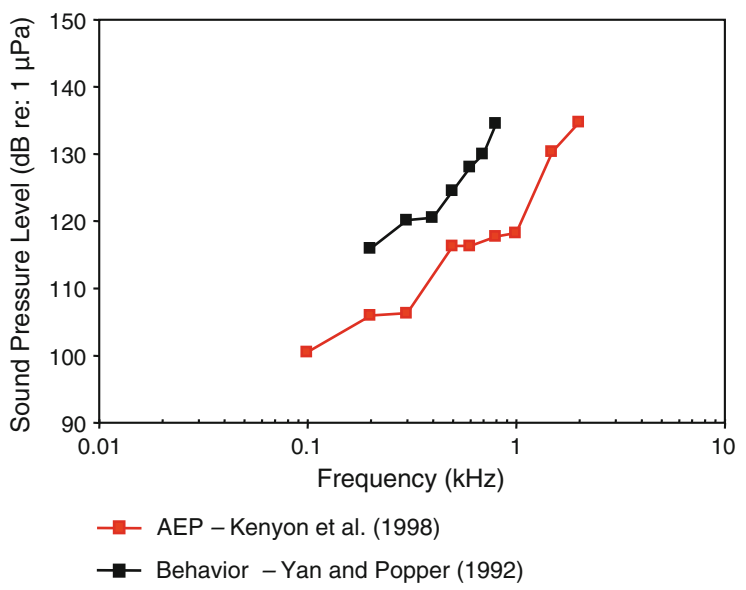

Fig. 7 Audiograms for the oscar Astronotus ocellatus using behavioral (operant conditioning) (Yan and Popper 1992) and AEP (Kenyon et al. 1998) techniques 
high variability among studies and laboratories. Thus, any one audiogram, whether behavioral or AEP, cannot be regarded as the proper definition of the species' auditory capability with any certainty. However, within one laboratory and with the application of consistent techniques, the determined audiogram will still be useful and valid as a baseline measure of hearing against which the effects of manipulations of sound conducting structures, development, and acoustical manipulations can be evaluated (see next sections).

One generalization that arises from some of the comparisons above is that AEP measures tend to produce thresholds that are higher than the behavioral values at low frequencies, and produce lower thresholds than the behavioral thresholds at the higher frequencies. We can only be certain of this statistical tendency in the comparison between the median thresholds of six behavioral audiograms and the $10 \mathrm{AEP}$ audiograms for the goldfish. Further evidence for this tendency comes from studies on the oyster toadfish (Fig. 4) but not from common carp (Fig. 2), the oscar (Fig. 7) and, possibly, the European perch (Fig. 5). Thus, it appears that the goal of discovering a "factor" for estimating behavioral thresholds from AEP measures is not possible. This is particularly the case when there is one AEP audiogram available for a given species (see "Systematic description of baseline AEP-audiograms" section below). In the absence of a behavioral audiogram, we recommend that such an AEP audiogram be accepted on its own terms as a reasonable estimate of auditory response for the species.

\section{Systematic description of baseline AEP- audiograms}

AEP-audiograms of 110 fish species out of 22 orders out of 51 families have been published and are dealt with in this review (see Table 1; Figs. 8, 9, 10, 11, 12, $13,14,15,16,17,18,19,20,21,22,23,24,25,26,27$, 28). We use the term baseline audiogram to indicate that animals have not been manipulated in any (known) way such as by prior noise exposure, eliminating accessory hearing structures etc. We grouped species and subsequently presented their audiograms according to their systematic relationship following the systematics by Nelson (2006) starting with cartilaginous fishes, followed by bony fishes and ending with lungfishes (see Table 1). In the majority of species (with a few exceptions) auditory thresholds have been described in terms of sound pressure level (SPL) and in a few cases only in terms of particle acceleration levels (PAL), and in some cases, in both. Seven cartilaginous species (5 shark species, 2 ray species, Fig. 8a, b) have been described in contrast to more than 100 bony fish species.

Families most often investigated in terms of species numbers are sciaenids or drums (11 species), cyprinids and cichlids ( 9 species), and pomacentrids or damselfish $(8$ species). The species most often chosen for investigations in AEP-studies is the goldfish (17 studies). Baseline audiograms were not the main purpose of many of these studies but were determined to investigate other issues such as the effects of accessory hearing structures, of noise exposure or masking, or of changes during ontogeny (see following sections and the column labelled "Additional Variable" in Table 1).

The particle acceleration (Fig. 8b) audiograms for elasmobranchs indicate a general low-frequency, lowpass characteristic. Most species have been studied at very low frequencies (below $100 \mathrm{~Hz}$ ), but the audiograms for the nurse shark Ginglyostoma cirratum and the yellow stingray Urobatis jamaicensis, (Casper and Mann 2006) have not.

These particle acceleration audiograms are probably the best estimates of sensitivity because elasmobranchs lack a swim bladder or any other gas-filled structures that could give them sound pressure sensitivity. The various elasmobranch species differ in sensitivity by approximately $30 \mathrm{~dB}$ in the frequency range between 20 and $200 \mathrm{~Hz}$, and are similar in particle acceleration sensitivity to all other species tested (Figs. 18b, 19b, 21b, 24b) except lungfish (Fig. 27b). There is no suggestion in these AEP audiograms of the remarkably great sensitivity suggested in behavioral studies of sound source localization (e.g., Myrberg et al. 1972).

The audiograms for the lake sturgeon Acipenser fluvescens (family Acipenseridae) and paddlefish Polyodon spathula (family Polyodontidae) (Fig. 9) (Lovell et al. 2005) are at least $30 \mathrm{~dB}$ less sensitive than the black baby whale Brienomyrus brachyistius (family Mormyridae). The former two species are likely sensitive to particle acceleration while the latter species is likely sound-pressure sensitive (Yan and Curtsinger 2000). For species that differ in the acoustic quantity to which they are most sensitive 


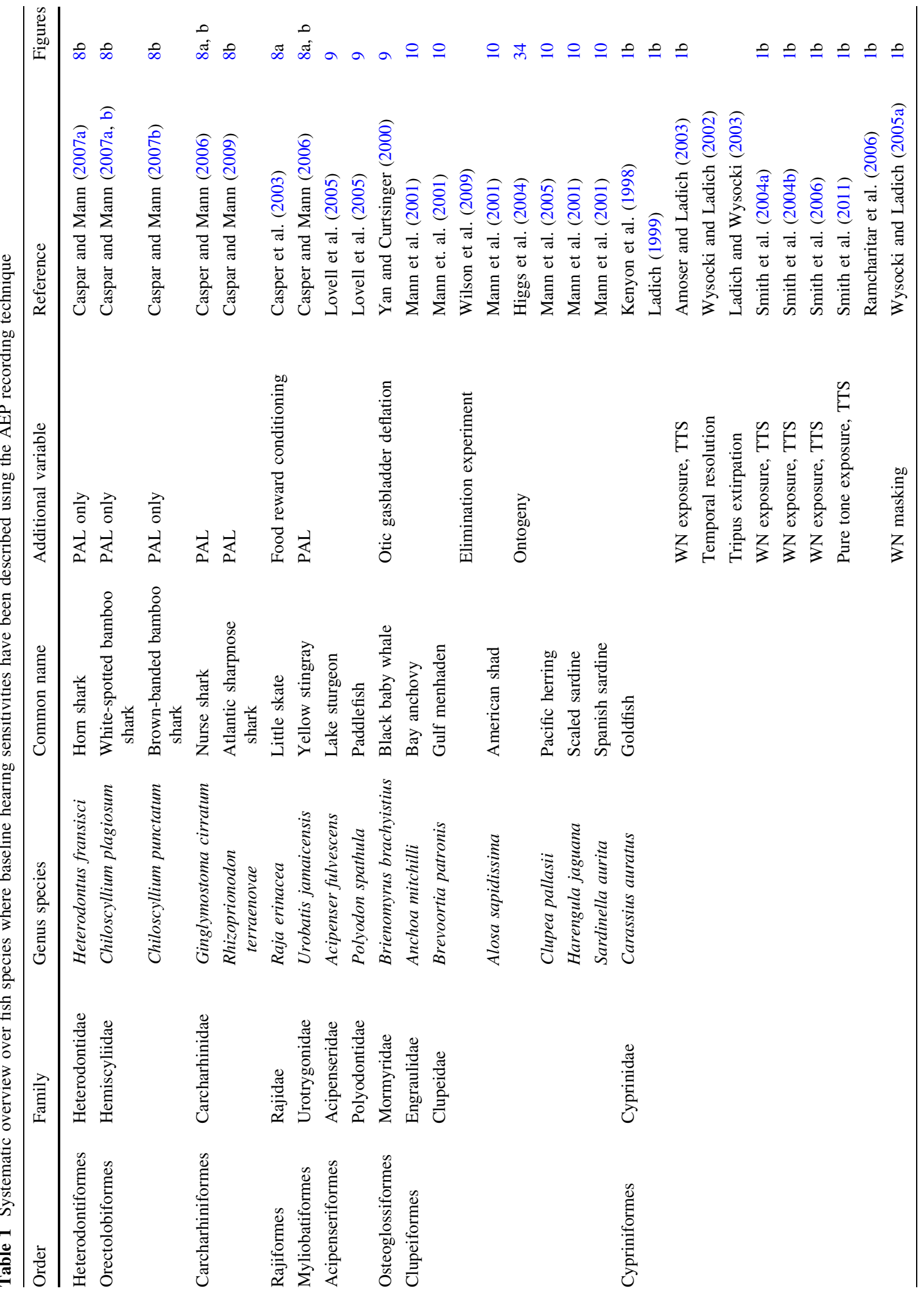




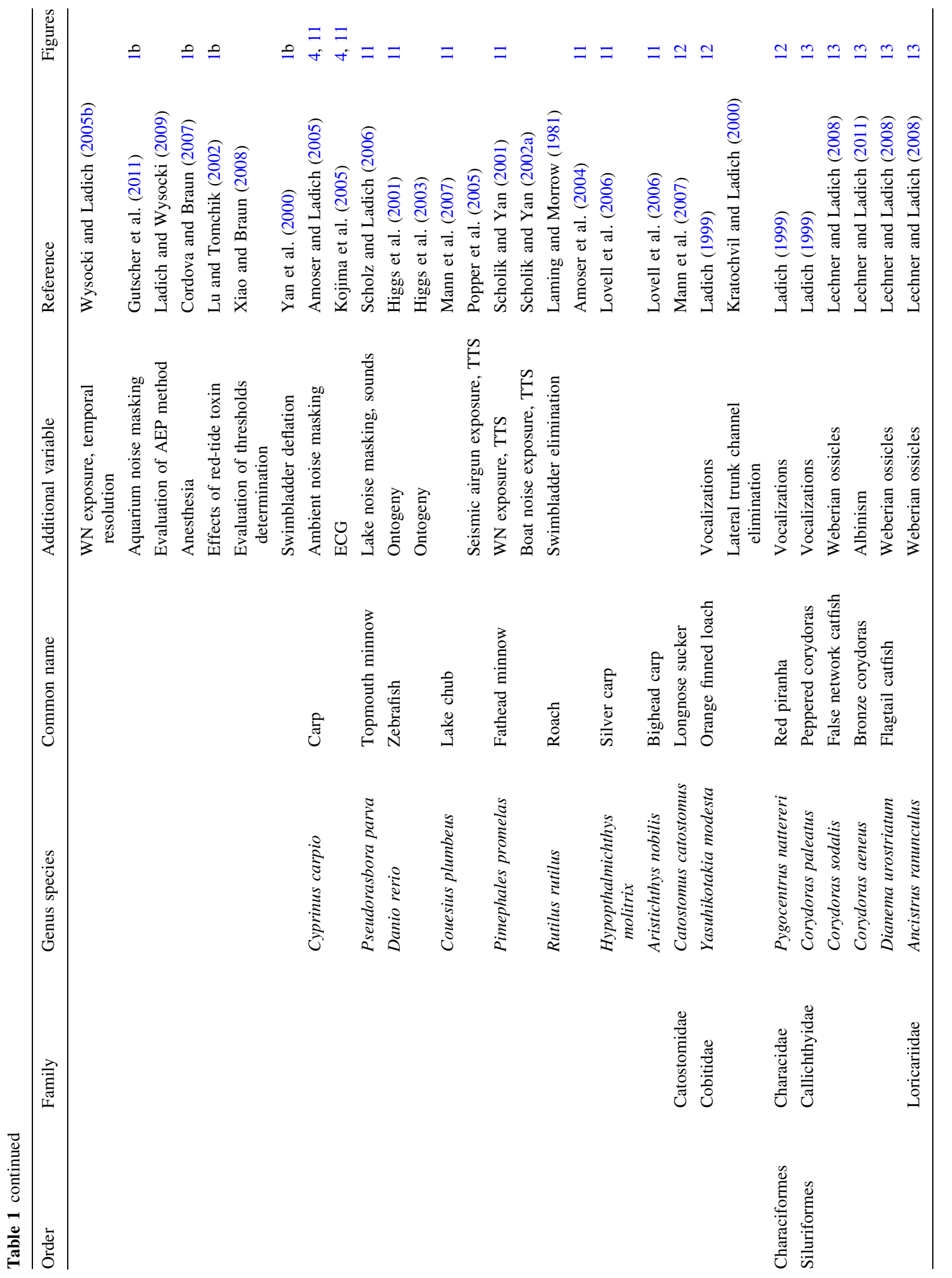




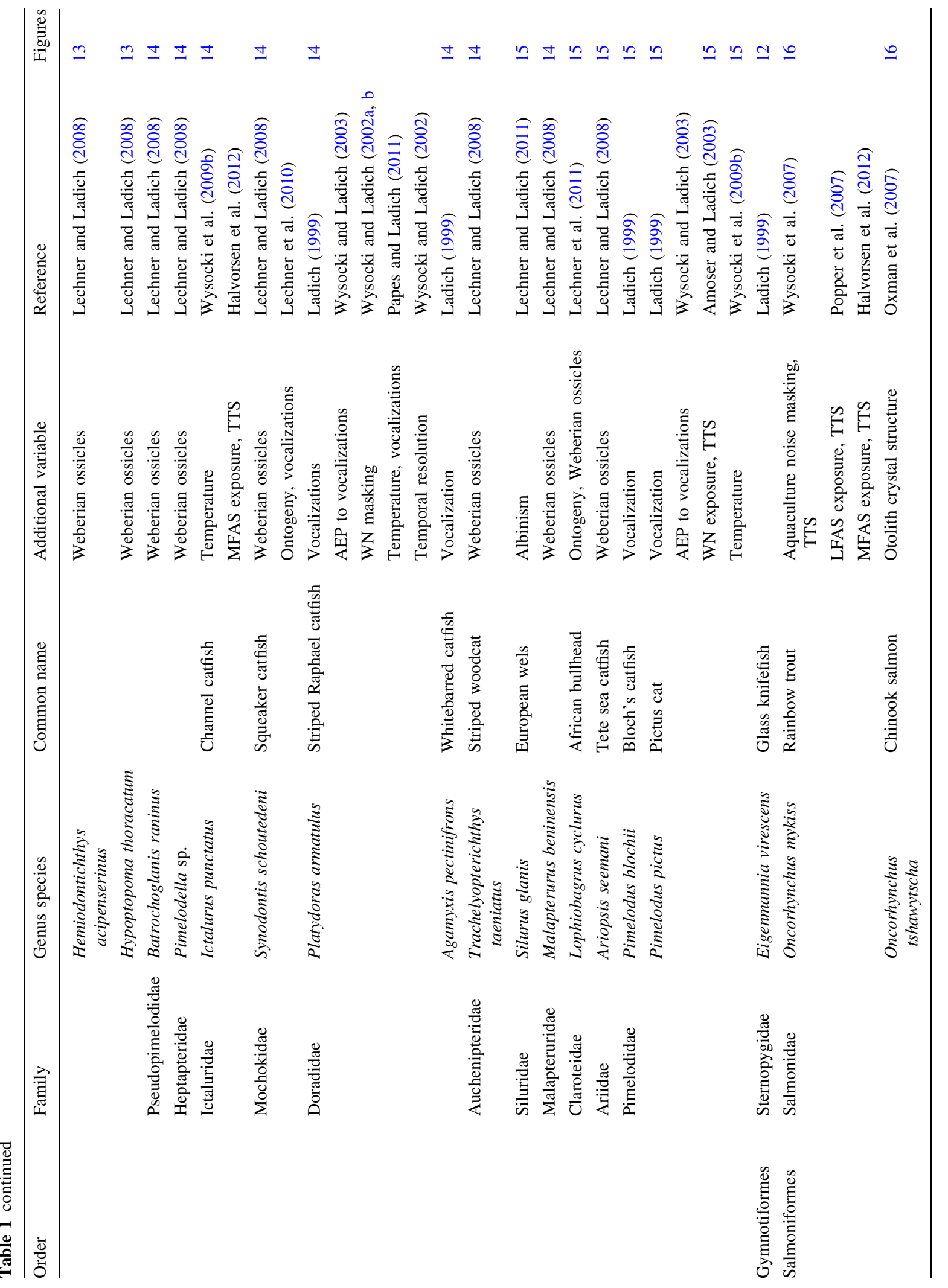




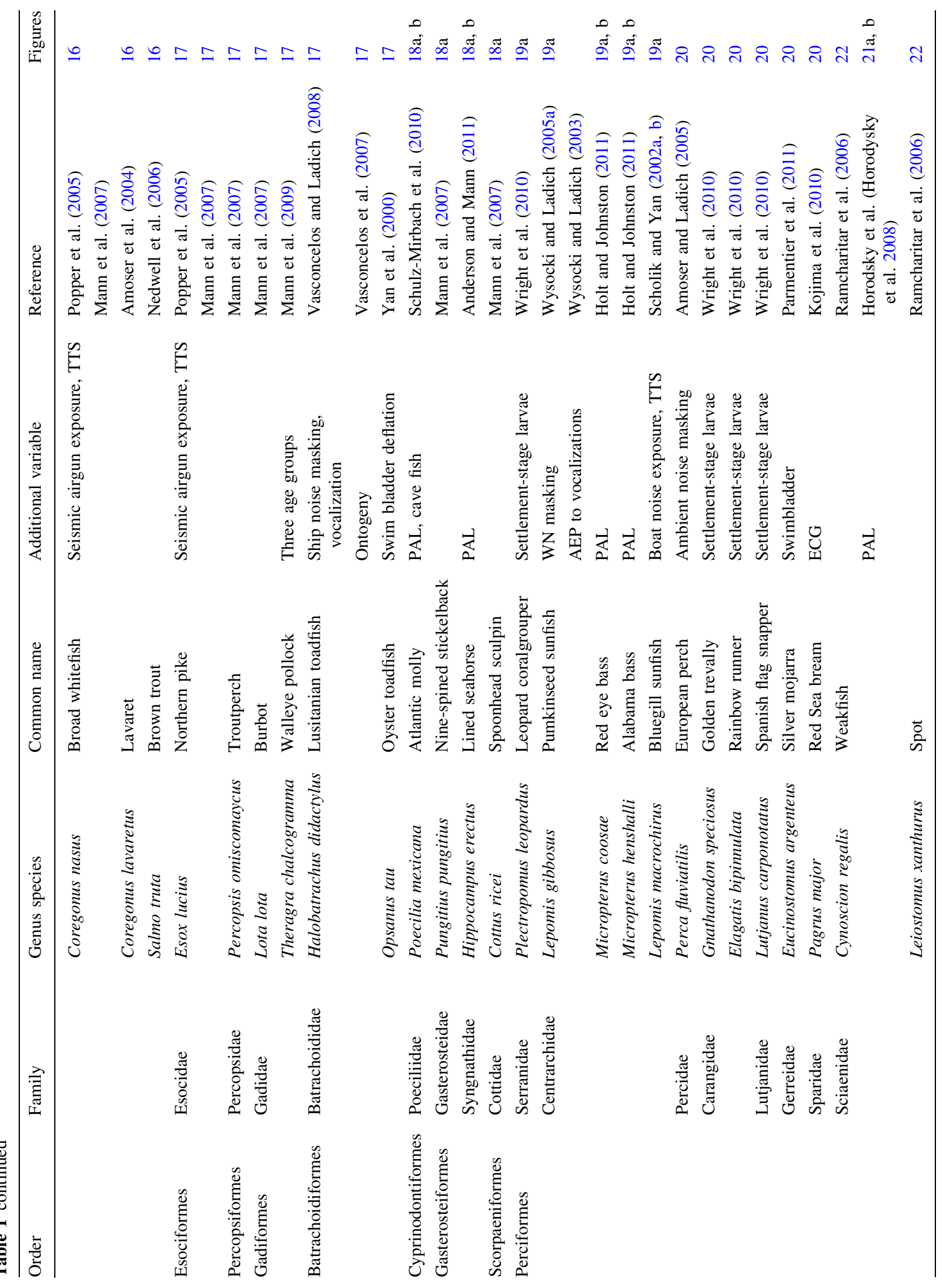




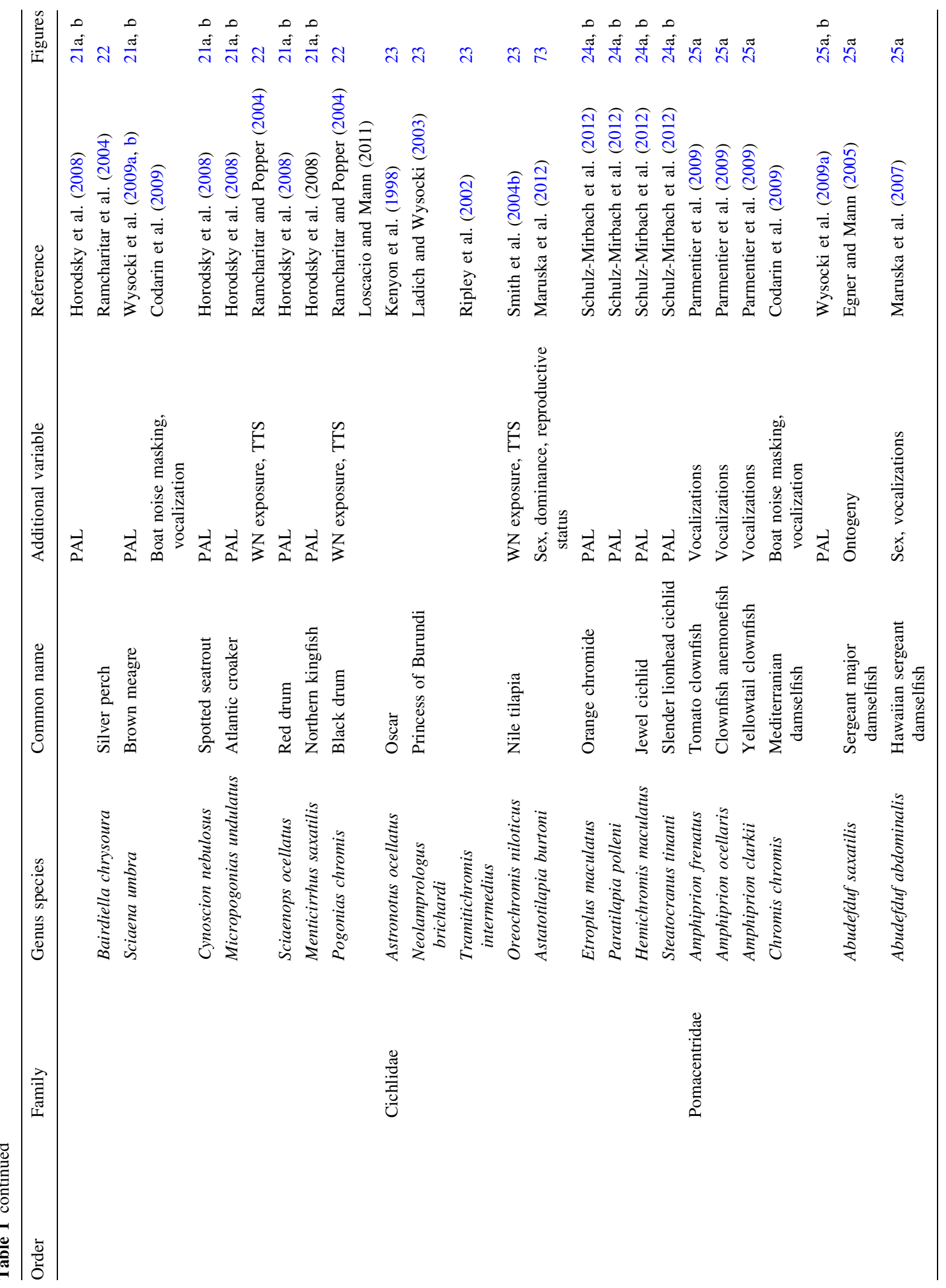




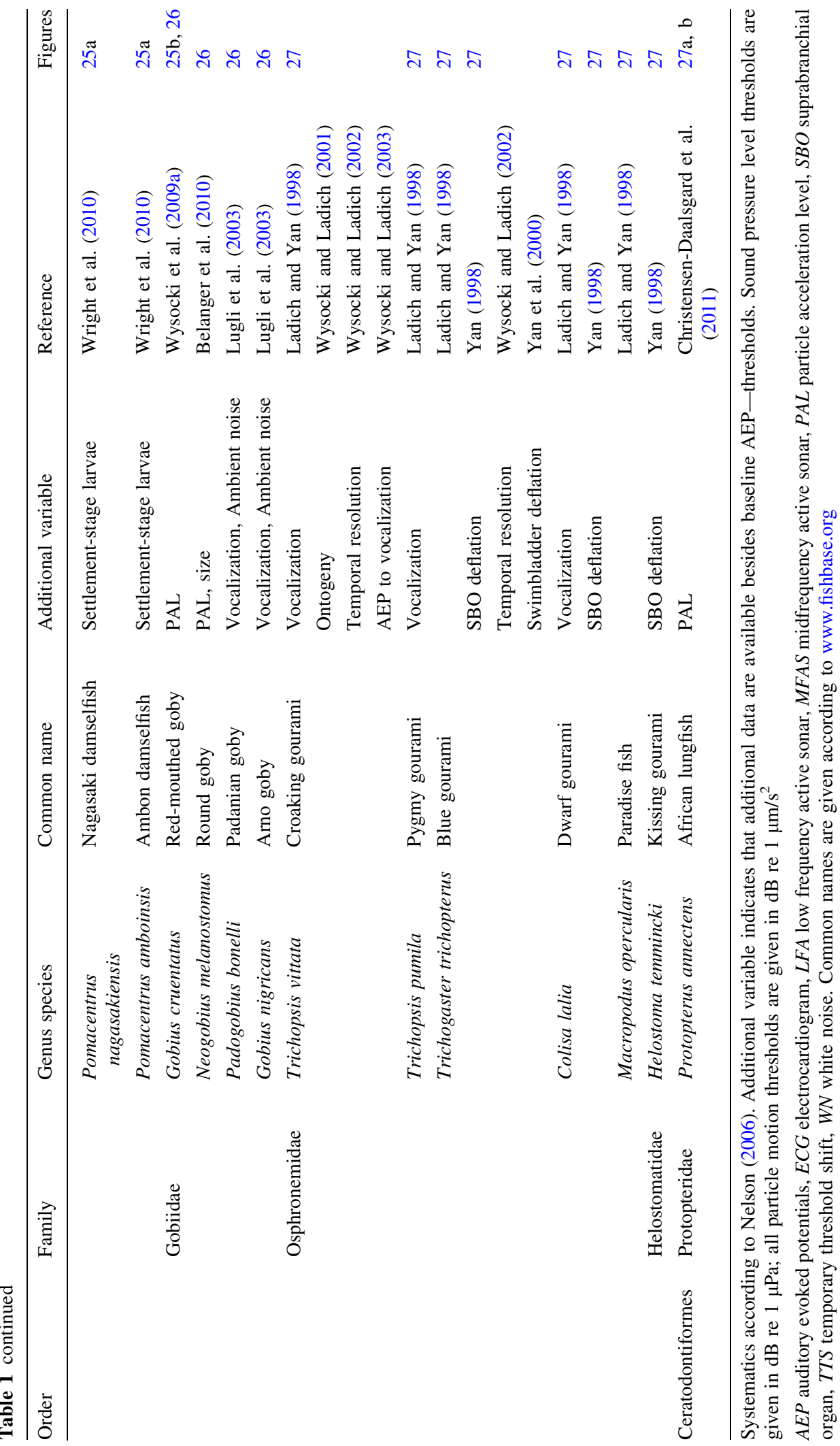




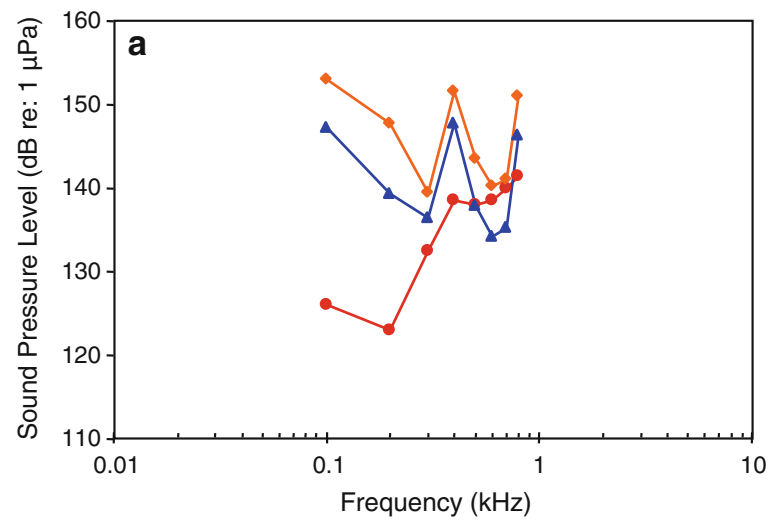

- Nurse shark (Ginglymostoma cirratum - Casper and Mann 2006)

$\neg-$ Yellow stingray (Urobatis jamaicensis - Casper and Mann 2006)

$\rightarrow$ Little skate (Raja erinacea - Casper et al. 2003)

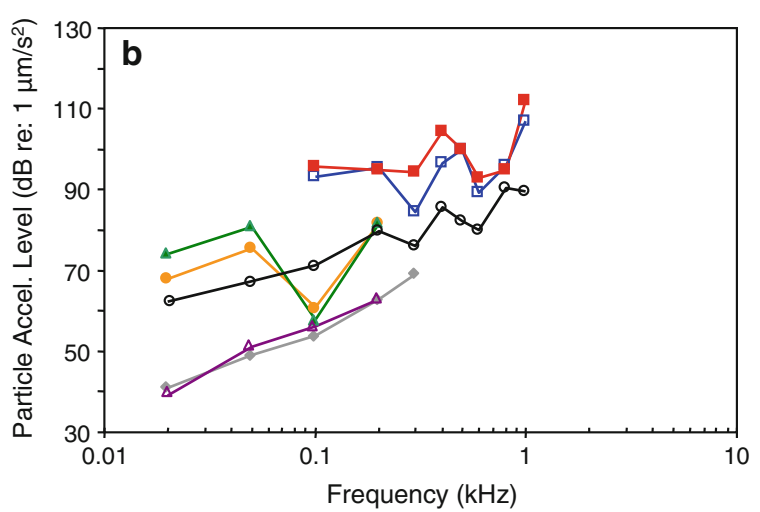

$\begin{aligned} \rightarrow & \text { Nurse shark (Ginglyostoma cirratum - Casper and Mann 2006) } \\ \rightarrow & \text { Yellow stingray (Urobatis jamaicensis - Casper and Mann 2006) } \\ \rightarrow & \text { Horn shark (Heterodontus francisci - Casper and Mann 2007a) } \\ \rightarrow & \text { White-spotted bamboo shark } \\ & \text { (Chiloscyllium plagiosum - Casper and Mann 2007a) } \\ \rightarrow & \text { White spotted bamboo shark } \\ & \text { (Chiloscyllium plagiosum - Casper and Mann 2007b) } \\ \rightarrow & \text { Brown-banded bamboo shark } \\ & \text { (Chiloscyllium punctatum - Casper and Mann 2007b) } \\ \rightarrow & \text { Atlantic sharpnose shark } \\ & \text { (Rhizoprionodon terranovae - Casper and Mann 2009) }\end{aligned}$

Fig. 8 Audiograms for elasmobranchs studied using AEP technique. a SPL audiograms and b PAL audiograms. After Casper et al. (2003) and Casper and Mann (2006, 2007a, b, 2009)

(sound pressure vs. particle acceleration), there is no rational way to compare thresholds when audiograms are expressed in sound pressure as in Fig. 9, except to say that particle acceleration species should appear less sensitive (by an unpredictable amount) and have a lower best frequency $(<200 \mathrm{~Hz})$ than pressure-sensitive species $(500 \mathrm{~Hz})$. The baby black whale exhibits a sensitivity and bandwidth generally similar to other species that are specialized for sound pressure detection.

Representatives of the family Clupeidae are specialized for sound pressure detection by virtue of an air-filled bulla adjacent to the utricle. Audiograms for these species in the region between 100 and 4,000 Hz (Fig. 10) have uncharacteristically high thresholds compared with other species that are specially adapted to detect sound pressure. The shapes of the lowfrequency $(<2,000 \mathrm{~Hz})$ portions of these audiograms are typical of species specialized for detecting sound pressure, but were possibly masked by ambient noise.

Some clupeids (American shad Alosa sapidissima and gulf menhaden Brevoortia patronus; subfamily Alosinae) respond to ultrasound (in the range between
20 and about 90 kHz; Fig. 10), although sensitivity in this frequency range is poor compared with other species that are sound pressure sensitive. Alosinae have been shown to respond to frequencies of over $180 \mathrm{kHz}$ (e.g., Mann et al. 1997). There is some evidence that the main receptor organs that may play a role in this sensitivity are the utricle and the cephalic lateral line organs in combination with the air-filled bullae (Wilson et al. 2009).

Representatives of all four otophysine orders (Cypriniformes, Siluriformes, Characiformes, Gymnotiformes) have been investigated. Among the order Cypriniformes the largest number of species has been investigated in the family Cyprinidae. Audiograms gained in representatives of the family Cyprinidae reveal considerable variation (Fig. 11). The hearing curves of common carps, the lake chub Couesius plumbeus, the topmouth minnow Pseudorasbora par$v a$ and the fathead minnow Pimephales promelas are similar to one another. Best thresholds for the zebrafish Danio rerio, the bighead carp Aristichthys nobilis and silver carp Hypopthalmichthys molitrix are 40-50 dB higher than thresholds of common carps. 


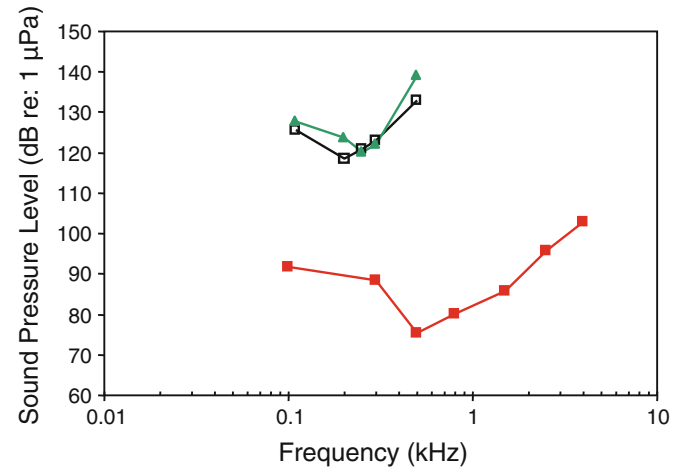

๑- Lake sturgeon (Acipenser fluvescens - Lovell et al. 2005)

- - Paddlefish (Polyodon spathula - Lovell et al. 2005)

- - Black baby whale (Brienomyrus brachyistius - Yan and Curtsinger 2000)

Fig. 9 Audiograms for the lake sturgeon Acipenser fluvescens, the paddlefish Polyodon spathula and the black baby whale Brienomyrus brachyistius. After Yan and Curtsinger (2000) and Lovell et al. (2005)

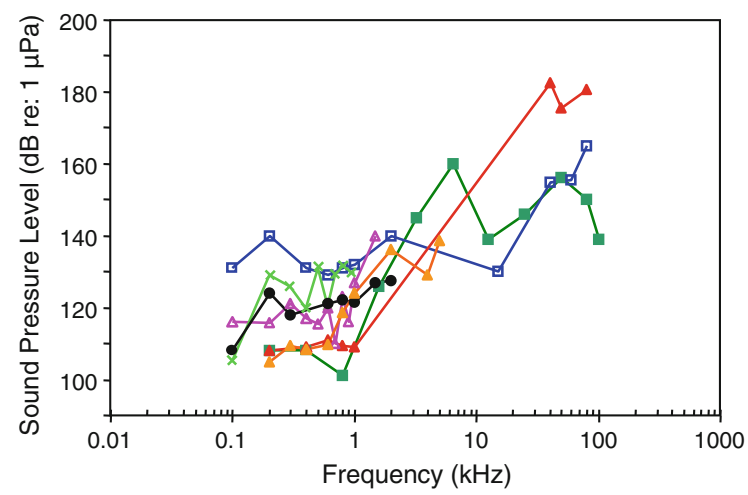

$\because$ ๑-American shad (Alosa sapidissima - Mann et al. 2001)

_- American shad (Alosa sapidissima - Mann et al. 1998)

$\multimap-$ Gulf menhaden (Brevoortia patronus - Mann et al. 2001)

$\triangle$ - Scaled sardine (Harengula jaguana - Mann et al. 2001)

$\rightarrow$ Bay anchovy (Anchoa mitchili - Mann et al. 2001)

- Pacific herring (Clupea pallasii - Mann et al. 2005)

$\leftarrow$ Spanish sardine (Sardinella aurita - Mann et al. 2001)

Fig. 10 Audiograms for six representatives of the order Clupeiformes; After Mann et al. (1998, 2001, 2005)

The difference of up to $50 \mathrm{~dB}$ between audiograms for these sound pressure sensitive species cannot be explained morphologically because all species possess swim bladders and Weberian ossicles. This is in contrast to catfishes which show a reduction in swim bladder size and number of Weberian ossicles (Bird and Hernandez 2007; Lechner and Ladich 2008). It is assumed that this difference is due to one of the

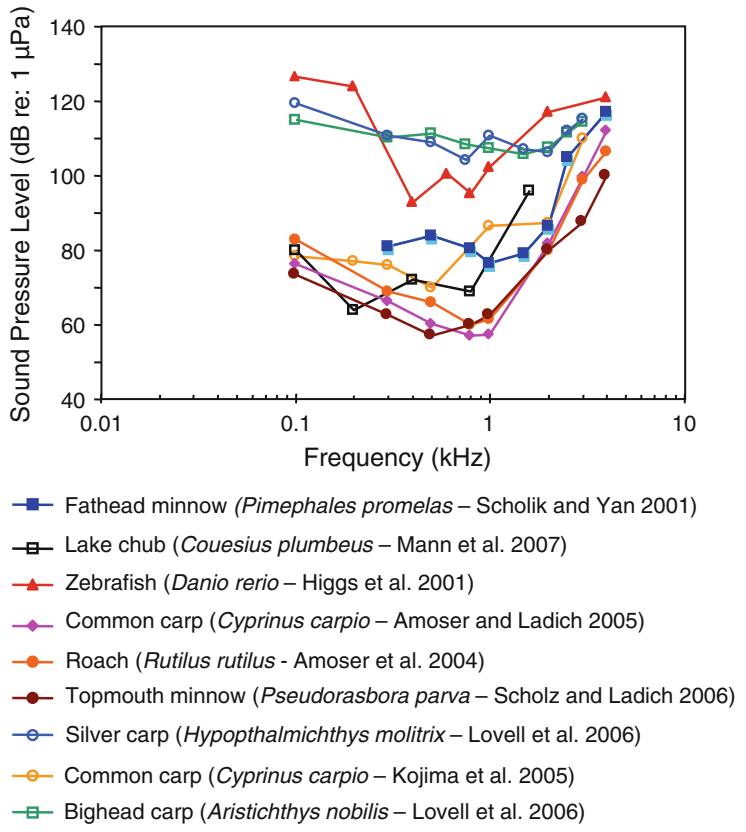

Fig. 11 Audiograms for eight representatives of the family Cyprinidae. After Higgs et al. (2001), Scholik and Yan (2001), Amoser et al. (2004), Amoser and Ladich (2005), Kojima et al. (2005), Scholz and Ladich (2006), Lovell et al. (2006) and Mann et al. (2007)

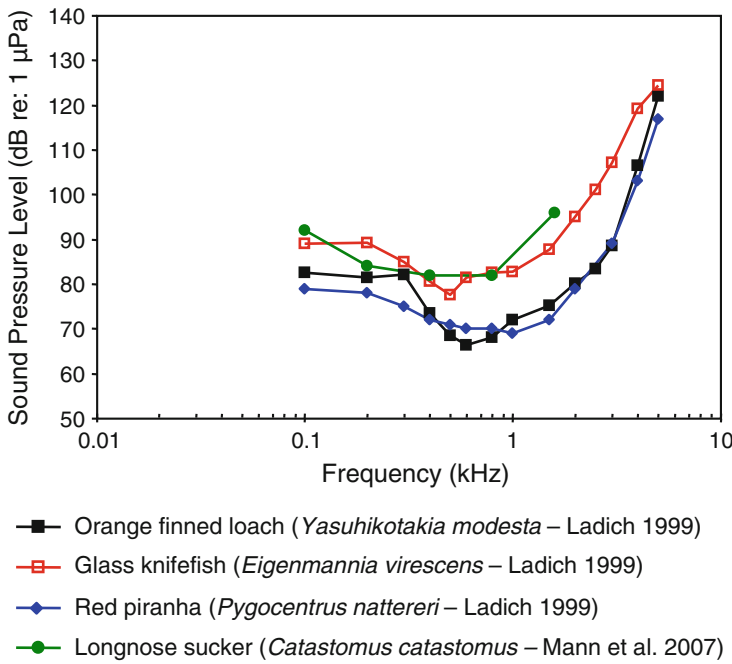

Fig. 12 Audiograms for the longnose sucker Castotomus catostomus, orange finned loach Yasuhikotakia modesta, the red piranha Pygocentrus (formerly Serrasalmus) nattereri and the glass knifefish Eigenmannia virescens After Ladich (1999) and Mann et al. (2007)

technical factors described in "Behavioral and AEP thresholds in the goldfish Carassius auratus" section and discussed by Ladich and Wysocki (2009). 


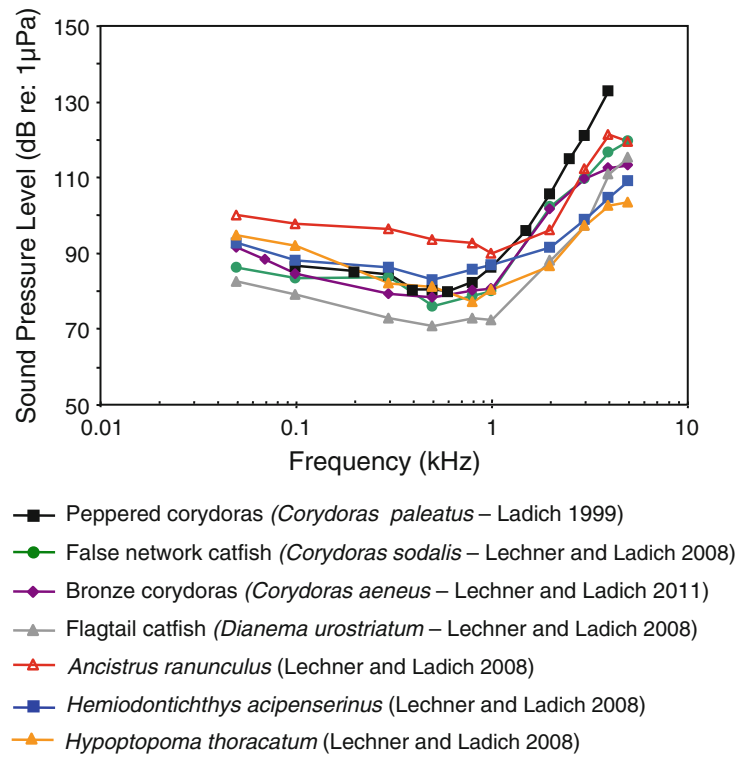

Fig. 13 Audiograms of eight representatives of the catfish families Doradidae, Auchenipteridae, Pseudopimelodidae, Heptateridae, Malapteruridae, Mochokidae and Ictaluridae. After Ladich (1999), Lechner and Ladich (2008) and Wysocki et al. (2009b)

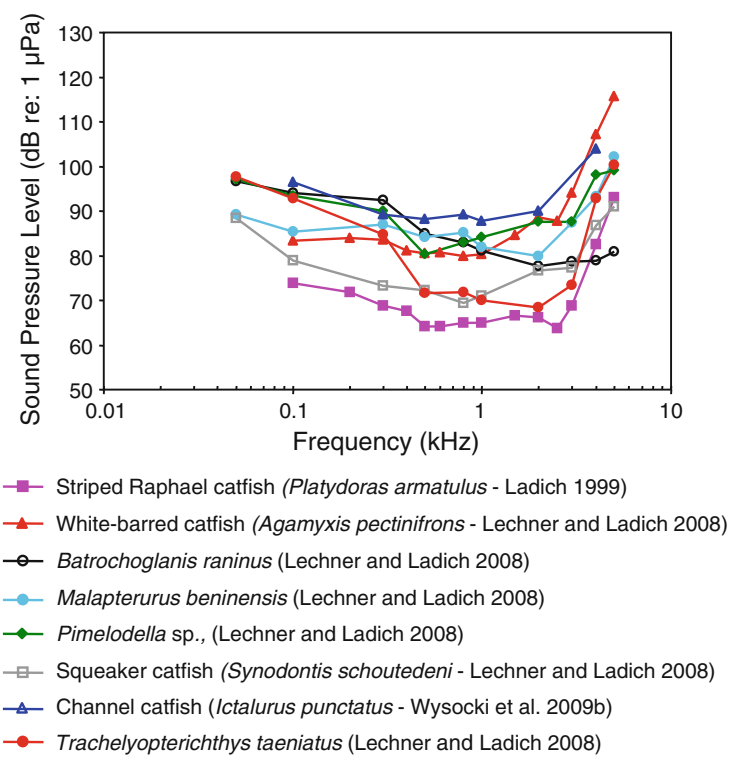

Fig. 14 Audiograms of eight representatives of the catfish families Doradidae, Auchenipteridae, Pseudopimelodidae, Heptateridae, Malapteruridae, Mochokidae and Ictaluridae. After Ladich (1999), Lechner and Ladich (2008) and Wysocki et al. (2009b)

Representatives of three otophysan orders (Fig. 12) (longnose sucker Catostomus catostomus, family Catostomidae, order Cypriniformes; red piranha Pygocentrus (formerly Serrasalmus) nattereri, family

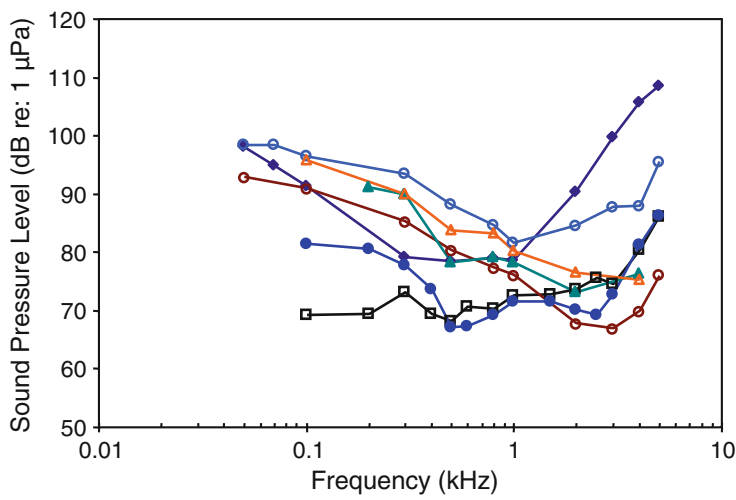

$\multimap$ European Wels (Silurus glanis - Lechner and Ladich 2011)

$\because$ Bloch's catfish (Pimelodus blochii - Ladich 1999)

$\longrightarrow$ Pictus cat (Pimelodus pictus - Ladich 1999)

- Tete sea catfish (Ariopsis seemani - Lechner and Ladich 2008)

- Lophiobagrus cyclurus (Lechner et al. 2011)

—- Pictus cat (Pimelodus pictus - Amoser and Ladich 2003)

$\triangle$ Pictus cat (Pimelodus pictus - Wysocki et al. 2009b)

Fig. 15 Audiograms for seven representatives of the catfish families Siluridae, Pimelodidae, Ariidae and Claroteidae. After Ladich (1999), Lechner and Ladich (2008, 2011), Wysocki et al. (2009b) and Lechner et al. (2011)

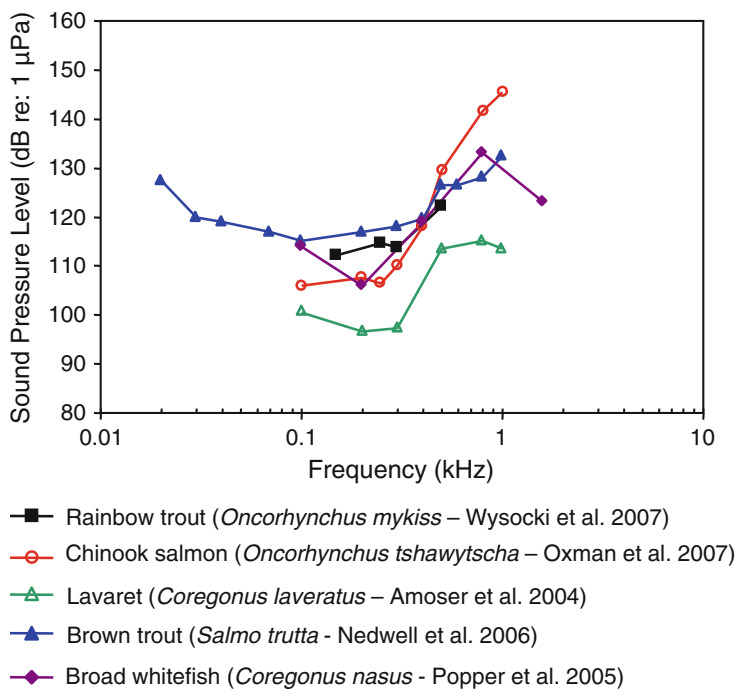

Fig. 16 Audiograms for five representatives of the family Salmonidae. After Amoser et al. (2004), Popper et al. (2005), Nedwell et al. (2006), Oxman et al. (2007) and Wysocki et al. (2007)

Characidae, order Characiformes; glass knifefish Eigenmannia virscens, family Sternopygidae, order Gymnotiformes) are all specialized for sound pressure detection, and they all have similar audiograms in 


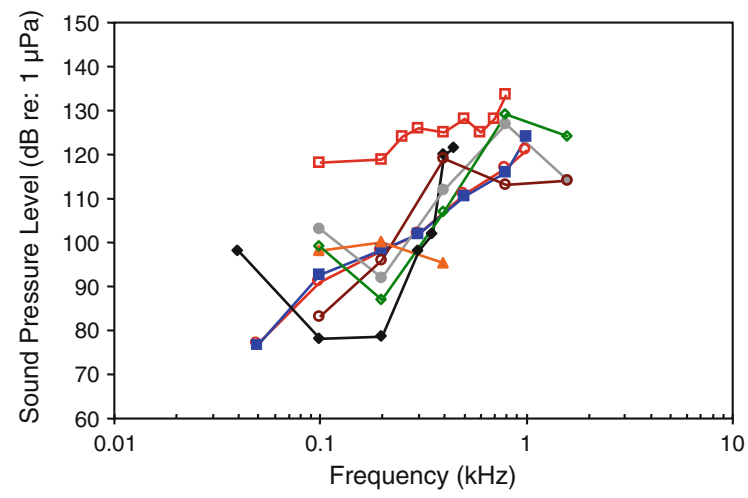

$\begin{aligned} \rightarrow- & \text { Oyster toadfish (Opsanus tau - Yan et al. 2000) } \\ \rightarrow- & \text { Lusitanian toadfish } \\ & \text { (Halobatrachus didactylus - Vasconcelos and Ladich 2008) } \\ \rightarrow- & \text { Lusitanian toadfish } \\ & \text { (Halobatrachus didactylus - Vasconcelos et al. 2007) } \\ \rightarrow & \text { Walleye pollock (Theragra chalcogramma - Mann et al. 2009) } \\ \rightarrow & \text { Burbot (Lota lota - Mann et al. 2007) } \\ \rightarrow & \text { Troutperch (Percopsis omiscomaycus - Mann et al. 2007) } \\ \rightarrow- & \text { Northern pike (Esox lucius - Popper et al. 2005) } \\ \rightarrow & \text { Northern pike (Esox lucius - Mann et al. 2007) }\end{aligned}$

Fig. 17 Audiograms for six representatives of the orders Esociformes, Percopsiformes, Batrachoidiformes and Gadiformes. After Yan et al. (2000), Popper et al. (2005), Vasconcelos et al. (2007), Mann et al. (2007, 2009) and Vasconcelos and Ladich (2008)

terms of sensitivity (maximum difference 15-20 dB) and frequency range of best hearing $(0.6-1 \mathrm{kHz})$.

Siluriformes (catfishes-Figs. 13, 14, 15) are the most species-rich otophysan order (more than 3,300 species) possessing relatively great sensitivity to sound pressure (lowest thresholds below $90 \mathrm{~dB}$ ) and a high frequency range of best hearing $(500-1,000 \mathrm{~Hz})$. Representatives of the families Callichthyidae and Loricariidae possess paired, tiny and encapsulated swim bladders and 1-2 Weberian ossicles which result in poorer sensitivities above $1 \mathrm{kHz}$ as compared to the other catfish families. Representatives of all other families investigated-Doradidae, Auchenipteridae, Pseudopimelodidae, Heptapteridae, Mochokidae, Siluridae, Pimelodidae, Ariidae and Claroteidae-possess large unpaired swim bladders and typically 3-4 Weberian ossicles (Lechner and Ladich 2008). Best thresholds within the latter families differ by about $25 \mathrm{~dB}$ (Fig. 14) and $35 \mathrm{~dB}$ (Fig. 15), respectively.

Salmonids (Fig. 16) are primarily particle acceleration sensitive, as has been demonstrated behaviorally for the Atlantic salmon (Hawkins and Johnstone 1978). Therefore, these sound pressure audiograms are almost certainly inappropriate as estimates of their hearing. However, the relatively high sound pressure thresholds and the low-frequency range of best hearing $(100-300 \mathrm{~Hz})$ are to be expected from particle acceleration sensitive species.

Batrachoidiformes (toadfishes), Esociformes (pikes) and Percopsiformes (trout-perches) are sensitive to particle acceleration, not sound pressure (Fig. 17). This was demonstrated for the oyster toadfish by Yan et al. (2000; however, see caveat in "Using AEPtechnique to investigate accessory hearing structures"
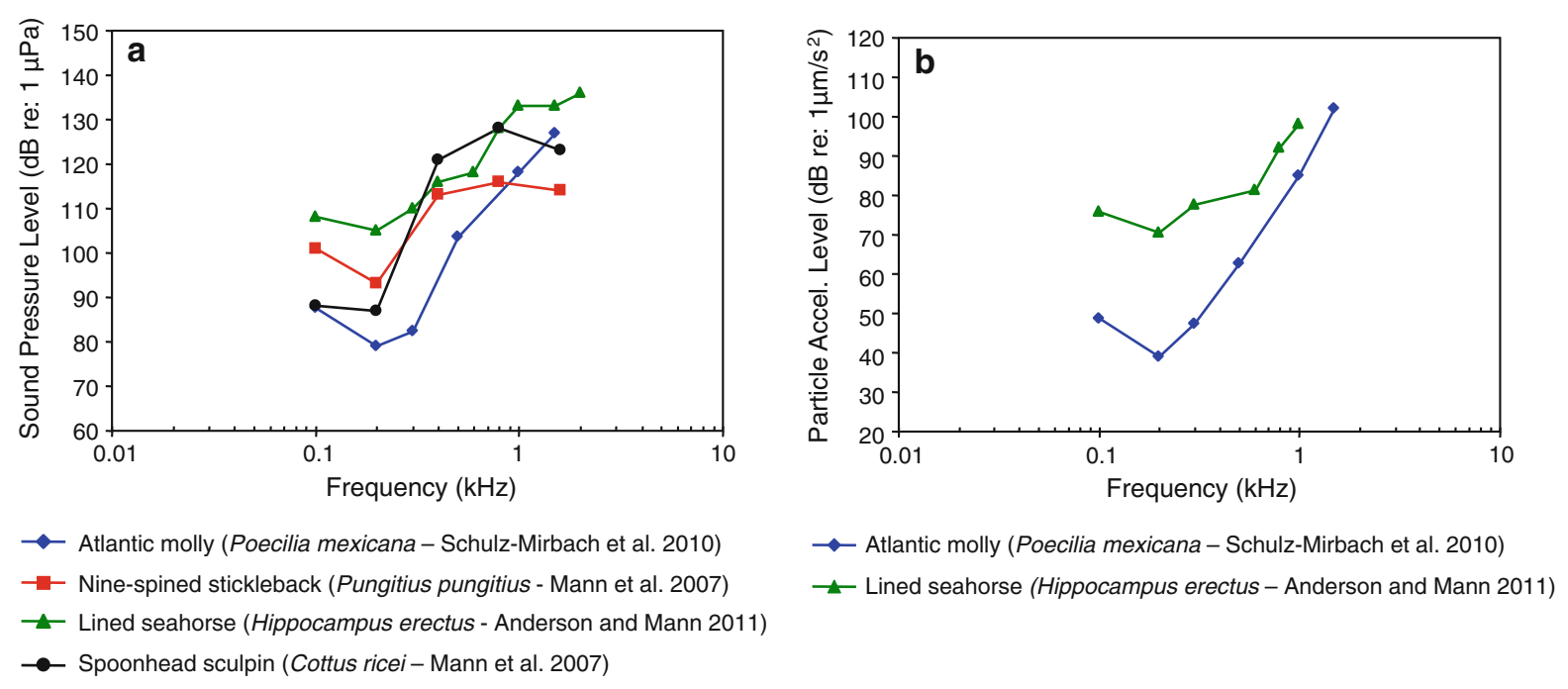

\footnotetext{
$\multimap$ Atlantic molly (Poecilia mexicana - Schulz-Mirbach et al. 2010)

-는 Nine-spined stickleback (Pungitius pungitius - Mann et al. 2007)

- Lined seahorse (Hippocampus erectus - Anderson and Mann 2011)

$\longrightarrow$ Spoonhead sculpin (Cottus ricei - Mann et al. 2007)
}

Fig. 18 Audiograms of four representatives of the orders Cyprinodontiformes, Gasterosteiformes and Scorpaeniformes. a SPL audiograms and b PAL audiograms. After Mann et al. (2007), Schulz-Mirbach et al. (2010) and Anderson and Mann (2011) 


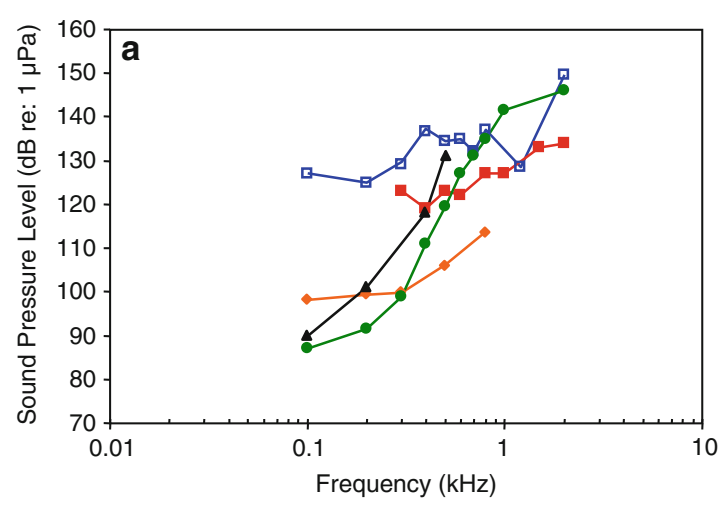

$\square$ Leopard coral grouper (Plectropomus leopardus - Wright et al. 2010)

$\multimap$ Pumpkinseed sunfish (Lepomis gibbosus - Wysocki and Ladich 2003)

- - Bluegill sunfish (Lepomis macrochirus - Scholik and Yan 2002a)

- - Red eye bass (Micropterus henshalli - Holt and Johnson 2011)

$\rightarrow$ Alabama bass (Micropterus coosae - Holt and Johnson 2011)

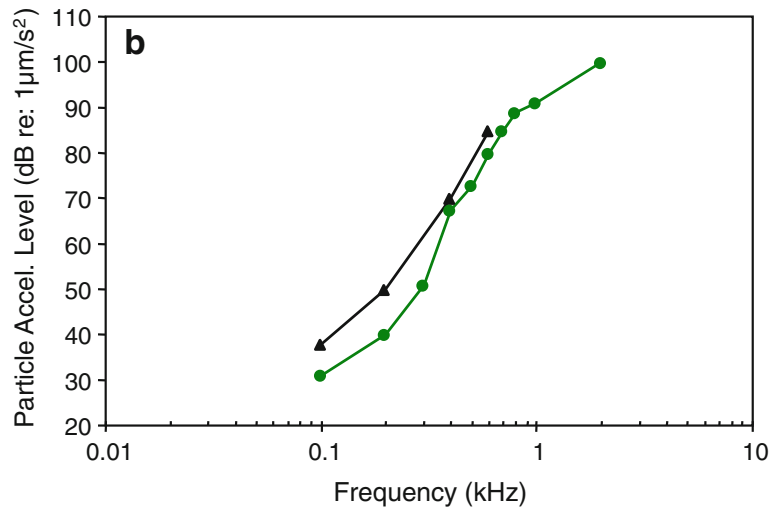

- - Red eye bass (Micropterus henshalli - Holt and Johnson 2011)

$\rightarrow$ Alabama bass (Micropterus coosae - Holt and Johnson 2011)

Fig. 19 Audiograms for one representative of the family Serranidae and four of the family Centrarchidae. a SPL audiograms and b PAL audiograms. After Wright et al. (2010), Scholik and Yan (2002a), Wysocki and Ladich (2003) and Holt and Johnston (2011)

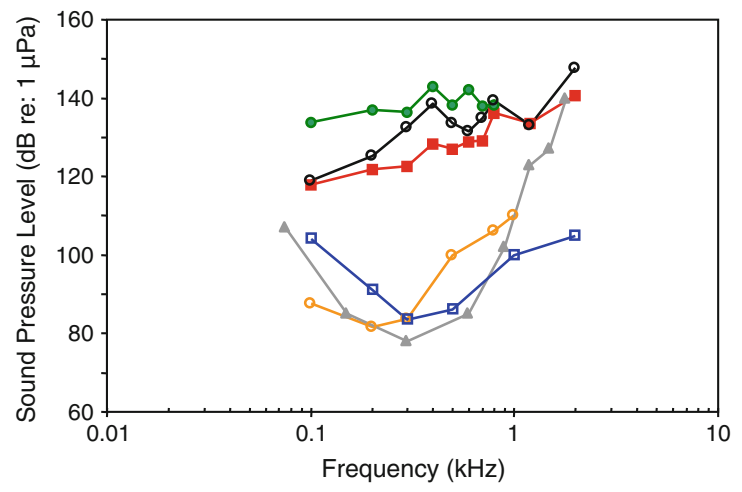

- - Spanish flag snapper (Lutjanus carponotatus - Wright et al. 2010)

$\rightarrow$ Rainbow runner (Elagatis bipinnulata - Wright et al. 2010)

- Golden trevally (Gnathonodon speciosus - Wright et al. 2010)

- - European perch (Perca fluviatilis - Amoser and Ladich 2005)

- Silver mojarra (Eucinostomus argenteus - Parmentier et al. 2011)

$\square$ Red sea bream (Pagrus major - Kojima et al. 2010)

Fig. 20 Audiograms for representatives of the perciform families Percidae, Carangidae, Lutjanidae, Gerreidae and Sparidae. After Amoser and Ladich (2005), Kojima et al. (2010), Wright et al. (2010) and Parmentier et al. (2011)

section). Most of these species have a low or very low frequency of best hearing $(<50-200 \mathrm{~Hz})$. Gadiformes such as the Atlantic cod (family Gadidae), on the other hand, are sensitive to sound pressure at the higher frequencies (above $100 \mathrm{~Hz}$-Chapman and Hawkins
1973), and the swim bladder has been shown to function in hearing (see also Sand and Enger 1973).

Figure 18 shows four species out of three orders namely Cyprinodontiformes (killifishes), Gasterosteiformes (sticklebacks) and Scorpaeniformes (mailcheeked fishes) that have a low frequency of best hearing $(200 \mathrm{~Hz})$, suggesting that they are particle acceleration sensitive. Figure $18 \mathrm{~b}$ shows great sensitivity to particle acceleration at $200 \mathrm{~Hz}$ in the Atlantic molly Poecilia mexicana (family Poeciliidae), but about $30 \mathrm{~dB}$ less sensitivity for the lined seahorse Hippocampus erectus (family Syngnathidae).

Among Perciformes (perches), the most speciesrich fish order, representatives of 13 (out of 160) families have been investigated (Table 1). Representatives of the families Serranidae and Centrarchidae (Fig. 19) are probably particle acceleration sensitive as they all have a low or very low frequency of best hearing $(<100-300 \mathrm{~Hz})$ and relatively poor sound pressure sensitivity. The particle acceleration function (Fig. 19b) for the two basses correspond well with the sound pressure functions (Fig. 19a) in indicating a frequency of best hearing below $100 \mathrm{~Hz}$.

The perciform audiograms depicted in Fig. 20 fall into two groups based on the sensitivity. The Spanish flag snapper Lutjanus carponotatus (family Lutjanidae), the rainbow runner Elagatis bipinnulata, and the golden trevally Gnathonodon speciosus (family 


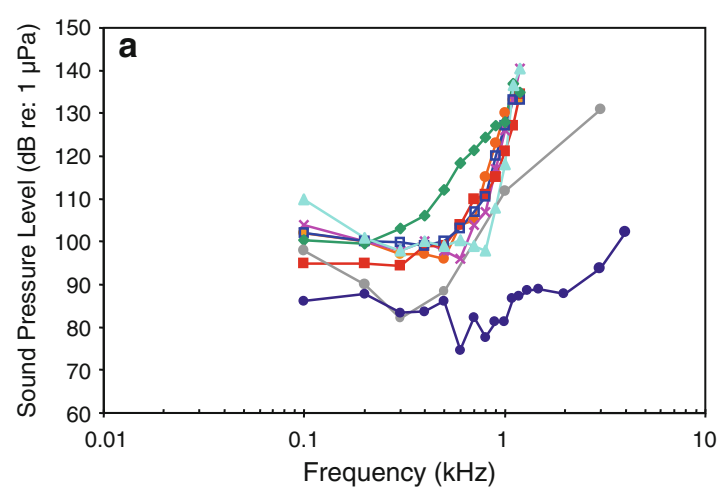

- - Spotted seatrout (Cynoscion nebulosus - Horodysky et al. 2008)

$\rightarrow$ Weakfish (Cynoscion regalis - Horodysky et al. 2008)

- - Atlantic croaker (Micropogonias undulatus - Horodysky et al. 2008)

七- Red drum (Sciaenops ocellatus - Horodysky et al. 2008)

$\multimap$ Spot (Leiostomus Xanthurus - Horodysky et al. 2008)

- Northern kingfish (Menticirrhus saxatilis - Horodysky et al. 2008)

- Brown meagre (Sciaena umbra - Wysocki et al. 2009a)

$\multimap-$ Silver perch (Bairdiella chrysoura - Ramcharitar et al. 2004)

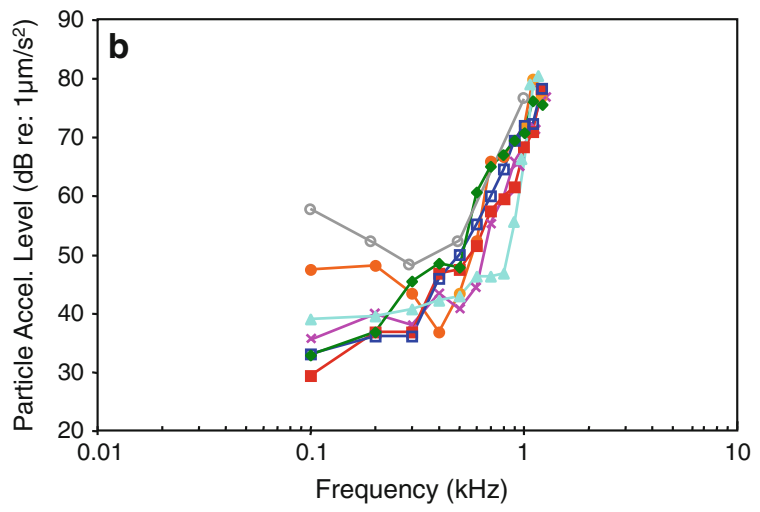

- - Spotted seatrout (Cynoscion nebulosus - Horodysky et al. 2008)

$*$ Weakfish (Cynoscion regalis - Horodysky et al. 2008)

- - Atlantic croaker (Micropogonias undulatus - Horodysky et al. 2008)

$\square-$ Red drum (Sciaenops ocellatus - Horodysky et al. 2008)

$\multimap$ Spot (Leiostomus xanthurus - Horodysky et al. 2008)

- Northern kingfish (Menticirrhus saxatilis - Horodysky et al. 2008)

- - Brown meagre (Sciaena umbra - Wysocki et al. 2009a)

Fig. 21 Audiograms for eight representatives of the perciform family Sciaenidae. a SPL audiograms and b PAL audiograms. After Ramcharitar et al. (2004), Horodysky et al. (2008), and Wysocki et al. (2009a)

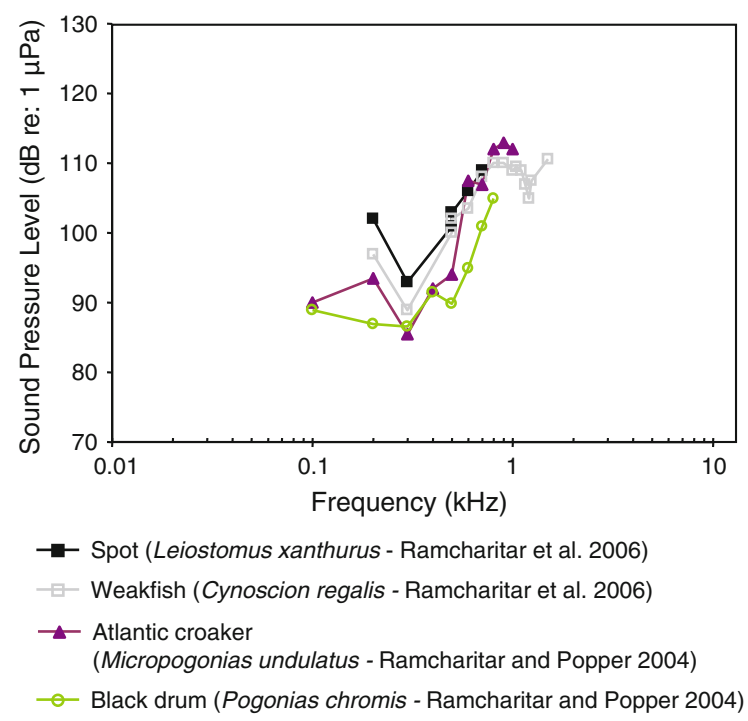

Fig. 22 Audiograms for four representatives of the perciform family Sciaenidae. After Ramcharitar and Popper (2004) and Ramcharitar et al. (2006)

Carangidae) (Wright et al. 2010) have low-pass audiogram shapes and poor sensitivity. The remaining three species have bandpass audiograms with a best frequency at $200 \mathrm{~Hz}$, and seem to be more sensitive. We assume that the difference between the first group

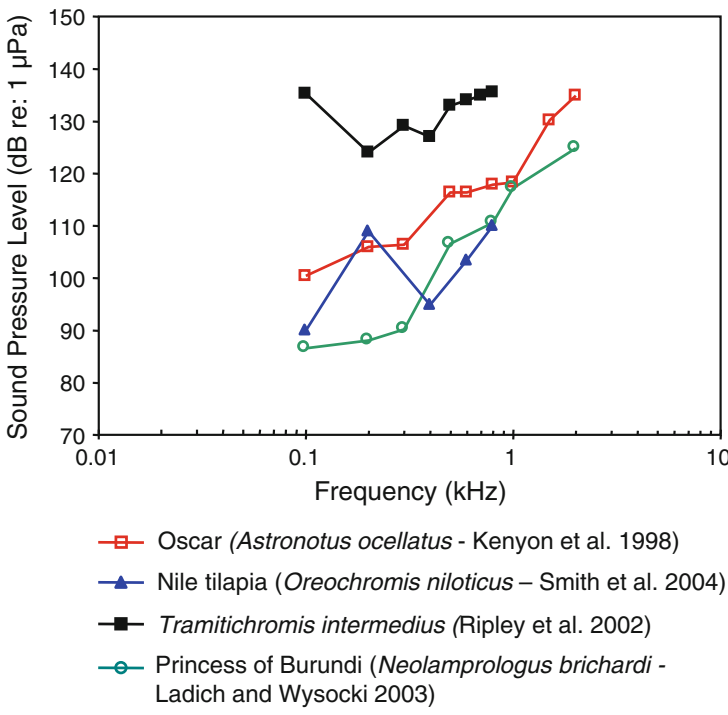

Fig. 23 Audiograms for four representatives of the perciform family Cichlidae. After Kenyon et al. (1998), Ripley et al. (2002), Ladich and Wysocki (2003) and Smith et al. (2004b)

and the second group is mostly based on methodical differences.

Most of the representatives of the family Sciaenidae of Fig. 21a and b (Horodsky et al. 2008) were studied using the same techniques in the same lab, except for 


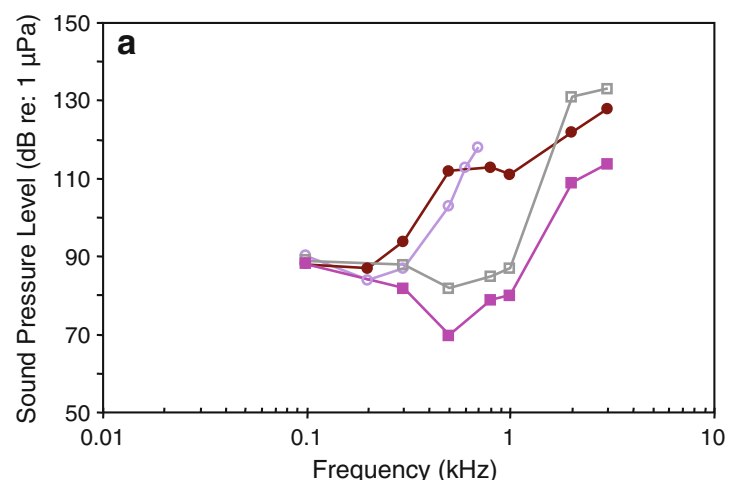

- Jewel Cichlid (Hemichromis guttatus - Schulz-Mirbach et al. 2012)

$\because$ Paratilapia polleni (Schulz-Mirbach et al. 2012)

- - Orange chromide (Etroplus maculatus - Schulz-Mirbach et al. 2012)

$\multimap$ Slender lion head cichlid

(Steatocranus tinanti - Schulz-Mirbach et al. 2012)

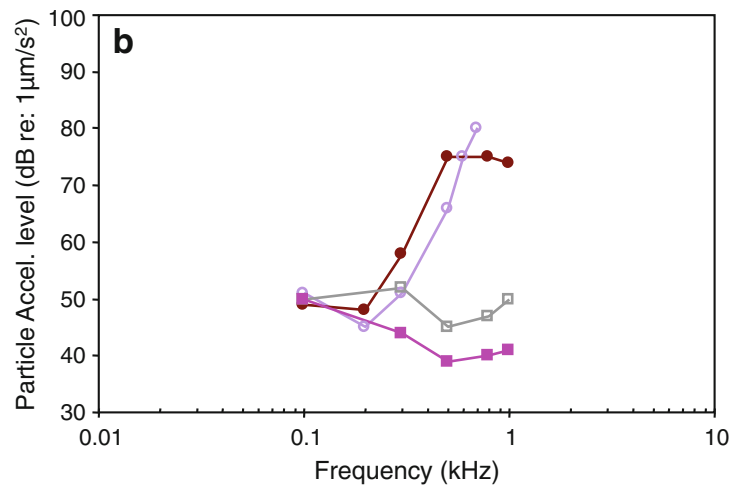

$\longrightarrow$ Jewel Cichlid (Hemichromis guttatus - Schulz-Mirbach et al. 2012)

$\because$ Paratilapia polleni (Schulz-Mirbach et al. 2012)

$\rightarrow$ Orange chromide (Etroplus maculatus - Schulz-Mirbach et al. 2012)

- Slender lion head cichlid

(Steatocranus tinanti - Schulz-Mirbach et al. 2012)

Fig. 24 Audiograms of four representatives of the perciform family Cichlidae in which a SPL and b PAL audiograms have been determined. After Schulz-Mirbach et al. (2012)

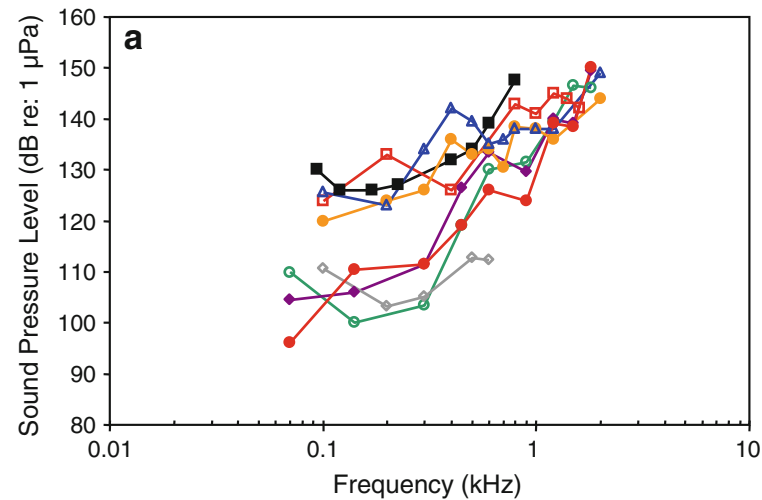

$\triangle$ Ambon damselfish (Pomacentrus amboinsis - Wright et al. 2010)

- Yellow clownfish (Amphiprion clarkii - Parmentier et al. 2009)

느 Hawaiian sergeant damselfish (Abudefduf abdominalis - Maruska et al. 2007)

- Tomato clown fish (Amphiprion frenatus - Parmentier et al. 2009)

$\multimap$ Clown anemone fish (Amphiprion ocellaris - Parmentier et al. 2009)

$\rightarrow$ Mediterranean damselfish (Chromis chromis - Wysocki et al. 2009a)

$\square$ Sergeant major damselfish (Abudefduf saxatilis - Egner and Mann 2005)

- - Nagasaki damselfish (Pomacentrus nagasakiensis - Wright et al. 2010)

Fig. 25 Audiograms for eight representatives of the perciform family Pomacentridae. a SPL audiograms and b PAL audiogram for the damselfish Chromis chromis and the red-mouthed goby

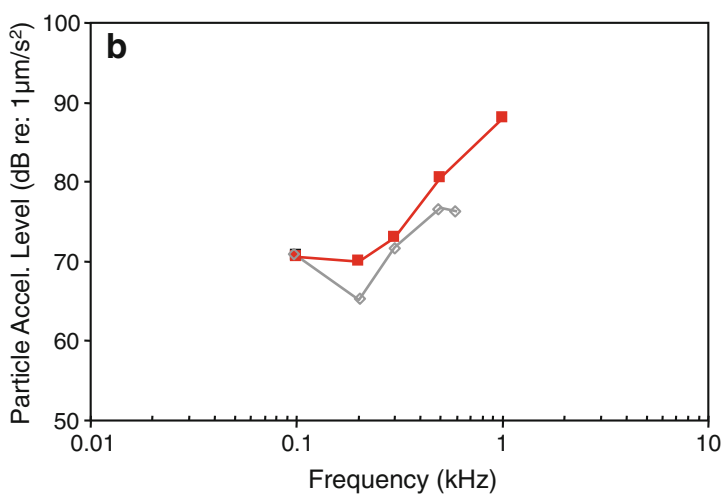

$\checkmark$ Mediterranean damselfish (Chromis chromis - Wysocki et al. 2009a)

Red-mouthed goby (Gobius cruentatus - Wysocki et al. 2009a)

Gobius cruentatus. After Egner and Mann (2005), Maruska et al. (2007), Wysocki et al. (2009a), Parmentier et al. (2009) and Wright et al. (2010) 


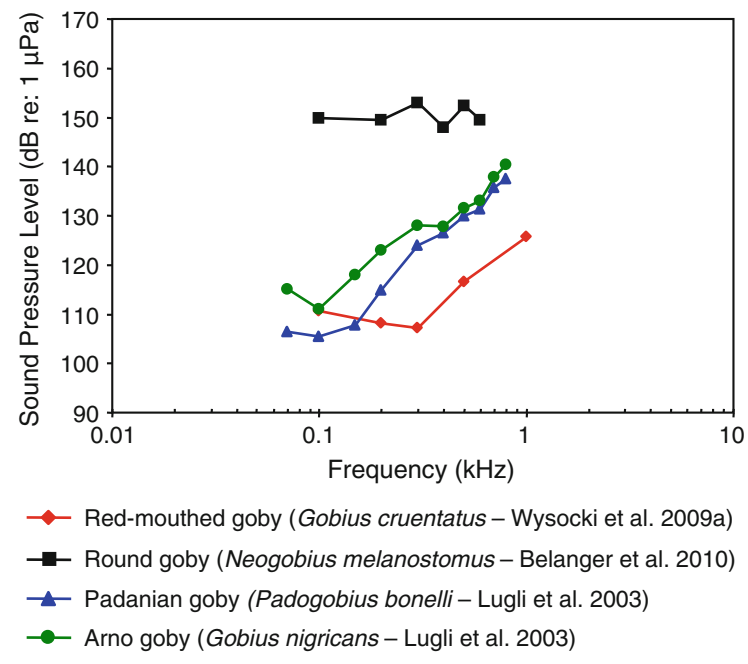

Fig. 26 Audiograms for four representatives of the perciform family Gobiidae. SPL audiograms are shown. The PAL audiogram of the red-mouthed goby Gobius cruentatus is shown in Fig. 25b. After Lugli et al. (2003), Wysocki et al. (2009a) and Belanger et al. (2010)

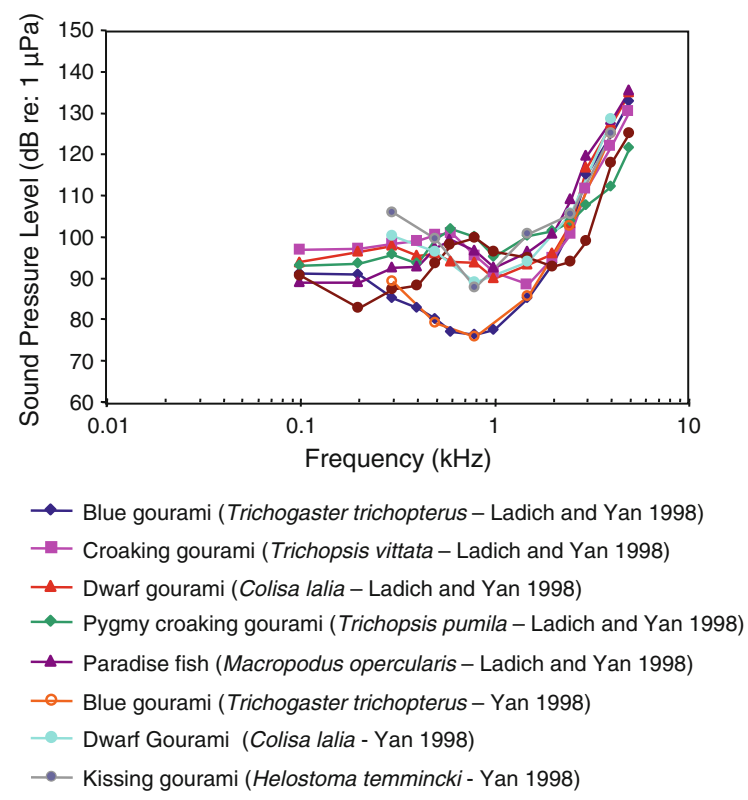

Fig. 27 Audiograms for representatives of the closely related perciform families Osphronemidae and Helostomatidae (labyrinth fishes or gouramis). After Ladich and Yan (1998) and Yan (1998)

the brown meagre Sciaena umbra (Wysocki et al. 2009a). In general, they have similar audiograms, with a very low frequency of best hearing in terms of particle acceleration $(<100-400 \mathrm{~Hz}-$ Fig. 21b). The relatively high sound pressure thresholds (above $90 \mathrm{~dB}$ in Fig. 21a) and the low frequency shape of the particle acceleration audiograms (Fig. 21b) suggest that they are not primarily sound-pressure sensitive. The brown meagre (Wysocki et al. 2009a) and the silver perch Bardiella chrysoura (Ramcharitar et al. 2004) may be exceptions, having relatively low sound pressure thresholds and a wide bandwidth of hearing, suggesting that they may respond primarily to sound pressure. The silver perch possess forward extentions of the swim bladder that increase the probability that they respond primarily to sound pressure but such extensions are lacking in the brown meagre. The sciaenid audiograms shown in Fig. 22 were determined in essentially the same lab using similar techniques. These species are likely to be more sensitive to particle acceleration because of the lowfrequency hearing range and the relatively high sound pressure thresholds.

Representatives of the species-rich family Cichlidae (more than 1,300 species) of Figs. 23 and 24a and $\mathrm{b}$ represent a large diversity in hearing sensitivities due to the large differences in swim bladder anatomy. Some possess tiny reduced swim bladders (slender lionhead cichlid Steatocranus tinanti), some large swim bladders (jewel cichlid Hemichromis guttatus) and some anterior extensions of the swim bladder contacting the inner ear (orange chromide Etroplus maculatus and Paratilapia polleni) (Schulz-Mirbach et al. 2012). Thus some are likely particle acceleration sensitive due to the low-pass nature of the audiogram shapes (best frequency of hearing $<100 \mathrm{~Hz}$ ) and some sound pressure sensitive. The audiograms of the cichlid Astatotilapia burtoni are given in Fig. 73.

Comparison of the SPL and PAL audiograms for Etroplus and Paratilapia (Fig. 24a, b) reveals that the particle acceleration audiograms show good sensitivity out to much higher frequencies than is the case for some other cichlids (Hemichromis and Steatocranus). The sound pressure curves for Etroplus and Paratilapia are similarly quite sensitive at the higher frequencies. This comparison could be explained in at least two ways. The first possible explanation is that Etroplus and Paratilapia are both primarily sensitive to sound pressure and that plotting their audiograms in particle acceleration terms only reflects PALs in the tank at threshold. A second possible explanation is that these two species possess additional frequency-selective peripheral channels tuned at higher frequencies 
that are also activated by particle acceleration. Presently, we do not have enough experimental data to critically evaluate these two possibilities.

Members of the family Pomacentridae of Fig. 25a and $\mathrm{b}$ fall into two groups based on sound pressure thresholds, with the tomato clownfish Amphiprion frenatus, Mediterranean damselfish Chromis chromis, yellow clownfish Amphiprion clarkii, and clown anemone fish Amphiprion ocellaris much more sensitive below about $800 \mathrm{~Hz}$. However, all these species have relatively high sound pressure thresholds $(>90-100 \mathrm{~dB})$ and a low-pass shaped audiogram, suggesting that they are primarily sensitive to particle acceleration. Figure 25b, however, indicates relatively high particle acceleration thresholds for the two species investigated.

The Gobiidae of Fig. 26 have relatively high sound pressure thresholds $(>100 \mathrm{~dB})$ but diverse audiogram shapes. The round goby Neogobius melanostomus is probably sensitive only to particle acceleration based on its high sound pressure thresholds, as is probably the Padanian goby Padogobius bonelli (formerly martensi) and the Arno goby Gobius nigricans, based on their low-frequency best hearing frequency $(<100 \mathrm{~Hz})$. Gobiids sometimes lack swim bladders.

The gouramis (families Osphronemidae and Helostomatidae) of Fig. 27 are probably all sensitive to sound pressure due to their suprabranchial air-breathing organ closely attached to the inner ear. Audiogram reveal wide bandwidth of hearing and fairly sensitive sound pressure thresholds. The blue gourami Trichogaster trichopterus seems unusual in having a bandpass shaped audiogram with a best frequency of $800 \mathrm{~Hz}$, although it is similar to the others in having relatively good high-frequency hearing $(>3,000 \mathrm{~Hz})$ (See "Using AEP-technique to investigate accessory hearing structures" section).

The African lungfish Protopterus annectens (family Protopteridae) of Fig. 28a and b has been shown to be particle acceleration sensitive (Fig. 28b), although its particle acceleration thresholds seem unusually high, and its bandwidth of hearing is relatively wide $(>2,000 \mathrm{~Hz})$. The AEP method used here (Christensen-Dalsgaard et al. 2011) was unique in that the thresholds were obtained using a masking paradigm in which a broad band impulse, containing a wide range of frequencies was the signal and long duration pure tones of various frequencies served as maskers. This technique was used in order to obtain reliable thresholds at especially low frequencies, but the thresholds obtained this way were not compared at higher frequencies with thresholds obtained using the standard AEP method (e.g., Kenyon et al. 1998).

General discussion of baseline audiograms

A comparison of hearing sensitivities in closely related species reveals a variety of trends. Hearing thresholds are either quite similar in some taxa such as catfishes (order Siluriformes, Figs. 13, 14 and 15) or in different species of drums (family Sciaenidae, Figs. 21a, b, 22), or audiograms resemble each other at certain frequencies e.g., in salmonids (family Salmonidae, Fig. 16). In some species or families audiograms deviate from each other considerably such as in toadfishes (family Batrachoididae, Fig. 17), cyprinids and damselfish (family Pomacentridae, Fig. 25a). In cyprinids differences in thresholds of up to $50 \mathrm{~dB}$ were found at particular frequencies (Fig. 11). Differences between species within a family could be due to real differences in sensitivity but, as it is suggested for cyprinids, toadfishes and gobiids, these could be due to different methods applied, including the acoustic characteristics of the test tanks. Reasons for this phenomenon have been discussed in goldfish by Hawkins (1981) for the diversity of behavioral audiograms and by Ladich and Wysocki (2009) and in "Comparison of different AEP-protocols"section for AEP audiograms.

Comparing audiograms from different taxa reveals general trends. Fishes lacking hearing spezializations such as elasmobranchs (sharks and rays), sturgeons, salmonids, pikes (Esocidae), gobiids, some cichlids, damselfish, sunfish (Centrarchidae) have best sound pressure hearing thresholds at $90 \mathrm{~dB}$ re $1 \mu \mathrm{Pa}$ or higher and maximal upper frequencies of 1-2 kHz (Figs. 8, 9, $16,17,18,19,23)$. For most species lacking hearing specializations and having particle acceleration threshold measurements, minimum thresholds are in the range between 30 and $40 \mathrm{~dB}$ re: $1 \mu \mathrm{m} \mathrm{s}^{-2}$, and best detection frequencies tend to be very low $(<100 \mathrm{~Hz})$. In contrast, species possessing hearing specializations such as weakly electric fish (family Mormyridae), otophysines and gouramis (Figs. 9, 11, 12, 13, 14, 15, 27) have best hearing thresholds (sound pressure) below $90 \mathrm{~dB}$ and upper frequency limits of 3-6 kHz (Ladich 1999; Yan and Curtsinger 2000; Lechner and 
Ladich 2008 etc.). In additional species such as the silver perch (family Sciaenidae, Fig. 22), the cichlids (Etroplus and Paratilapia, Figs. 23 and 24a), and the silver mojarra Eucinostomus argenteus (family Gerreidae, Fig. 20) a close connection between the swim bladder and the inner ear has been found and their sound pressure thresholds are accordingly low (Ramcharitar et al. 2004; Parmentier et al. 2011; SchulzMirbach et al. 2012). It must also be noted that the relationship between morphological connections and hearing sensitivities are not always straightforward. In clupeids swim bladders are connected to the inner ear via an anterior extension but hearing sensitivities are relatively poor (Fig. 10). None of the clupeid species exhibits auditory thresholds below $100 \mathrm{~dB}$ (Mann et al. 2001). The hearing specialization obviously evolved for detecting ultrasound in some species (subfamily Alosinae) (Fig. 10), but is not particularly effective for detecting low levels at the lower frequencies (American shad, Gulf menhaden, subfamily Alosinae). Among sciaenids bearing swim bladders, those possessing diverticulae (weakfish Cynoscion regalis, spotted seatrout Cynoscion nebulosus and Atlantic croaker Micropogonias undulatus) had generally lower pressure thresholds than species lacking diverticulae (spot and red drum). However, the lowest sound pressure thresholds at higher frequencies (800-1,100 Hz) occurred in northern kingfish Menticirrhus saxatilis, a species with low hair cell densities and swim bladder that atrophies as adults (Ramcharitar et al. 2001). These lower sound pressure thresholds of kingfish may be due to a combination of particle acceleration and sound pressure sensitivity (Horodysky et al. 2008).

\section{Using AEP-technique to investigate accessory hearing structures}

Many fish taxa possess accessory hearing structures which are thought to enhance their hearing sensitivities by extending the detectable frequency range and by lowering their hearing thresholds. This is made possible by connecting the inner ear to air-filled cavities and transmitting the oscillations of the wall of these cavities in a field of fluctuating sound pressure to the inner ears. Accessory hearing structures have developed in numerous species. Some taxa such as some holocentrids and clupeids develop anterior swim bladder horns, otophysines possess Weberian ossicles, whereas gouramis and mormyrids possess air-filled bubbles touching the inner ear without being connected to the swim bladder (for reviews see Ladich and Popper 2004; Braun and Grande 2008). Experiments that include removal of the gas cavity are one of the ways to help determine whether or not the species studied is primarily pressure sensitive or particle acceleration sensitive. If removal of the gas bladder results in a reduction of sound pressure sensitivity, then the species studied is probably primarily soundpressure sensitive; if not, then the species is primarily particle acceleration sensitive, at least in the acoustic test tank environment employed. After a swim bladder is deflated, the fish becomes, in effect, only sensitive to particle motion which was generally not measured in the studies reviewed here. The differences in pre- and post-deflation audiograms possibly reflect differences in PAL in the tanks used, and/or differences in particle motion sensitivity of the species studied. Before the introduction of the AEP-technique several authors investigated the functional significance using behavioral or microphonic techniques to study this question (Schneider 1941; Poggendorf 1952; Kleerekoper and Roggenkamp 1959; Fay and Popper 1974, 1975).

The AEP-techniques proved to be a useful tool to measure the status of auditory sensitivity after eliminating the accessory hearing structures. The AEPtechnique is typically a non-invasive approach and thus animals can be measured repeatedly before and after the elimination of various morphological structures.

Removal of the gas from the otic gas bladder in black baby whale, a weakly electric mormyrid, resulted in a nearly parallel decline in sensitivity (about $6 \mathrm{~dB}$ to a maximum of $15 \mathrm{~dB}$ at $500 \mathrm{~Hz}$ ) from $100 \mathrm{~Hz}$ to $4 \mathrm{kHz}$ (Yan and Curtsinger 2000) (Fig. 29).

Clupeids possess anterior bulla-like extensions of the swim bladder which are in contact with the utricle and lateral line canal on the head. Wilson et al. (2009) investigated in what way this accessory hearing structure contributes to sensitivity to ultrasound in the Gulf menhaden. Filling the gas-filled bullae with Ringer solution reduced the response of the auditory system to $40 \mathrm{kHz}$ tone bursts measured by the AEP technique indicating that the air-filled bullae are necessary for ultrasonic hearing.

The function of the swim bladder and the Weberian apparatus has been investigated in the goldfish using different experimental approaches. Ladich and 

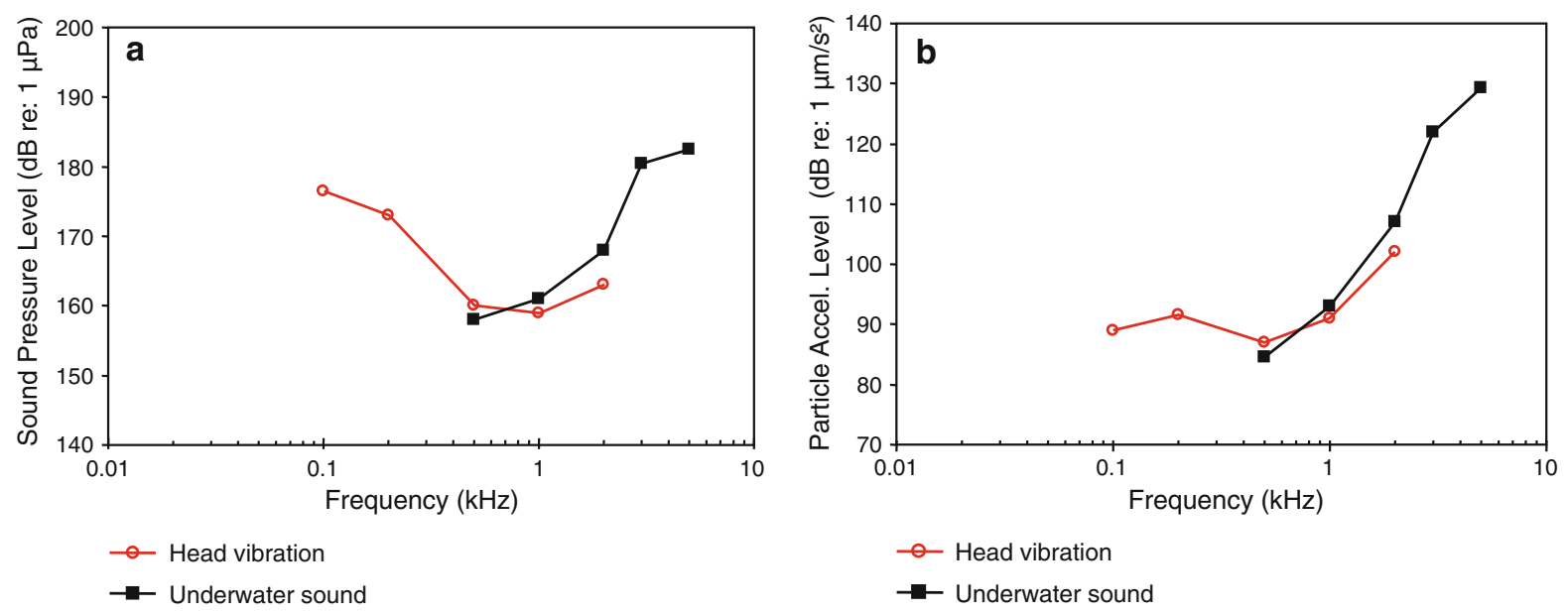

Fig. 28 Audiograms for the African lungfish Protopterus annectens. a SPL audiogram and b PAL audiogram. After ChristensenDaalsgard et al. (2011)

Wysocki (2003) removed the tripodes, the most caudal of the Weberian ossicles, and observed a highly frequency-dependent increase in thresholds from $7 \mathrm{~dB}$ at $100 \mathrm{~Hz}$ up to $35 \mathrm{~dB}$ at $2 \mathrm{kHz}$ (Fig. 30).

Yan et al. (2000) investigated the effect of swim bladder deflation in the goldfish and observed a rise in thresholds of approximately $50 \mathrm{~dB}$ between $300 \mathrm{~Hz}$ to $1.5 \mathrm{kHz}$ and a somewhat smaller drop at 2.5 and $4 \mathrm{kHz}$ (Fig. 31). Interestingly, elimination of the Weberian ossicles and the swim bladder had different effects in both goldfish studies (Figs. 30, 31). Swim bladder deflation affected hearing thresholds in the goldfish but not in the non-related oyster toadfish or the blue gourami (Yan et al. 2000). The latter two results indicate that the swim bladder is not connected acoustically to the inner ear in toadfishes and gouramis. One caveat regarding gas bladder deflation experiments is that negative findings (no effect of deflation) may not indicate the true effectiveness of the bladder for hearing in the species' normal habitat. In deeper water (deeper than in the AEP measurement situation), where the ratio between sound pressure to particle velocity is expected to be considerably higher (higher impedance) the contribution of the swim bladder to hearing will appear greater than at the surface (Poggendorf 1952).

In representatives of the family Cobitidae (loaches), an otophysine family closely related to cyprinids, a second accessory hearing structure evolved in addition to Weberian ossicles. Loaches have a cranial encapsulation of the anterior part of the swim bladder and in addition special channels stretching laterally from the swim bladder to the outer body wall. These lateral trunk channels form a muscle-free window beneath the skin. Filling the lateral trunk channels with cotton/rayon stapple in the red finned loach Yasuhikotakia modesta resulted in an increase in thresholds of 14-18 dB indicating mechanical damping of the swim bladder (Fig. 32) (Kratochvil and Ladich 2000). These experiments indicate that lateral trunk channels enhance hearing sensitivity of cobitid fishes.

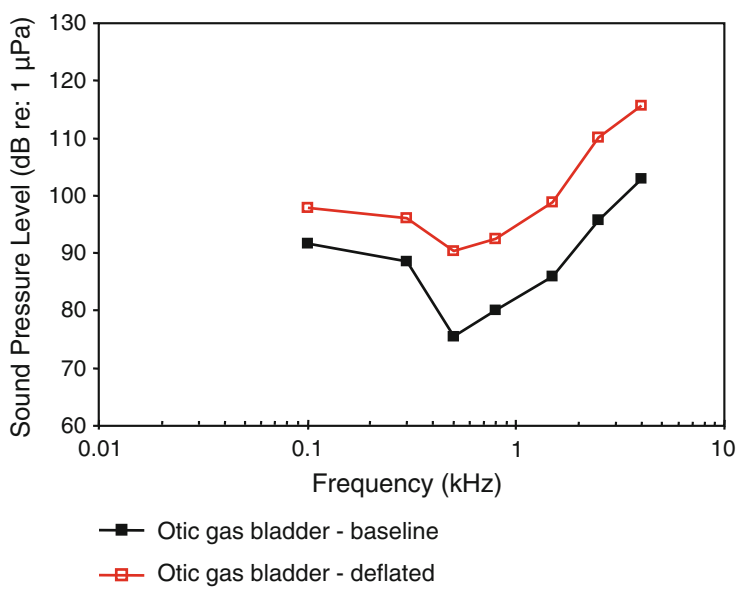

Fig. 29 Hearing sensitivity in the black baby whale Brienomyrus brachyistius before and after removal of the gas from the otic gas bladder. After Yan and Curtsinger (2000) 


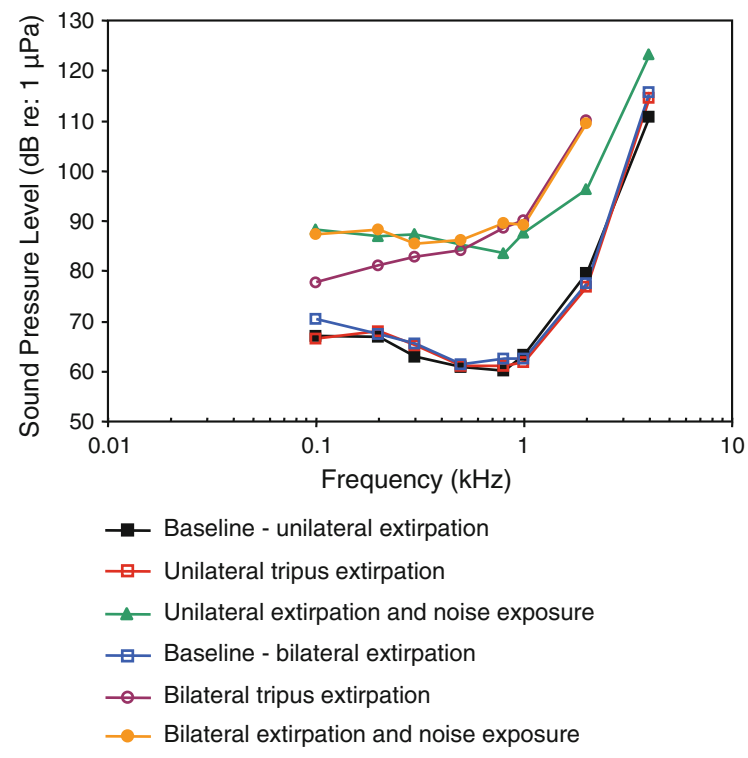

Fig. 30 Hearing sensitivity in the goldfish before and after unilateral and bilateral extirpation of the tripodes. In addition, the effects of noise exposure in unilaterally and bilaterally extirpated animals are shown. After Ladich and Wysocki (2003)

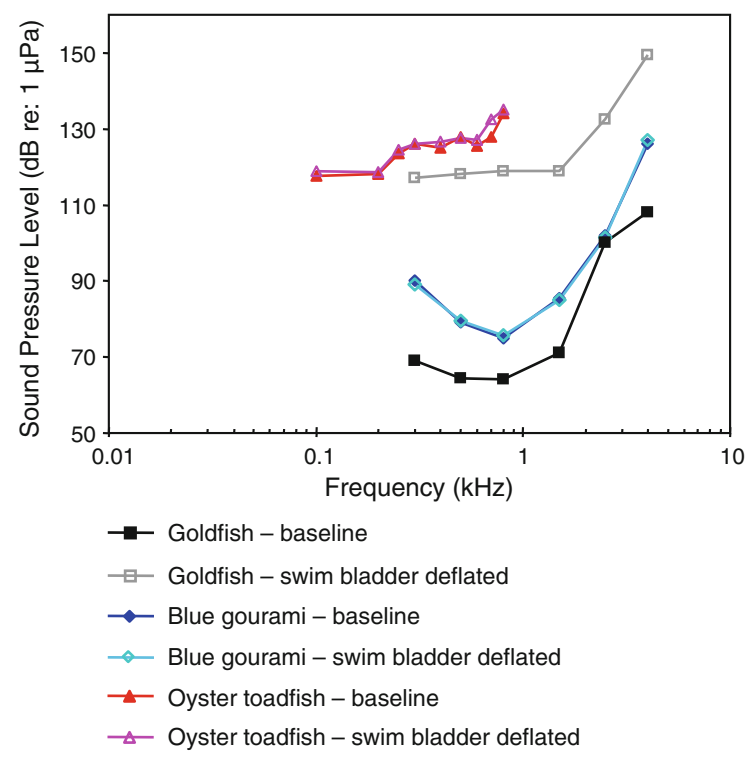

Fig. 31 Effects of swim bladder deflation in the goldfish, the oyster toadfish Opsanus tau and the blue gourami Trichogaster trichopterus. Swim bladder deflation affected hearing sensitivity only in the goldfish. After Yan et al. (2000)

Gouramis or labyrinth fishes (suborder Anabantoidei) possess suprabranchial air-breathing chambers which enhance their hearing sensitivity as demonstrated by Schneider (1941) by conditioning the fish. Filling the chambers with water in three more gourami species (blue gourami; kissing gourami Helostoma temminckii; dwarf gourami Colisa lalia) resulted in an increase in thresholds between 5 and $25 \mathrm{~dB}$ as shown by Yan (1998) using the AEP technique (Fig. 33). The decrease was lowest at the highest frequencies $(4 \mathrm{kHz})$. These results corroborate the hearing function of these airbreathing organs.

\section{Applying AEP-techniques to study ontogenetic development of hearing}

Due to the difficulty training or conditioning juvenile fish of a few millimeter length, just one study investigated the ontogenetic development of hearing sensitivity using behavioral techniques (Kenyon 1996). Kenyon (1996) measured the hearing sensitivity in the bicolor damselfish Stegastes (formerly Eupomacentrus) partitus. Since the introduction of the AEP protocol in 1998 the ontogenetic development of hearing sensitivity has been investigated in eight species using the AEP technique, one representative of the family Clupeidae, one of the family Cyprinidae, two catfish species, one toadfish species and two perciforms. In general, hearing thresholds were given in sound pressure units but it is assumed that all fish species including those possessing hearing specialization are also particle acceleration sensitive.

Following the systematics by Nelson (2006) the family Clupeidae will be discussed first. Higgs et al. (2004)

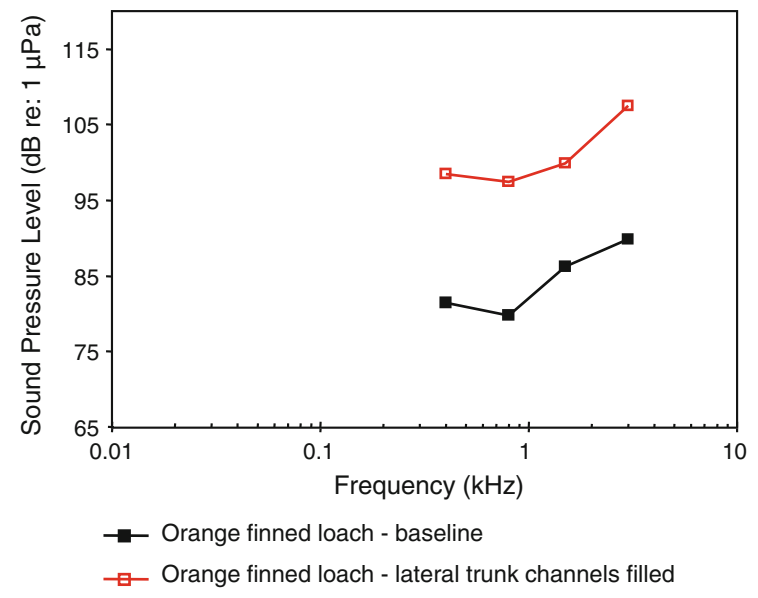

Fig. 32 Auditory thresholds of the red finned loach Yasuhikotakia modesta before (baseline) and after filling the lateral trunk channels. After Kratochvil and Ladich (2000) 


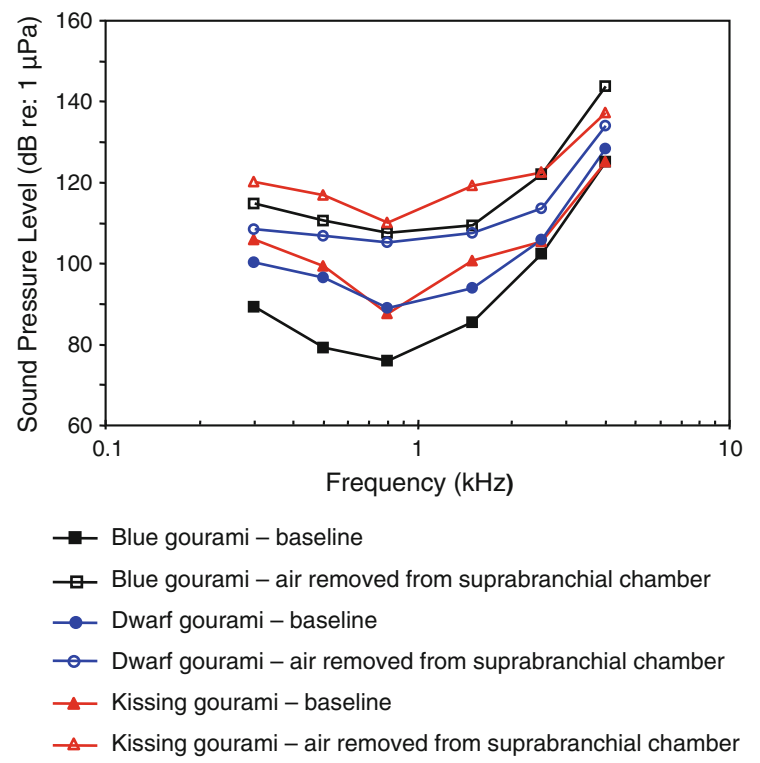

Fig. 33 Effects of the removal of gas from the suprabranchial air-breathing organs by filling it with water in three gourami species, the blue gourami Trichogaster trichopterus, the dwarf gourami Colisa lalia and the kissing gourami Helostoma temmincki. After Yan (1998)

investigated the development in the American shad in order to find out when ultrasound detection begins. AEP thresholds in 4 different stages starting from 30 to $39 \mathrm{~mm}$ from 0.1 to $90 \mathrm{kHz}$ were measured (Fig. 34). The sensitivity to sounds including ultrasound did not change developmentally for these size ranges.

Among otophysines the development in the zebrafish, a representative of the order Cypriniformes, and two catfish species have been studied. In the zebrafish, Higgs et al. (2001, 2003) observed an expansion of maximum detectable frequency from $200 \mathrm{~Hz}$ at $10 \mathrm{~mm}$ to $4,000 \mathrm{~Hz}$ at $45 \mathrm{~mm}$ total length (TL) but no change in auditory threshold, bandwidth, or best frequency over the size range of 34-50 mm TL (Fig. 35a, b).

In contrast to the zebrafish, a change in sensitivity was observed in both catfish species studied. In the squeaker catfish Synodontis schoutedeni (family Mochokidae) larger stages showed significantly lower thresholds at frequencies below $2 \mathrm{kHz}$ (Lechner et al. 2010) (Fig. 36). Similarly, in the African bullhead catfish Lophiobagrus cyclurus (family Bagridae), the smallest juveniles had the lowest auditory thresholds. They were unable to detect frequencies higher than 2 or $3 \mathrm{kHz}$ (Fig. 37). In the latter the increase in

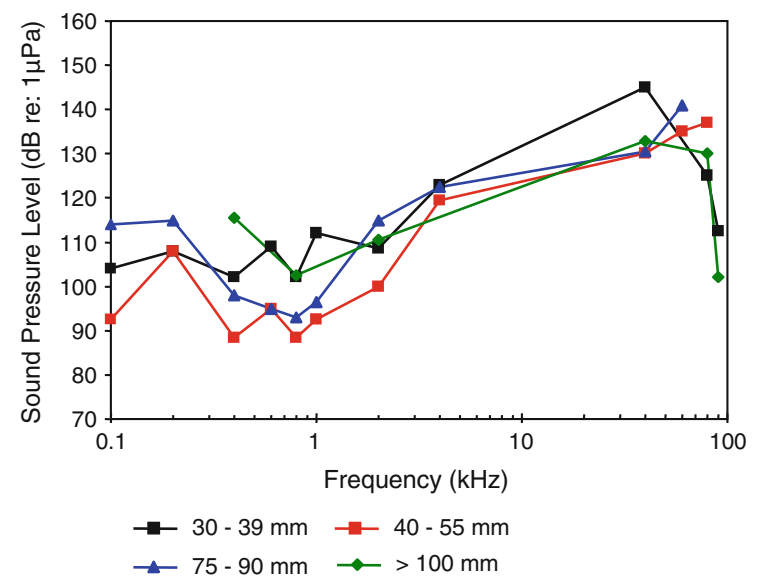

Fig. 34 Development of auditory sensitivity in the American shad Alosa sapidissima. After Higgs et al. (2004)

sensitivity and detectable frequency range was attributed to the development of interossicular ligaments between Weberian ossicles (Lechner et al. 2011).

Among toadfishes the development of auditory sensitivity was studied in the Lusitanian toadfish (Vasconcelos and Ladich 2008). The best hearing was below $300 \mathrm{~Hz}$ in all age/size groups. Statistically significant higher hearing thresholds were found in the smallest juveniles at $100 \mathrm{~Hz}$ as well as at higher frequencies $(800$ and $1,000 \mathrm{~Hz}$ ). A small increase in the detectable frequency range was observed with size increase (Fig. 38).

Within perciforms the ontogenetic development was measured in three species from three different families. Egner and Mann (2005) observed a change in sensitivity in the sergeant major damselfish Abudefduf saxatilis (family Pomacentridae) (Fig. 39) at 100 and $200 \mathrm{~Hz}$. Younger stages were more sensitive to sounds. The larger fish $(>50 \mathrm{~mm})$ were more likely to respond to higher frequencies $(1,000-1,600 \mathrm{~Hz})$.

In the round goby (family Gobiidae) Belanger et al. (2010) studied the hearing sensitivity in different sized stages from 40 to $120 \mathrm{~mm}$. No effect of size on hearing was observed. This lack of a change in sensitivity may partly be due to the fact that earlier stages have not been measured (Fig. 40). The sound pressure (Fig. 40a) and particle acceleration thresholds (Fig. 40b) are both unusually high in this study, but it is likely that this species is primarily sensitive to particle acceleration.

Within the third perciform family, the osphronemids, hearing development was investigated in the croaking 

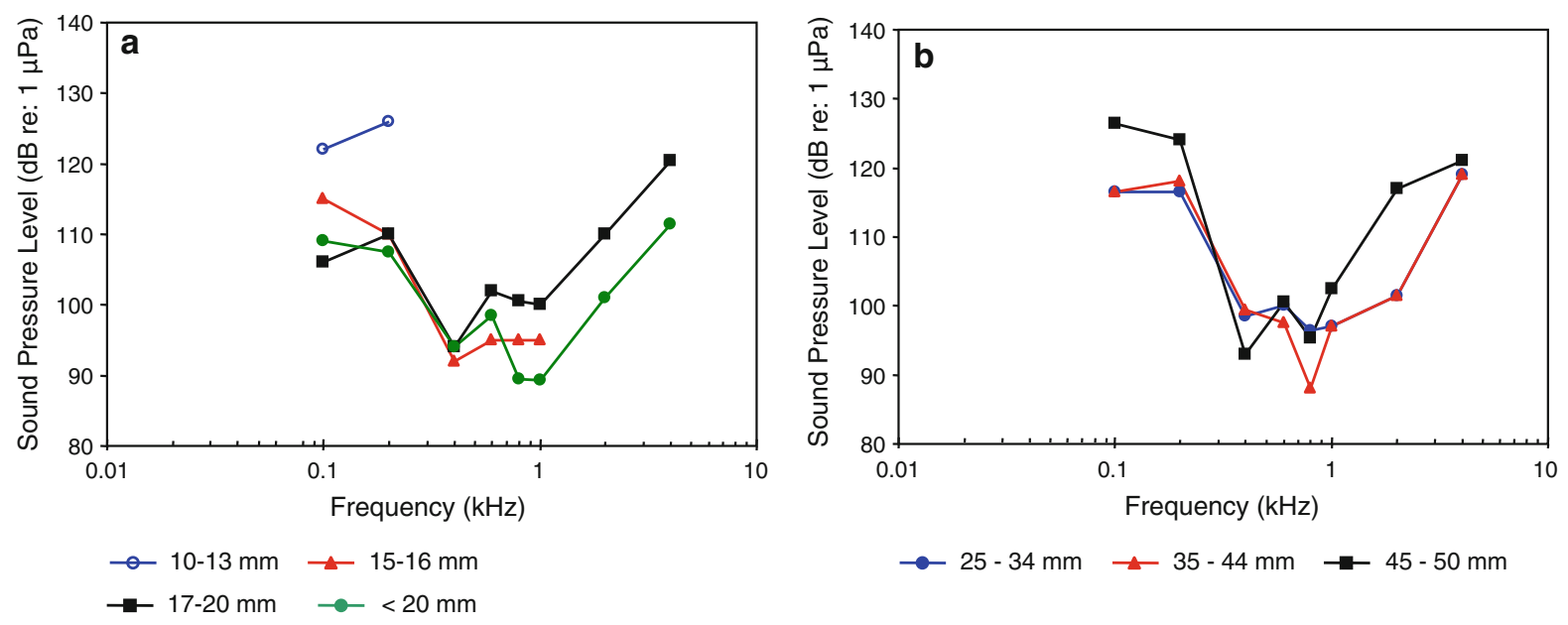

Fig. 35 Development of auditory sensitivity in the zebrafish Danio rerio from a 10-20 mm and b from $25-50 \mathrm{~mm}$. After Higgs et al. $(2001,2003)$

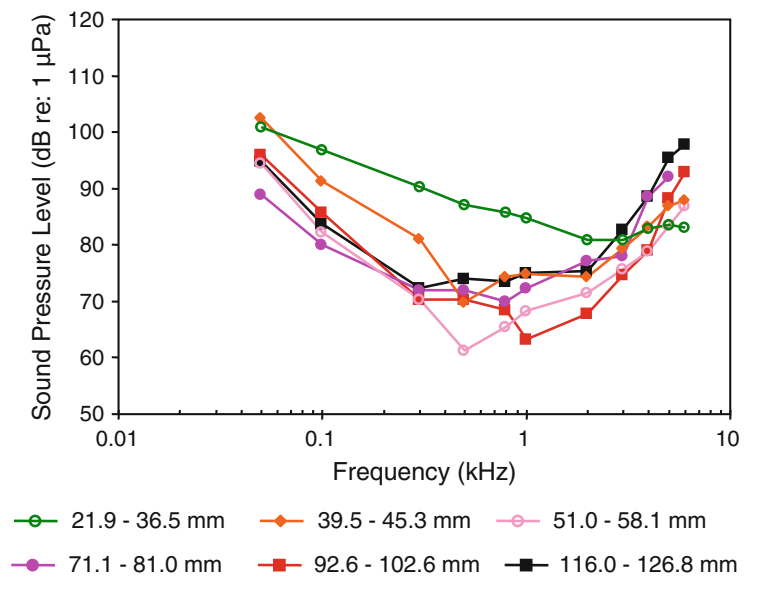

Fig. 36 Development of auditory sensitivity in the squeaker catfish Synodontis schoutedeni. After Lechner et al. (2010)

gourami Trichopsis vittata (Wysocki and Ladich 2001). Absolute sensitivity increased whereas the most sensitive frequency decreased with growth (Fig. 41). The changes in sensitivity were attributed to the developmental changes in the air-breathing suprabranchial chamber, which functions as an accessory hearing organ.

\section{Applying AEP-techniques to study the effects of noise exposure}

The effects of underwater noise on fish hearing have been investigated in two different ways. The first involved exposing fish to noise of high levels for different durations and studying the increase in

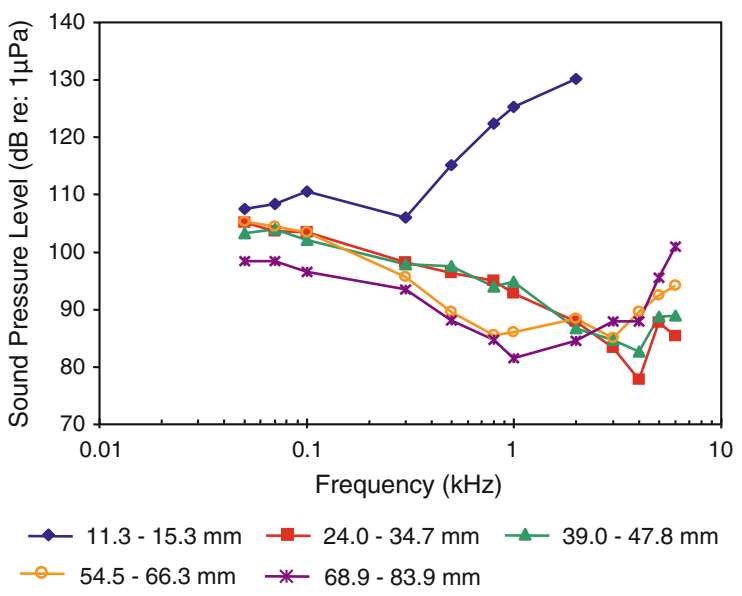

Fig. 37 Development of auditory sensitivity in the African bullhead catfish Lophiobagrus cyclurus. After Lechner et al. (2011)

auditory thresholds [temporary threshold shift (TTS)] afterwards. In addition, the time until fish recovered normal their hearing abilities was investigated. The second approach was to study the hearing sensitivity in the presence of noise (not after a certain period of noise exposure), a phenomenon known as masking. Masking effects are observable at much lower noise levels than effects of noise exposure, and occur in all vertebrates investigated (Fay 1988).

Noise exposure can result in a temporary increase in hearing thresholds (TTS) if the noise exposure levels are high enough; this varies considerably among species. The AEP-technique has proven to be very 


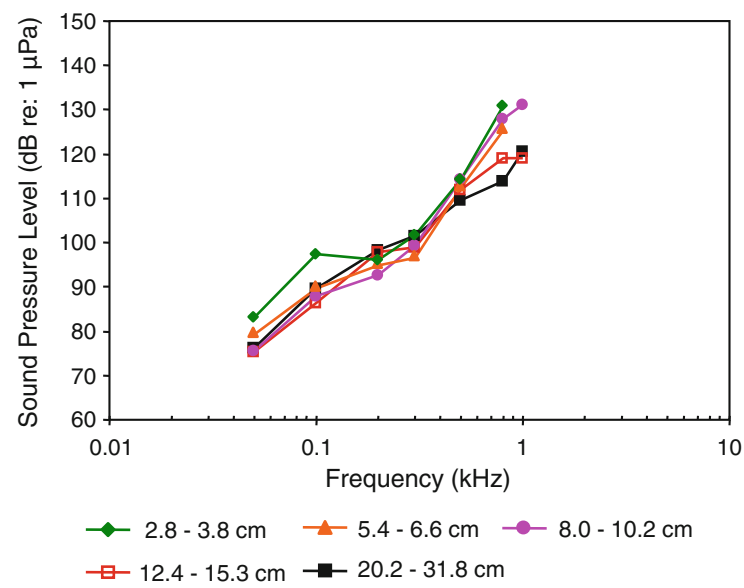

Fig. 38 Development of auditory sensitivity in Lusitanian toadfish Halobatrachus didactylus. After Vasconcelos and Ladich (2008)

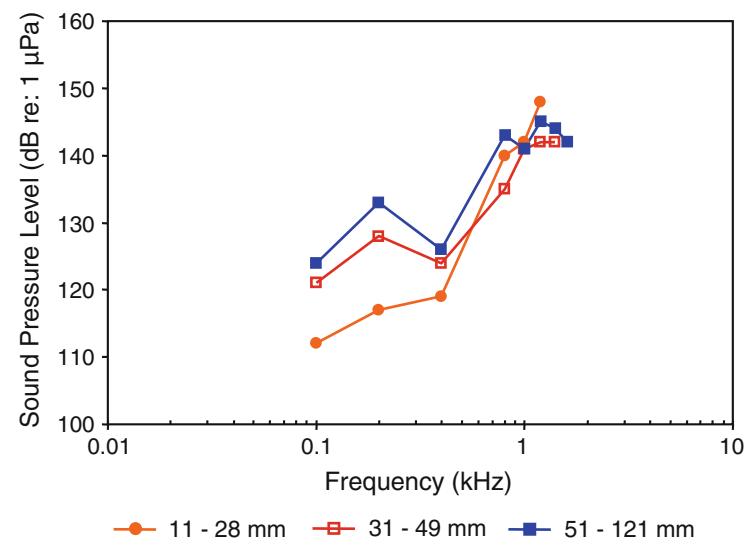

Fig. 39 Development of auditory sensitivity in sergeant major damselfish Abudefduf saxatilis. After Egner and Mann (2005)

useful for these investigations because fish could be measured repeatedly to study the degree and recovery from any TTS over short recovery periods. Different noise types have been used including white noise, ambient noise, sonar, seismic shots (the sounds from air guns used in seismic exploration) and pure tones.

Exposure to white noise

The majority of studies on white noise exposure were carried out in otophysines, in particular in cyprinids. The goldfish was the species most often used.

Amoser and Ladich (2003) studied TTS and recovery in the goldfish after exposure for 12 or $24 \mathrm{~h}$ of $158 \mathrm{~dB}$. The goldfish showed a significant rise (up to $26 \mathrm{~dB}$ ) in thresholds immediately after exposure. Exposure duration had no effect on thresholds in this study and recovery took 3 days (Fig. 42).

Smith et al. (2004a) exposed goldfish to different levels of white noise (between 110 and $160 \mathrm{~dB}$ ) for $24 \mathrm{~h}$ and found a correlation between time of exposure and TTS (Fig. 43a). Extending the exposure for 7 or 28 days resulted in no additional TTS in the goldfish or in the Nile tilapia Oreochromis niloticus (family Cichlidae) (Fig. 43b). In a subsequent study Smith et al. (2004b) found out that even $10 \mathrm{~min}$ of noise exposure $(160-170 \mathrm{~dB}$ ) resulted in a TTS of $5 \mathrm{~dB}$ (Fig. 44a). After 14 days of recovery thresholds were similar to baseline thresholds (Smith et al. 2004b) (Fig. 44a). In a subsequent study Smith et al. (2006) exposed goldfish to white noise of $170 \mathrm{~dB}$ for $48 \mathrm{~h}$ and found a small $4 \mathrm{~dB}$ TTS after 7 days of recovery (Fig. 44b).

Scholik and Yan (2001) exposed fathead minnows (family Cyprinidae) to white noise between 0.3 and $4 \mathrm{kHz}$ at $142 \mathrm{~dB}$ re $1 \mu \mathrm{Pa}$ for 1 to $24 \mathrm{~h}$ (Fig. $45 \mathrm{a}$ ). Immediately after exposure, fish showed significantly higher thresholds compared to the control baseline fish at most test frequencies. The exposure effects appear to reach asymptote with a $2 \mathrm{~h}$ exposure. Recovery did not occur for at least 14 days (Fig. 45b).

Amoser and Ladich (2003) studied the TTS and recovery in one representative of catfishes, the Amazonian pimelodid pictus cat Pimelodus pictus (family Pimelodidae), after exposure for 12 or $24 \mathrm{~h}$ at $158 \mathrm{~dB}$. The catfish showed a significant rise of thresholds of up to $32 \mathrm{~dB}$ after exposure. Exposure duration had no effect on sensitivity. Recovery took 14 days in the pictus cat (Fig. 46).

Scholik and Yan (2002a) exposed the bluegill sunfish Lepomis macrochirus (family Centrarchidae) to white noise at $142 \mathrm{~dB}$ for $24 \mathrm{~h}$ (Fig. 47). The noise exposure had only a minimal effect (from about 1 to $6 \mathrm{~dB}$ TTS). It is likely that pre-exposure thresholds determine the magnitude of the effect of noise exposure, with the most sensitive species showing a greater effect of noise exposure (e.g., Smith et al. 2004b). The bluegill (Fig. 47) is not very sensitive to sound.

Exposure to pure tones

Exposure to intense pure tones was carried out to find out if different frequencies cause damage in different frequency regions and possibly to different regions of the sensory epithelium. Smith et al. (2011) exposed 

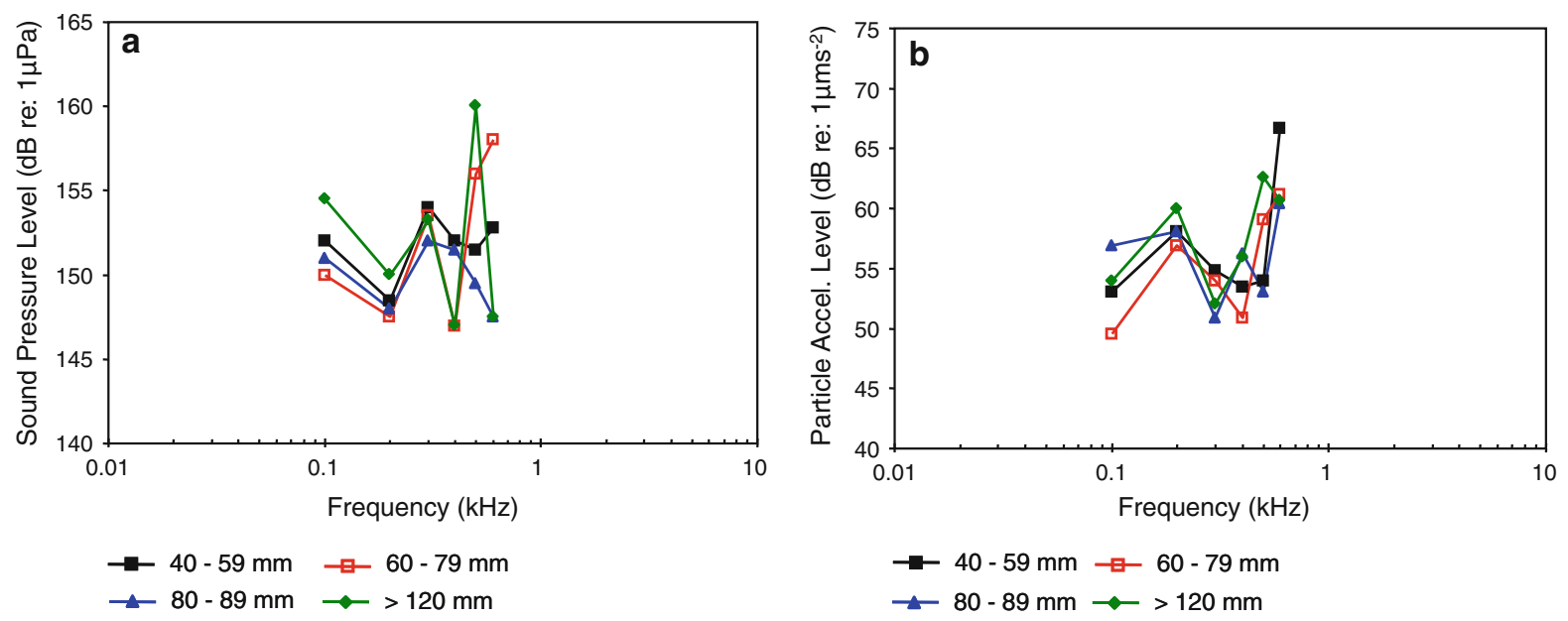

Fig. 40 Development of auditory sensitivity in round goby Neogobius melanostomus. a SPL audiograms and b PAL audiograms. After Belanger et al. (2010)

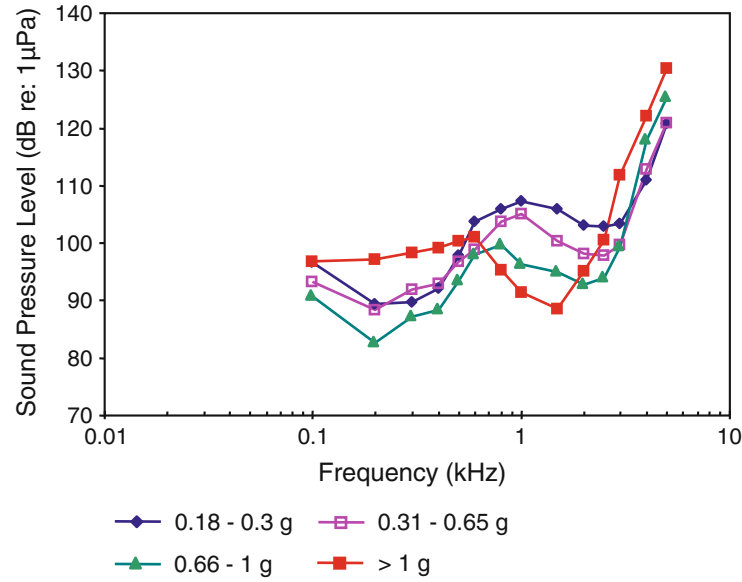

Fig. 41 Development of auditory sensitivity in croaking gourami Trichopsis vittata. After Wysocki and Ladich (2001)

goldfish to pure tones of 100, 800, 2,000 and 4,000 Hz for $48 \mathrm{~h}$ and found a frequency dependent TTS (Fig. 48). Smith et al. (2011) interpreted these findings as demonstrating a crude "place" representation of frequency on the saccular epithelium.

Exposure to anthropogenic noise

Exposure to anthropogenic noise of different origin again resulted in TTS depending on noise source and time of exposure indicating the negative effects of human-made noise on hearing thresholds in fishes. The effects of anthropogenic noise on fishes has recently become a significant topic in the field of hearing and other effects (e.g., Popper and Hawkins 2012). The literature on noise effects on fish hearing is relatively recent, and all of it has made use of AEP methods (see "Applying AEP-techniques to study the effects of masking in fish" section below for anthropogenic noise masking experiments).

Scholik and Yan (2002b) measured the effect of exposure to $2 \mathrm{~h}$ of recorded boat noise at $142 \mathrm{~dB}$ in the fathead minnow. TTS was primarily observed at frequencies at which main energies of engine noise was concentrated (Fig. 49).

Popper et al. (2005) investigated the effects of seismic shots from air guns (used in geophysical exploration) on the northern pike Esox lucius (Family Esocidae), the broad whitefish Coregonus nasus (family Coregonidae) and the lake chub Couesius plumbeus (family Cyprinidae) in the Mackenzie River Delta. Threshold shifts were found for exposed fish as compared to controls in the northern pike and lake chub, with recovery within 18 or $24 \mathrm{~h}$ of exposure, while there was no threshold shift in the broad whitefish (Fig. 50a, b).

Popper et al. (2007) measured the effects of lowfrequency active sonar (LFA) on the hearing thresholds of rainbow trout Oncorhynchus mykiss (Family Salmonidae). Animals were exposed to a maximum received SPL of $193 \mathrm{~dB}$ re $1 \mathrm{~Pa}^{2}$ for 324 or $648 \mathrm{~s}$. The TTS was more pronounced in one group of rainbow trout studied (group 1) than in another group (group 2) at $400 \mathrm{~Hz}$ (Figs. 51a, b).

Halvorsen et al. (2012) studied the effects of exposure to mid-frequency active sonar (MFA-a 


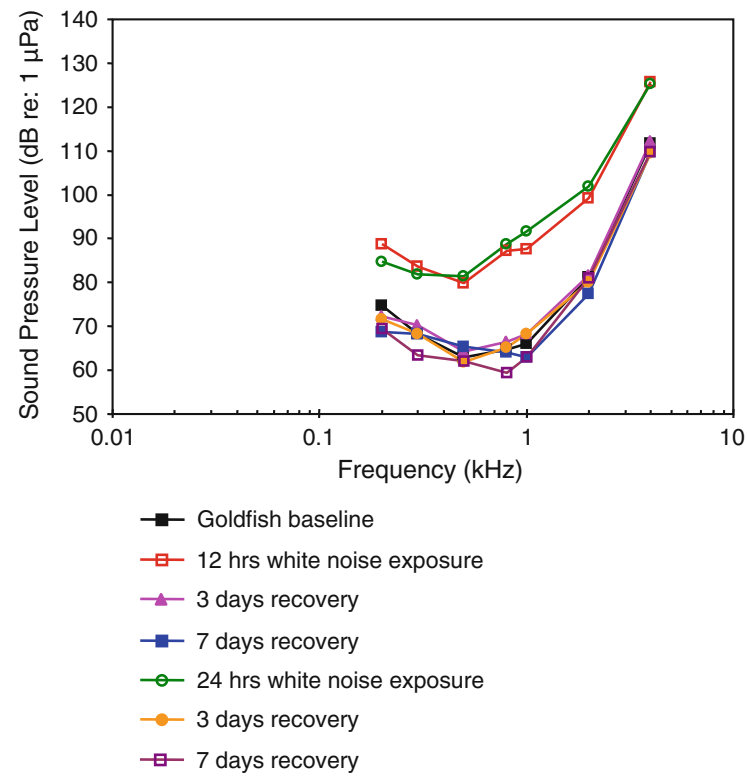

Fig. 42 Auditory sensitivity of the goldfish before (baseline) and after exposure to white noise for 12 or $24 \mathrm{~h}$ at $158 \mathrm{~dB}$. Thresholds are shown after 3 and 7 days of recovery. After Amoser and Ladich (2003)

military sonar) in rainbow trout and the channel catfish Ictalurus punctatus (family Ictaluridae) at SPLs of $210 \mathrm{~dB}$ between 2.8 and $3.6 \mathrm{kHz}$. The exposure level did not affect the hearing sensitivity of rainbow trout, a

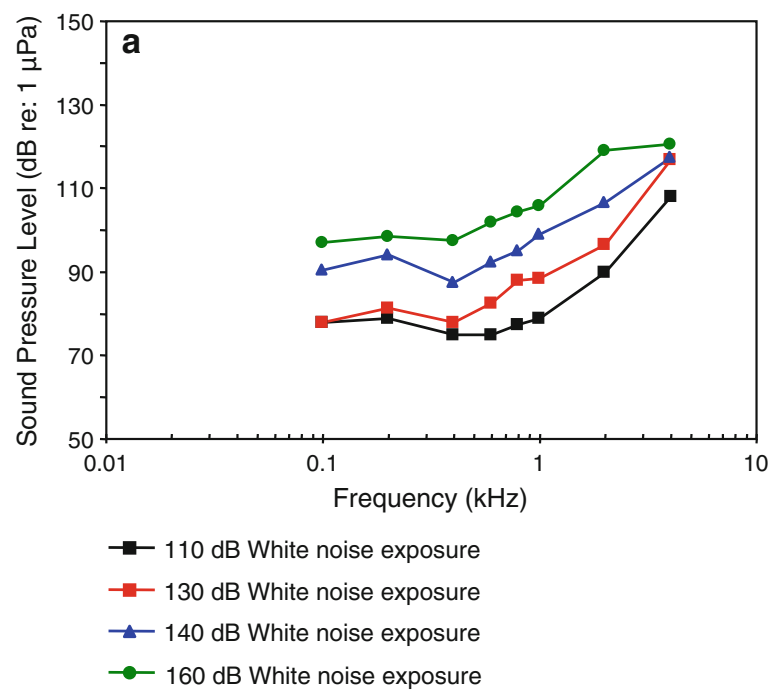

species whose hearing range is lower than the MFA frequencies, and is sensitive to particle acceleration. In contrast, one cohort of channel catfish (an otophysine) showed a TTS of 4-6 dB at $2.3 \mathrm{kHz}$, but not at lower tested frequencies, whereas a second cohort showed no change. The average of the two cohorts is plotted in Fig. 52.

To avoid mortality caused by passage through dam turbines and spillways, juvenile Chinook salmon Oncorhynchus tshawytscha are annually transported downstream by barges in the Western USA through the federal hydropower system on the Snake and Columbia rivers. Barging noise of about $136 \mathrm{~dB}$ resulted in a small but significant TTS in juveniles 7 days after barging (Halvorsen et al. 2009) (Fig. 53).

\section{Applying AEP-techniques to study the effects of masking in fish}

The hearing sensitivity in fish can be impaired in the presence of detectable noise, which raises the threshold above quiet conditions (masking). In contrast to the impairments mentioned in the previous section, the hearing thresholds are not measured after but during the occurrence of typically much

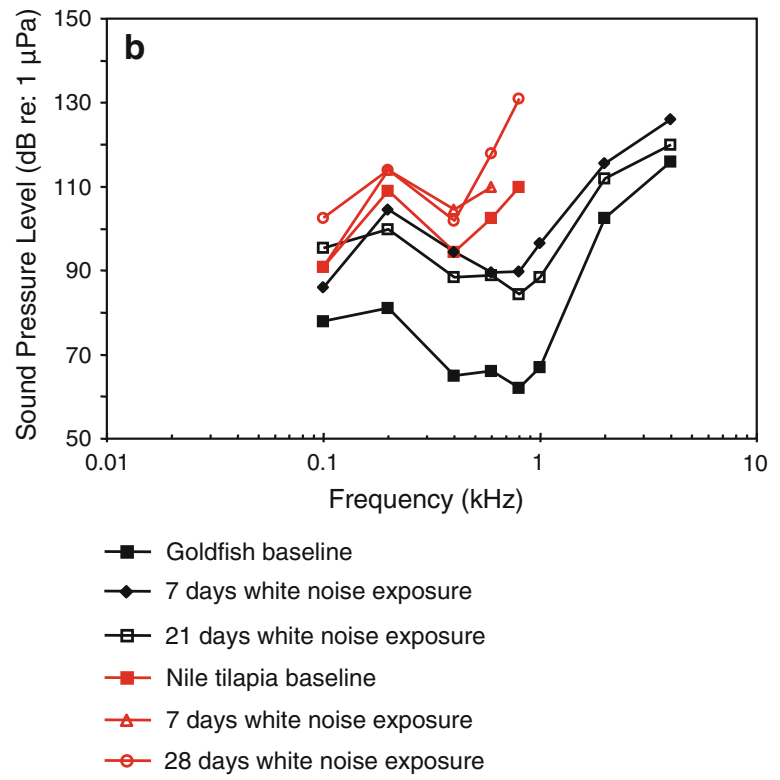

Fig. 43 Auditory sensitivity of the goldfish after exposure to white noise of a different levels and $\mathbf{b}$ different time periods. Effects of exposure to different time periods are also shown for the Nile tilapia Oreochromis niloticus. After Smith et al. (2004a) 

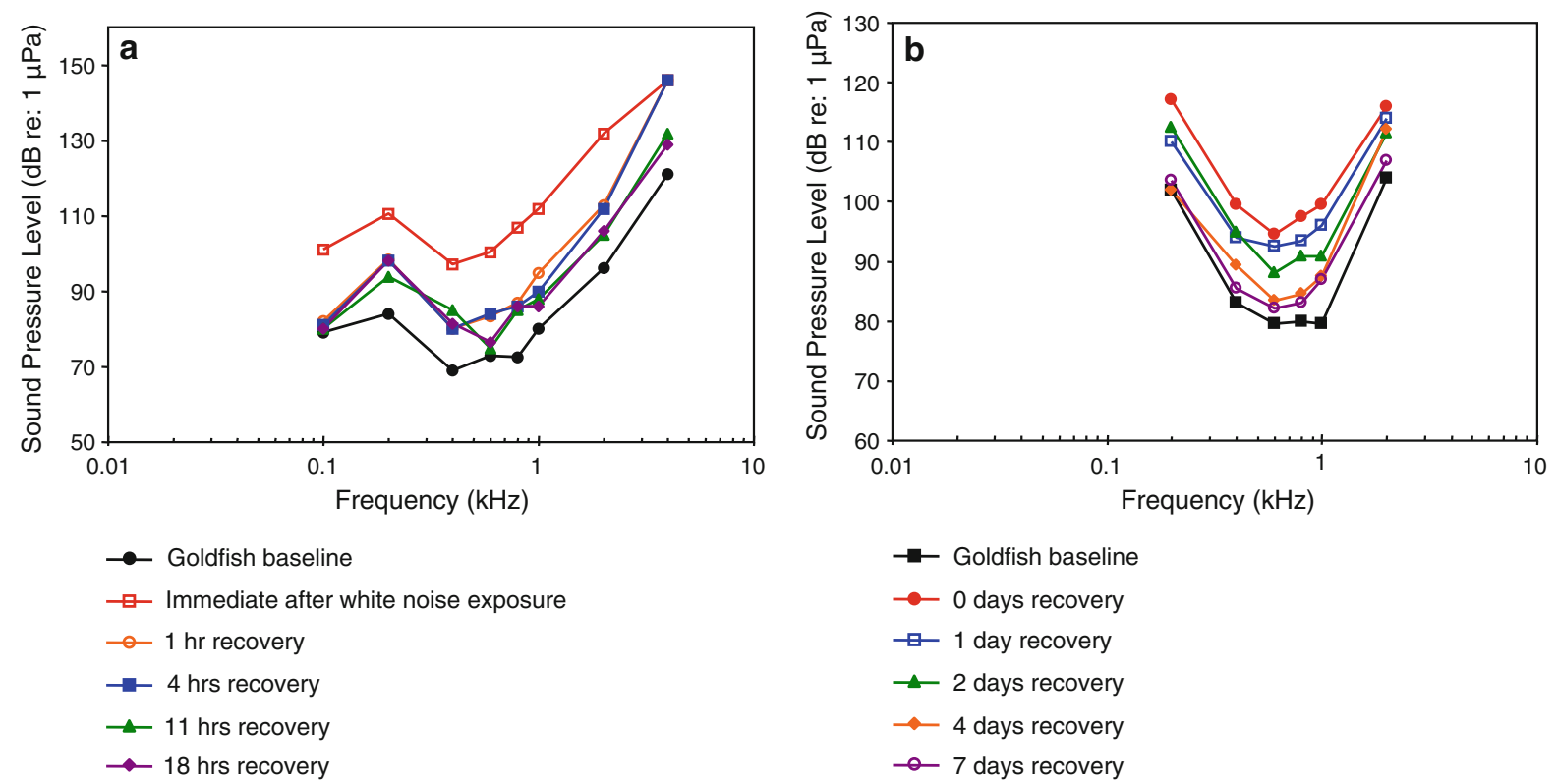

Fig. 44 Auditory sensitivity of the goldfish after exposure to white noise and after different periods of recovery. a Recovery for 0-18 $\mathrm{h}$ and b recovery for 0-7 days. After Smith et al. (2004b, 2006)
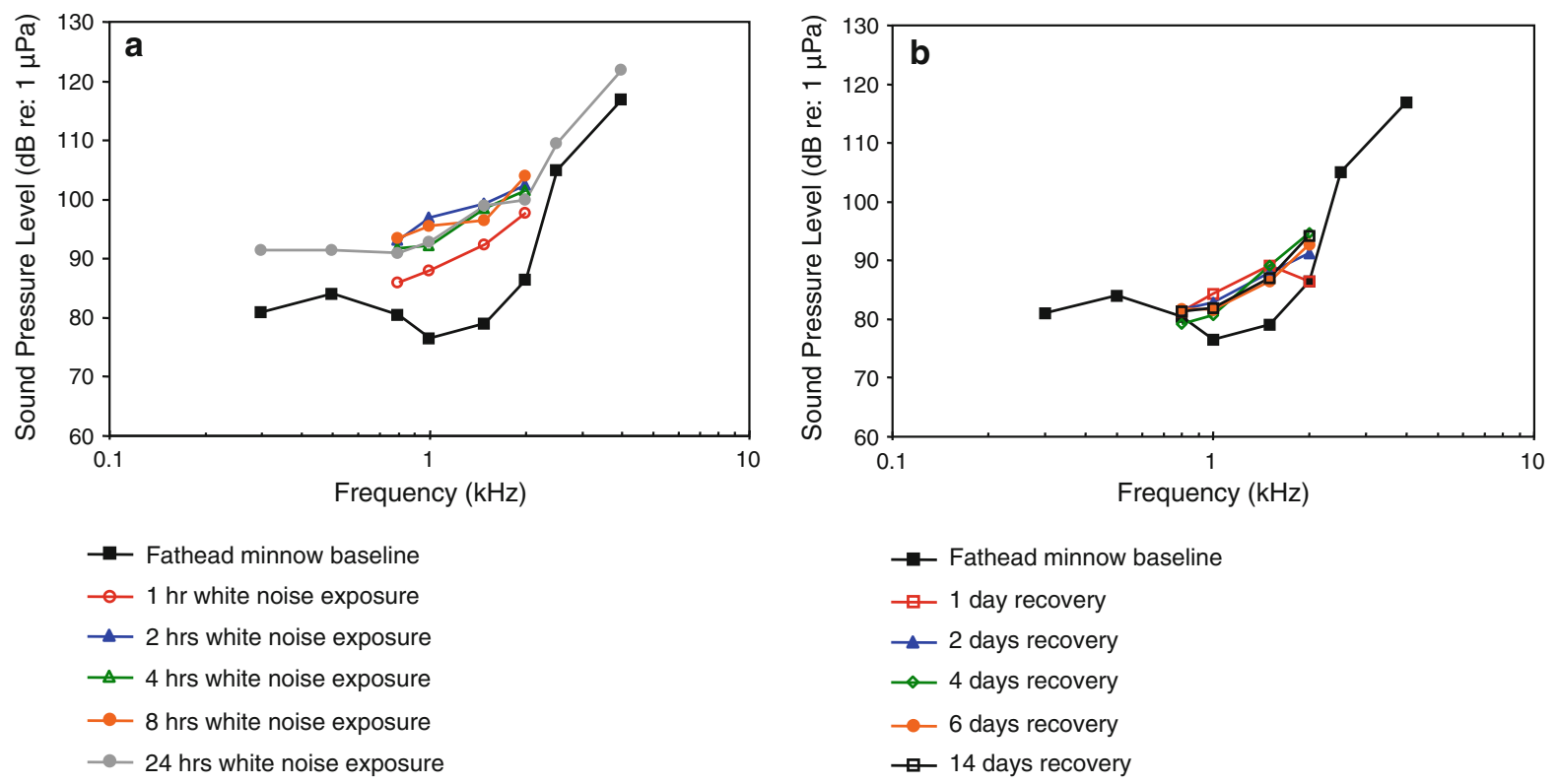

Fig. 45 Auditory sensitivity of the fathead minnow Pimephales promelas (a) before (baseline) and after exposure to white noise at $142 \mathrm{~dB}$ for 1-24 h. b gives thresholds after exposure to $24 \mathrm{~h}$ and recovery for certain time periods. After Scholik and Yan (2001)

lower noise levels and spectra. Different noise types have been applied to study masking effects, in particular white noise, natural ambient noise and anthropogenic noise. An increase in the background noise caused by natural or human activity sources may render the weakest sources undetectable, and may decrease the distance at which all sources can be detected. 


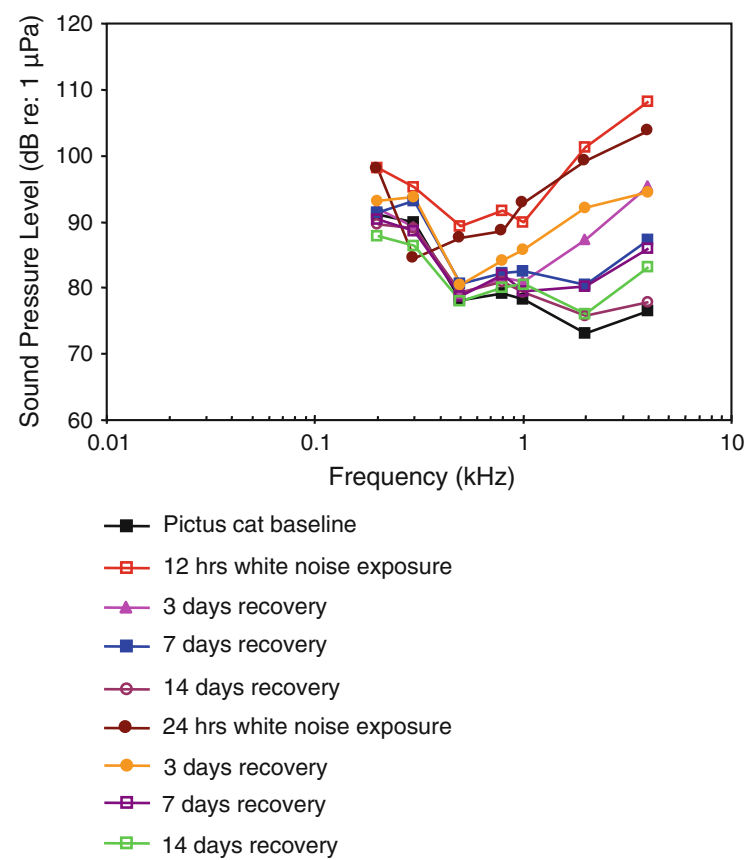

Fig. 46 Auditory sensitivity of the pictus cat Pimelodus pictus before (baseline) and after exposure to white noise at $158 \mathrm{~dB}$ for 12 or $24 \mathrm{~h}$. Thresholds are shown after 3 and 7 days of recovery. After Amoser and Ladich (2003)

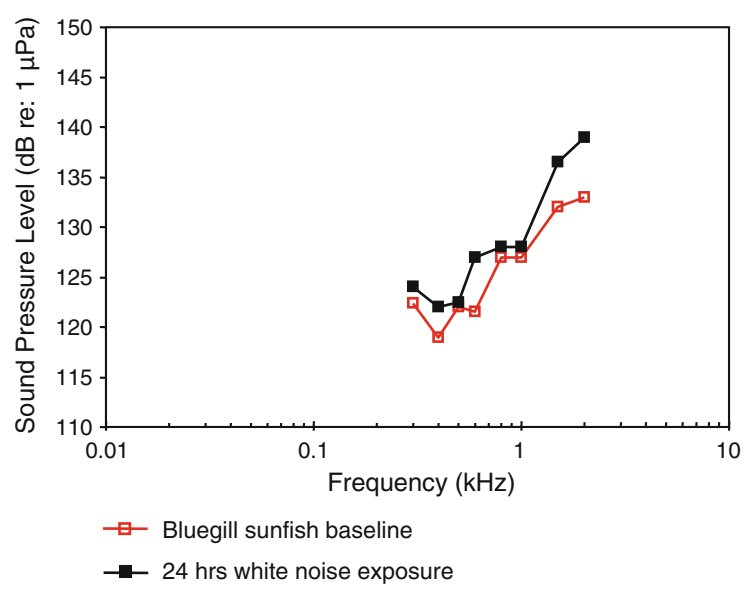

Fig. 47 Auditory sensitivity of the bluegill sunfish Lepomis macrochirus before (baseline) and after exposure to white noise (142 dB) for $24 \mathrm{~h}$. After Scholik and Yan (2002a)

White noise masking

Wysocki and Ladich (2005a) investigated the effects of white noise on the hearing sensitivity in the goldfish, the striped Raphael catfish Platydoras

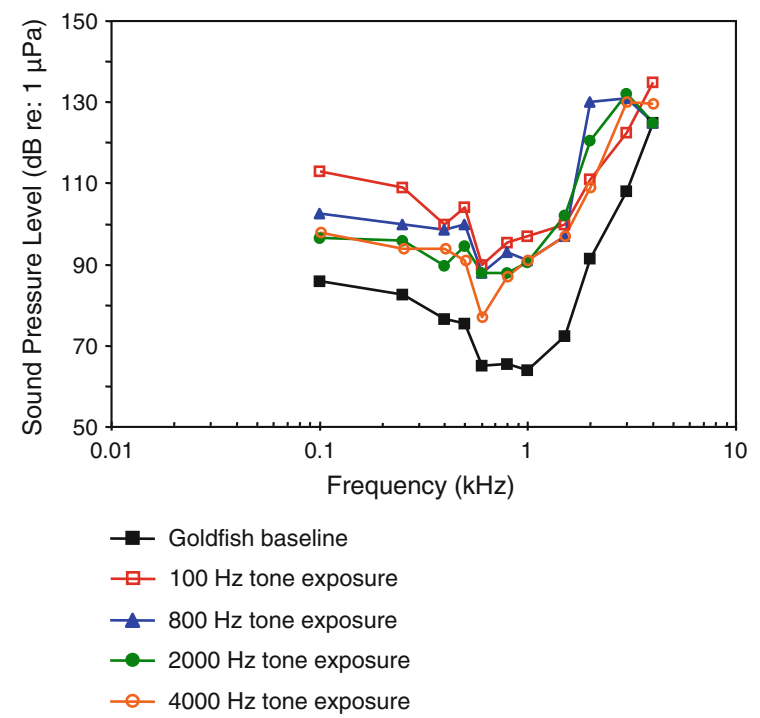

Fig. 48 Auditory sensitivity of the goldfish before (baseline) and after exposure to pure tones at $178 \mathrm{~dB}$ for $48 \mathrm{~h}$. After Smith et al. (2011)

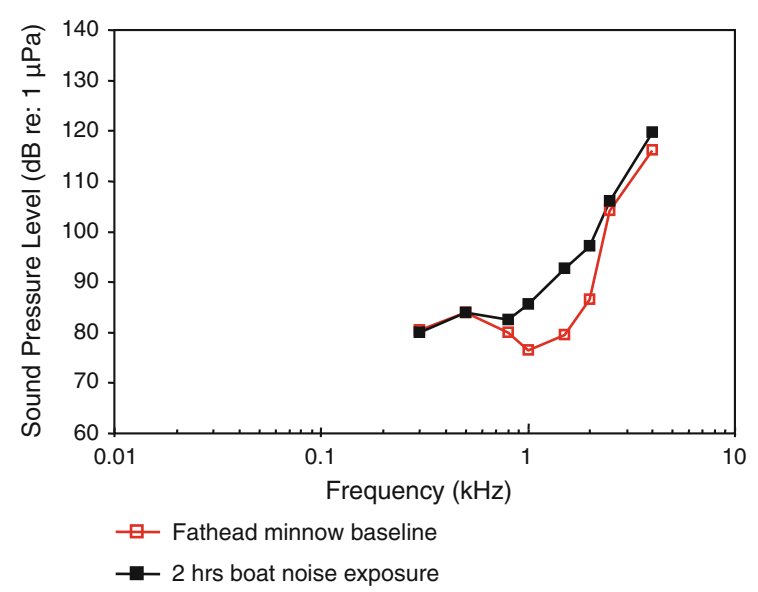

Fig. 49 Auditory sensitivity of the fathead minnow Pimephales. promelas before and after exposure to boat noise for $2 \mathrm{~h}$ at $142 \mathrm{~dB}$. After Scholik and Yan (2002b)

armatulus (family Doradidae) and the pumpkinseed sunfish Lepomis gibbosus (family Centrarchidae) at two different SPLs of uniform spectrum noise (white noise). Continuous white noise of $110 \mathrm{~dB}$ RMS elevated the thresholds by up to $22 \mathrm{~dB}$ in the goldfish and in striped Raphael catfish. White noise of $130 \mathrm{~dB}$ RMS elevated overall hearing thresholds up to $44 \mathrm{~dB}$ in both otophysines (Figs. 54, 55). In contrast, auditory thresholds in the sunfish increased only at the higher noise level by up to $11 \mathrm{~dB}$ (Fig. 56). 


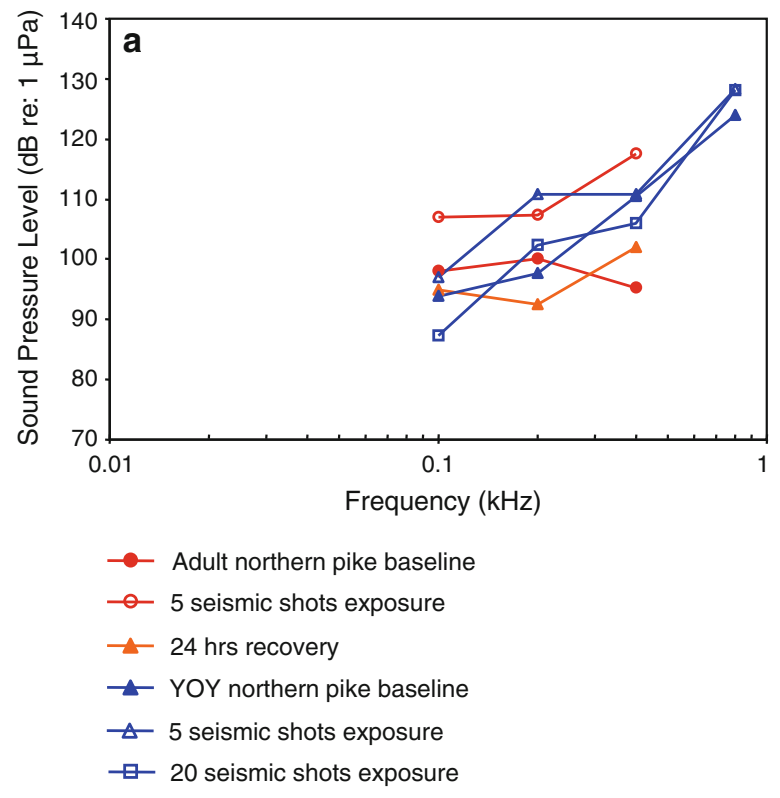

Fig. 50 Auditory sensitivity of a the northern pike Esox lucius and $\mathbf{b}$ the broad whitefish Coregonus nasus and the lake chub Couesius plumbeus before and after exposure to seismic gun
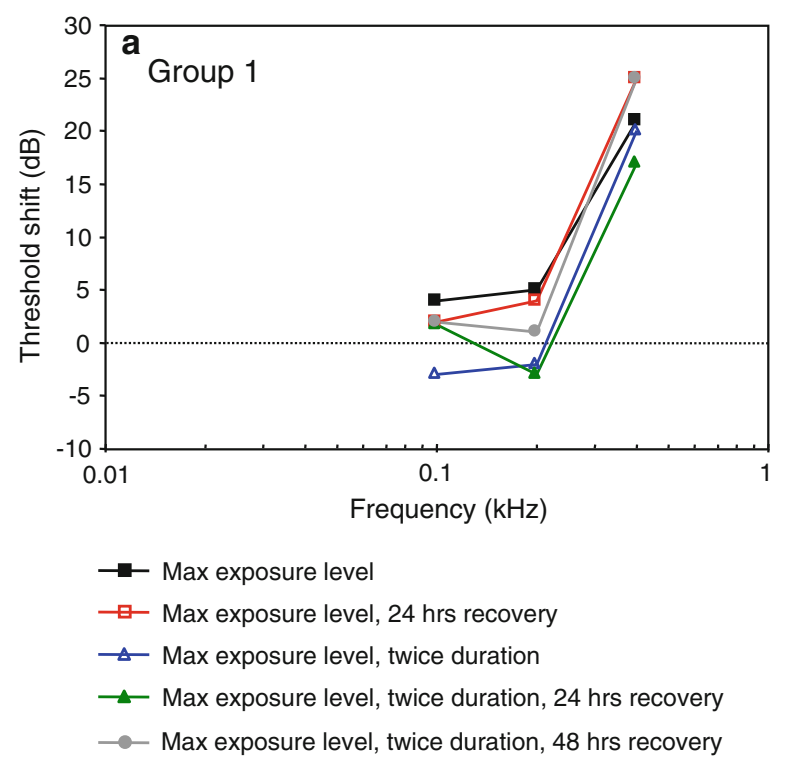

Fig. 51 Threshold shifts of the rainbow trout Oncorhynchus mykiss when exposed to LFA sonar $(193 \mathrm{~dB})$ for different periods (324 or $648 \mathrm{~s})$, different levels of attenuation $(0,12$ or

In behavioral masking experiments, the signal-tonoise ratio at masked threshold (signal level in dB SPL at hearing threshold minus the white noise spectrum

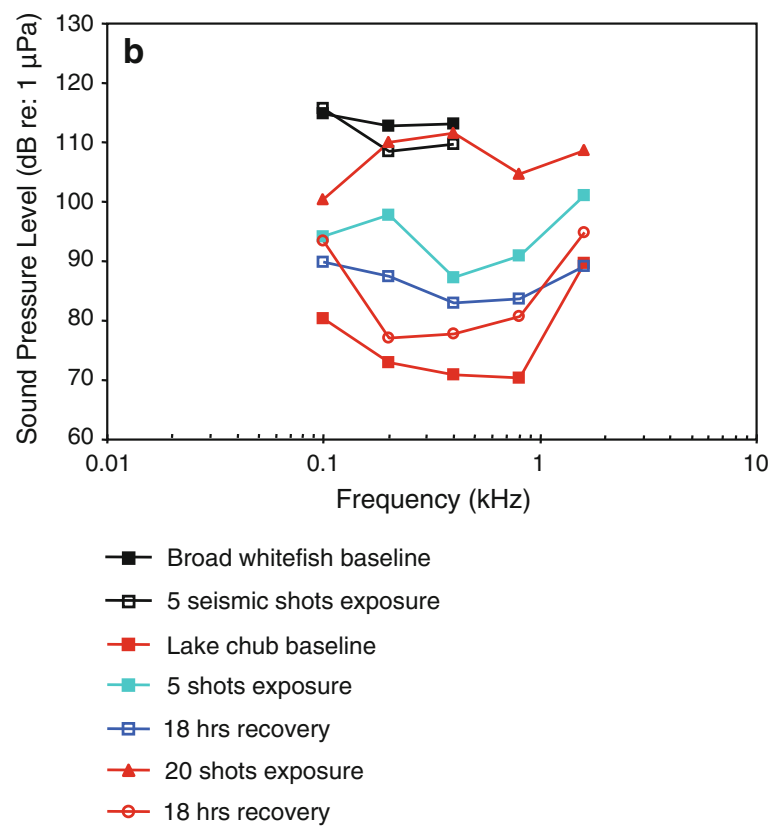

shots $(5,2)$ and different periods of recovery $(18,24 \mathrm{~h})$ (average of $210 \mathrm{~dB}$ at the fish's location). YOY Young of the year. After Popper et al. (2005)

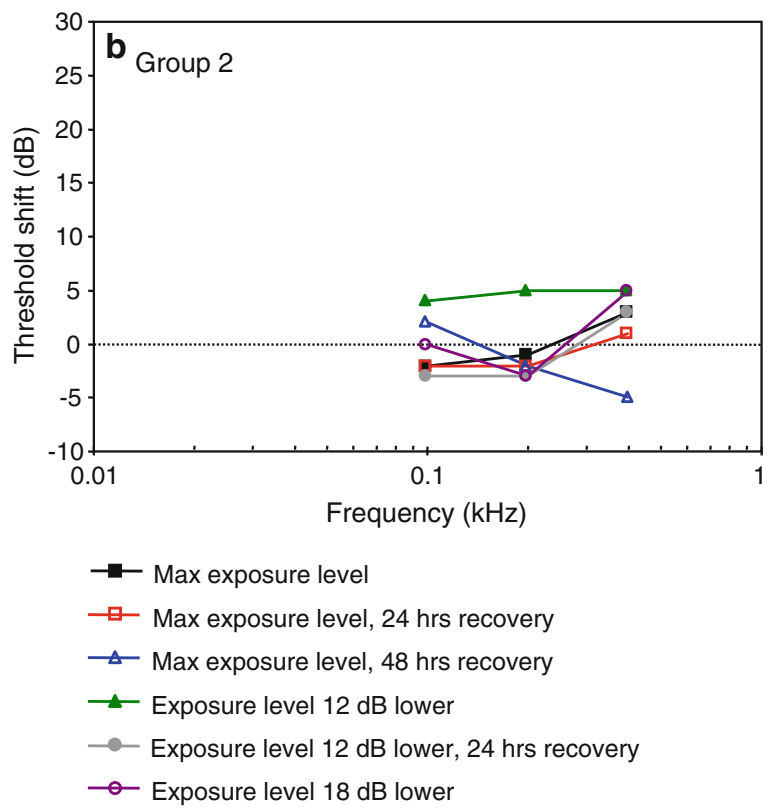

$18 \mathrm{~dB}$ ) and after different periods of recovery ( 24 or $48 \mathrm{~h}$ ). Note the differences between group 1 and group 2 (Figs. 51a, b). After Popper et al. (2007). LFA low-frequency active

level in $\mathrm{dB} / \mathrm{Hz}$ ) is termed the critical masking ratio (CR) (Fay 1974; Fay 1988). When the CR using AEP is calculated for the goldfish, the CR function of 


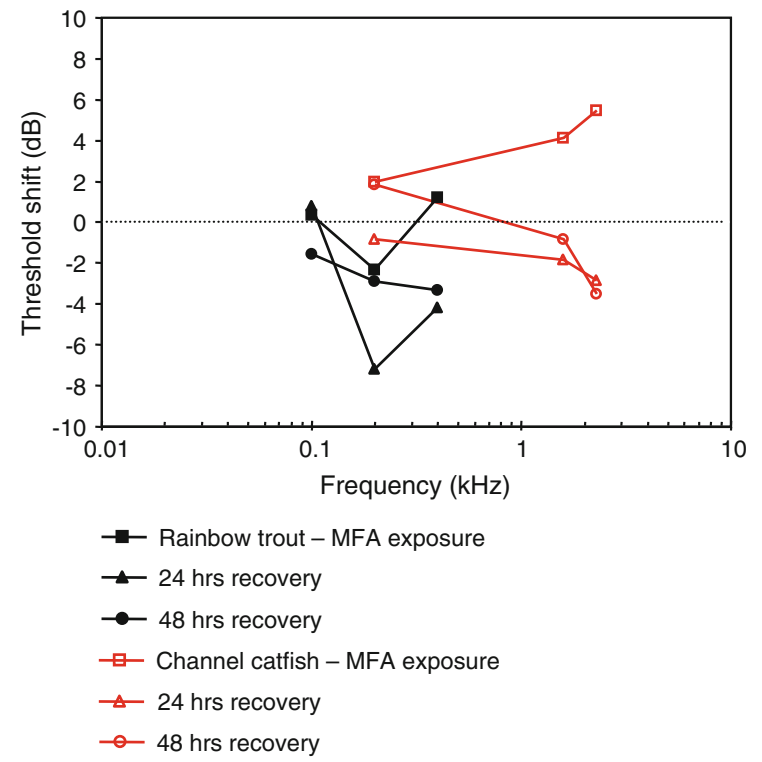

Fig. 52 Threshold shifts of the rainbow trout Oncorhynchus mykiss and the channel catfish Ictalurus punctatus immediately after being exposed to MFA sonar at $210 \mathrm{~dB}$ and after 24 or $48 \mathrm{~h}$ of recovery. The average of two groups is shown. After Halvorsen et al. (2012). MFA mid-frequency active sonar

frequency is not linear as is the behavioral CR function (and generally lower than the behavioral CRs) except at the lowest $(200 \mathrm{~Hz})$ and highest $(2,000 \mathrm{~Hz})$ frequencies tested. The lower CRs from the AEP studies indicate less masking than is evident in the behavioral experiments (Fay 1995; Tavolga 1974). Thus, the AEP method used to estimate CRs is not a good estimation of the behavioral CR, and cannot be interpreted in the same way.

Masking in the sunfish (Fig. 57) did not occur at $110 \mathrm{~dB}$, probably because the sunfish is less sensitive overall than the goldfish and catfish, and is likely only sensitive to particle acceleration as well.

Ramcharitar and Popper (2004) measured the effect of masking by white noise in the black drum Pogonias chromis and Atlantic croaker (family Sciaenidae) to investigate the effect of different connections between the ear and swim bladder on noise masking effects. At the $124 \mathrm{~dB}$ level of white noise both species showed similar changes in auditory sensitivity. However, in the presence of the $136 \mathrm{~dB}$ white noise masker the black drum showed significantly greater shifts (to be expected) in auditory thresholds between 300 and $600 \mathrm{~Hz}$, while the Atlantic croaker did not (Fig. 57).

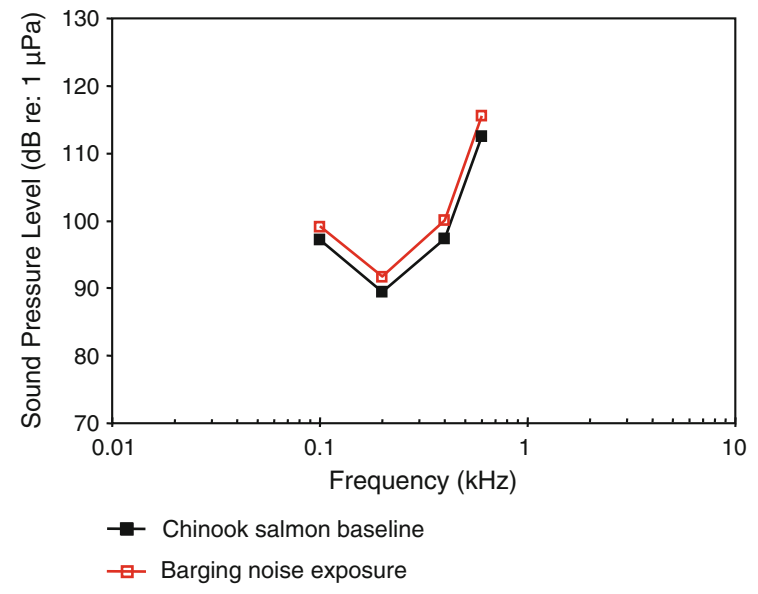

Fig. 53 Auditory sensitivity of juvenile Chinook salmon Oncorhynchus tshawytscha before (baseline) and 7 days after exposure to barging noise (136 dB noise). After Halvorsen et al. (2009)

Ambient noise masking

Several studies were carried out to investigate if fish are adapted to the natural ambient noise levels or if signal detection is masked in particular regions of their habitat.

Amoser and Ladich (2005) measured masked hearing thresholds of the common carp in the presence of ambient noise of four different habitats (Equivalent continuos SPL given for all habitats; Backwater: $92 \mathrm{~dB}$; Lake Neusiedl: $93 \mathrm{~dB}$; Triesting Stream: 114 dB; Danube River: 132 dB). The common carp's hearing is heavily affected (masked) by stream and river noise by up to $49 \mathrm{~dB}$ (Fig. 58), and less so in a relatively quiet lake. Similar results were achieved when presenting lake noise to the closely related topmouth minnow (both family Cyprinidae) (Fig. 59) (Scholz and Ladich 2006).

Masking effects by ambient noise were much smaller in the European perch (family Percidae). The perch's hearing thresholds were only slightly affected (mean up to $12 \mathrm{~dB}$ at $100 \mathrm{~Hz}$ ) by the highest noise levels presented because it most likely lacks hearing specializations that would contribute to sound pressure sensitivity (Amoser and Ladich 2005) (Fig. 60).

Masking by ambient noise was further studied in representatives of four marine families; the Lusitanian toadfish (family Batrachoididae), the brown meagre (family Sciaenidae), the Mediterranean damselfish (family Pomacentridae) and the redmouthed goby Gobius cruentatus (family Gobiidae). The ambient 


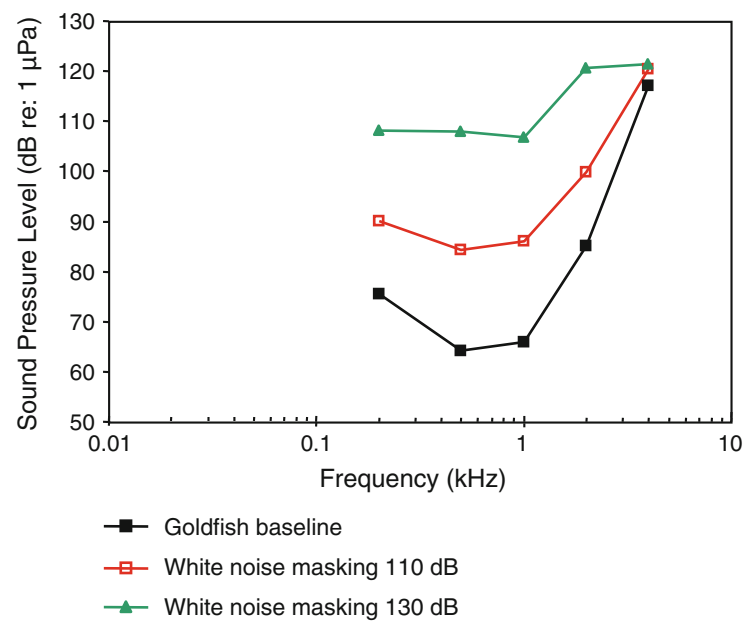

Fig. 54 Hearing thresholds of the goldfish obtained under normal laboratory conditions (baseline) and in the presence of white masking noise of 110 and $130 \mathrm{~dB}$. After Wysocki and Ladich (2005a)

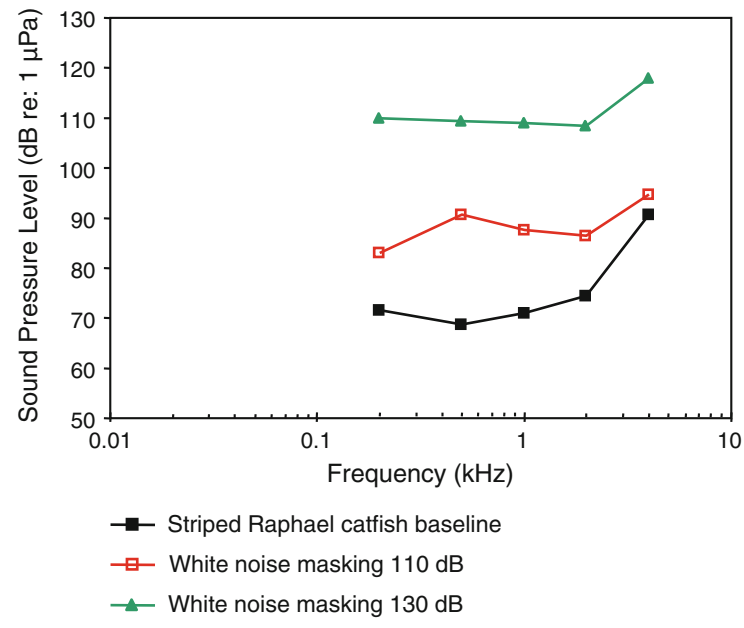

Fig. 55 Hearing thresholds of the Striped Raphael catfish Platydoras armatulus obtained under normal laboratory conditions (baseline) and in the presence of white masking noise of 110 and $130 \mathrm{~dB}$. After Wysocki and Ladich (2005a)

noise level was $111 \mathrm{~dB}$ for the toadfish and $97 \mathrm{~dB}$ for all other species. Data reveal that in all four species threshold shifts due to masking by ambient noise are small or insignificant, probably due to their adaptation to the ambient noise in their habitats (Vasconcelos et al. 2007, Codarin et al. 2009) (Fig. 61).

\section{Anthropogenic noise masking}

Hearing in fish is frequently masked by anthropogenic noise either when kept for aquaculture or leisure or in

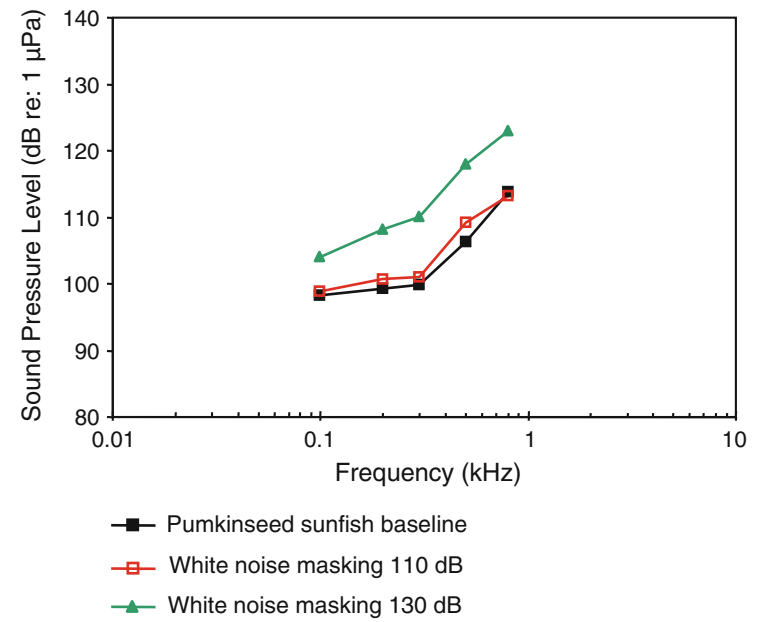

Fig. 56 Hearing thresholds of the pumpkinseed sunfish Lepomis gibbosus obtained under normal laboratory conditions (baseline) and in the presence of white masking noise of 110 and 130 dB. After Wysocki and Ladich (2005a)

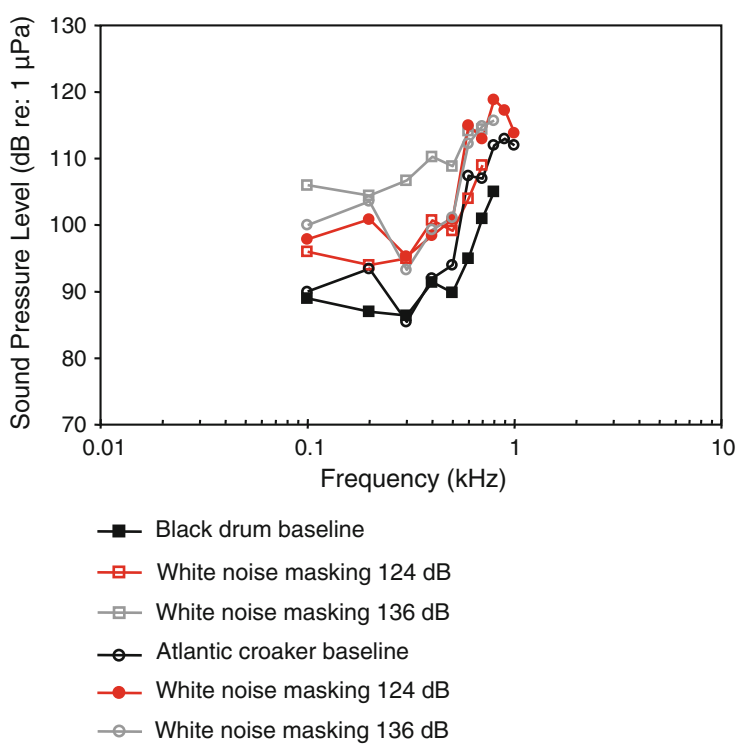

Fig. 57 Hearing thresholds of the black drum Pogonias chromis and Atlantic croaker Micropogonias undulatus obtained under normal laboratory conditions (baseline) and in the presence of white masking noise of 124 and $136 \mathrm{~dB}$. After Ramcharitar and Popper (2004)

the field by the presence of boat/ship noise, seismic air-gun shooting, various sonars, pile driving activity, and other sources.

Gutscher et al. (2011) investigated the noise within a pond and of various aquarium filter setups and their effects on hearing in the goldfish (external filter, water outflow below surface: $115 \mathrm{~dB}$; external filter, water 
outflow above surface: $119 \mathrm{~dB}$; internal filter: $114 \mathrm{~dB}$; pond noise: $95 \mathrm{~dB}$ ). Pond noise did not affect hearing whereas noise caused by external aquarium filters resulted in a masked threshold shift of more than $20 \mathrm{~dB}$ in their best hearing range (Fig. 62).

Ship noise is a major anthropogenic noise source in aquatic habitats. The masking effects of ship noise have been studied in the Lusitanian toadfish, the brown meagre, the Mediterranean damselfish and the redmouthed goby. The ship noise level was $131 \mathrm{~dB}$ for the toadfish and $132 \mathrm{~dB}$ for the other species. Data reveal that the presence of ship noise decreases hearing sensitivities up to $40 \mathrm{~dB}$ and reduces the detectability of communication sounds (Vasconcelos et al. 2007, Codarin et al. 2009) (Fig. 63).

\section{Other factors affecting auditory sensitivity}

A series of additional factors potentially affecting hearing sensitivity have been studied using the AEP technique. These include ecological (temperature, cave dwelling) and genetic factors (albinism), ototoxic drugs (gentamicin) and comparison of different AEPrecording protocols.

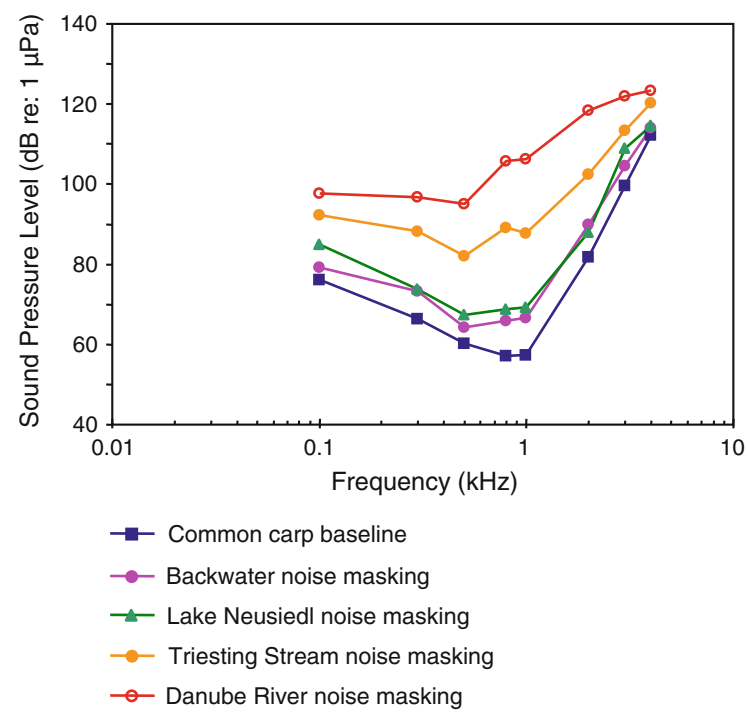

Fig. 58 Hearing thresholds of the common carp Cyprinus carpio during quiet laboratory conditions (baseline) and in the presence of four different ambient masking noise conditions (Backwater: $92 \mathrm{~dB}$; Lake Neusiedl: $93 \mathrm{~dB}$; Triesting Stream: $114 \mathrm{~dB}$; Danube River: $132 \mathrm{~dB}$ ). From Amoser and Ladich (2005)

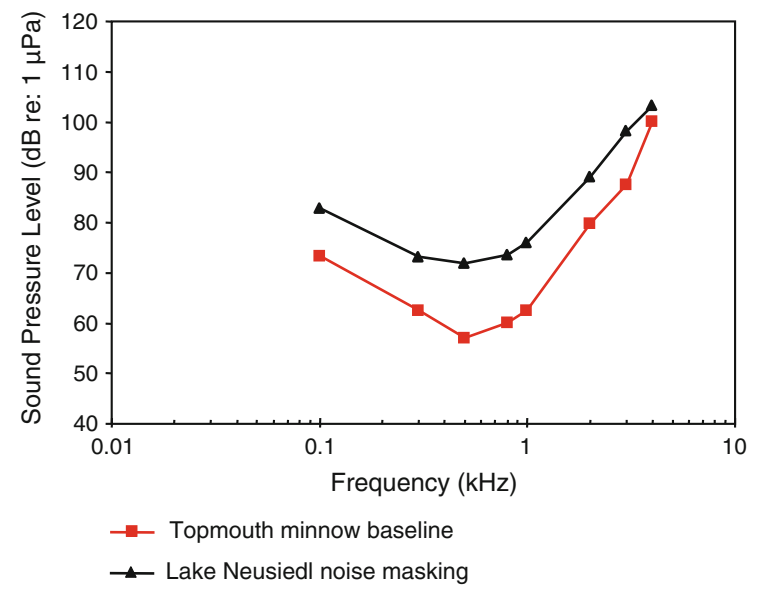

Fig. 59 Hearing thresholds of the topmouth minnow Pseudorasbora parva during quiet laboratory conditions (baseline) and in the presence of ambient masking noise of Lake Neusiedl (93 dB). From Scholz and Ladich (2006)

\section{Ecological factors}

Fishes are ectothermic animals and their body temperature generally depends on ambient water temperature. Thus, ambient temperature might affect various physiological processes including sensory system function. Two studies applied the AEP-technique to find out if the auditory sensitivity changes with temperature in fishes. In general, an increase in sensitivity with frequency was found on all three catfish species investigated.

Wysocki et al. (2009b) studied the sensitivity in the eurythermic channel catfish (family Ictaluridae) at 10 , 18 and $26{ }^{\circ} \mathrm{C}$ and found that fish were up to $30 \mathrm{~dB}$ more sensitive at the highest temperature tested (Fig. 64). Acclimation to certain temperatures affected thresholds minimally.

In contrast, the increase was much smaller in both Amazonian catfish species measured (stenothermic species). In the pictus cat (Pimelodidae) the hearing thresholds were maximally $7 \mathrm{~dB}$ higher at $30^{\circ} \mathrm{C}$ as compared to $22{ }^{\circ} \mathrm{C}$ (Fig. 65) (Wysocki et al. 2009b). In the striped Raphael catfish a similar difference of up to $9 \mathrm{~dB}$ was observed after acclimating animals to both temperatures (Fig. 66) (Papes and Ladich 2011).

Besides temperature, lack of visual stimuli might potentially influence hearing in fishes. A comparison revealed similar auditory sensitivity in surface and cave dwelling (blind) populations of the Atlantic molly (Poeciliidae) (Schulz-Mirbach et al. 2010) (Fig. 67a, b). 


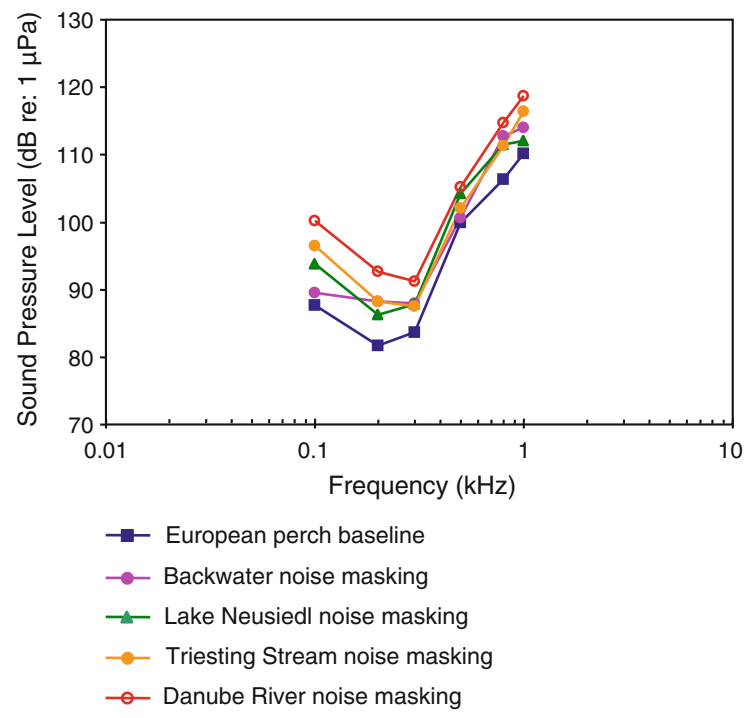

Fig. 60 Hearing thresholds of European perch Perca fluviatilis during quiet laboratory conditions (baseline) and in the presence of four different ambient masking noise conditions (for details see Fig. 58). From Amoser and Ladich (2005)

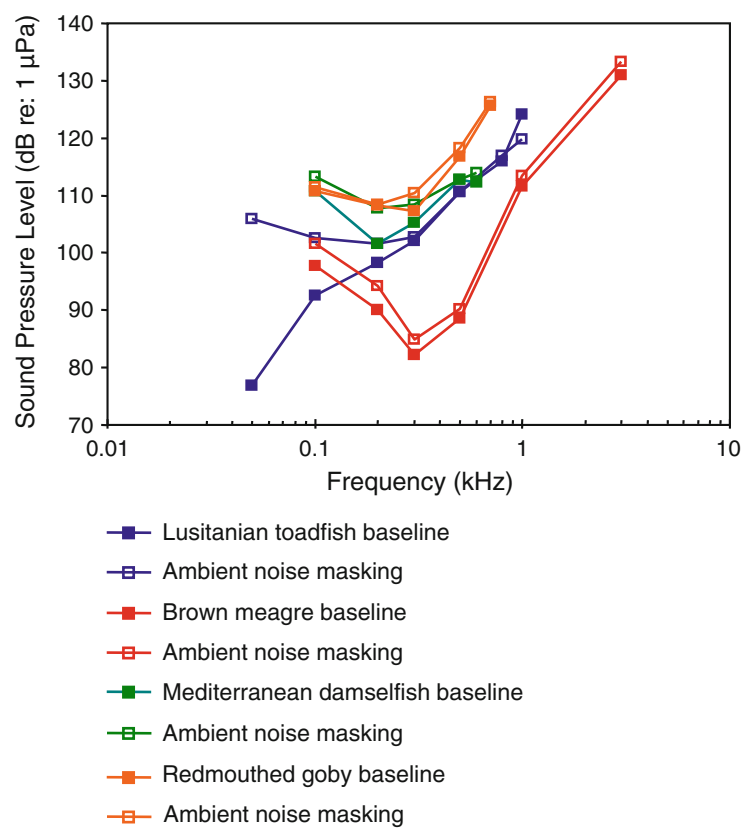

Fig. 61 Hearing thresholds of in the Lusitanian toadfish Halobatrachus didactylus, the brown meagre Sciaena umbra, the Mediterranean damselfish Chromis chromis and the redmouthed goby Gobius cruentatus during quiet laboratory conditions (baseline) and in the presence of ambient masking noise conditions $(111 \mathrm{~dB}$ for the toadfish and $97 \mathrm{~dB}$ for all other species) of their habitat. From Vasconcelos et al. (2007) and Codarin et al. (2009)

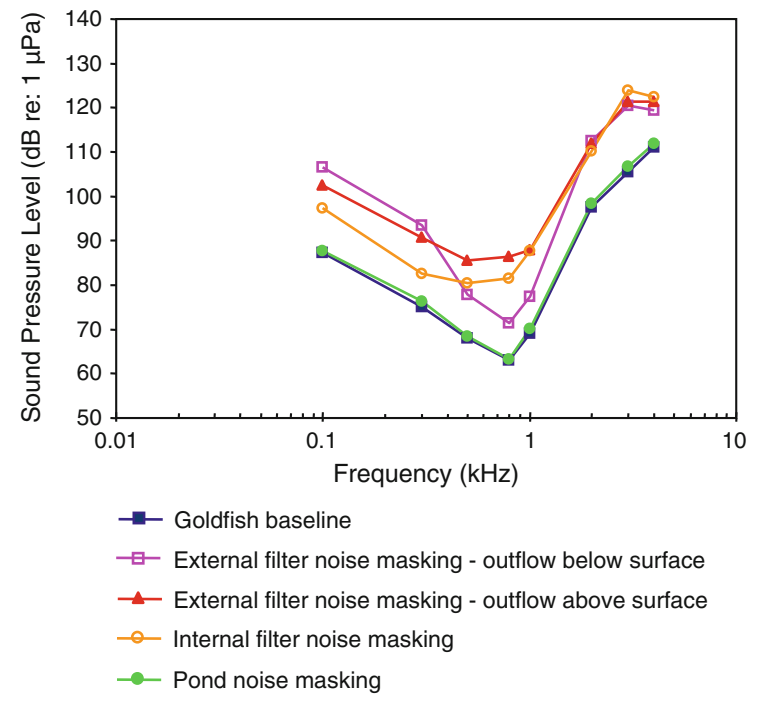

Fig. 62 Hearing thresholds of the goldfish during quiet laboratory conditions (baseline) as well as in a pond and in the presence of masking noise generated by various aquarium filter setups. External filter, water outflow below surface: $115 \mathrm{~dB}$; external filter, water outflow above surface: $119 \mathrm{~dB}$; internal filter: $114 \mathrm{~dB}$; pond noise: 95 dB. From Gutscher et al. (2011)

\section{Genetic factors}

Albinism, a genetic abnormality of the melanin system in which the synthesis of this pigment is reduced or lacking, is occasionally associated with hearing impairments in mammals. Therefore, Lechner and Ladich (2011) compared auditory thresholds in normally pigmented and albinotic specimens of two catfish species, the European wels Silurus glanis (family Siluridae) and the South American bronze catfish Corydoras aeneus (family Callichthyidae). Auditory thresholds did not differ for either species between normally pigmented and albinotic specimens at any frequency tested (Fig. 68).

\section{Effects of ototoxins}

Antibiotics and other substances have been known to affect hearing sensitivity in vertebrates. Ramcharitar and Brack (2010) and Ramcharitar and Selckmann (2010) showed that gentamicin, a well studied human ototoxin, reduced hearing sensitivity in goldfish between 300 and $600 \mathrm{~Hz}$ (Fig. 69).

$\mathrm{Lu}$ and Tomchik (2002) studied the effect of the red-tide neurotoxin from dinoflagellates on hearing in goldfish. Sublethal-dose injection of brevetoxin-3 


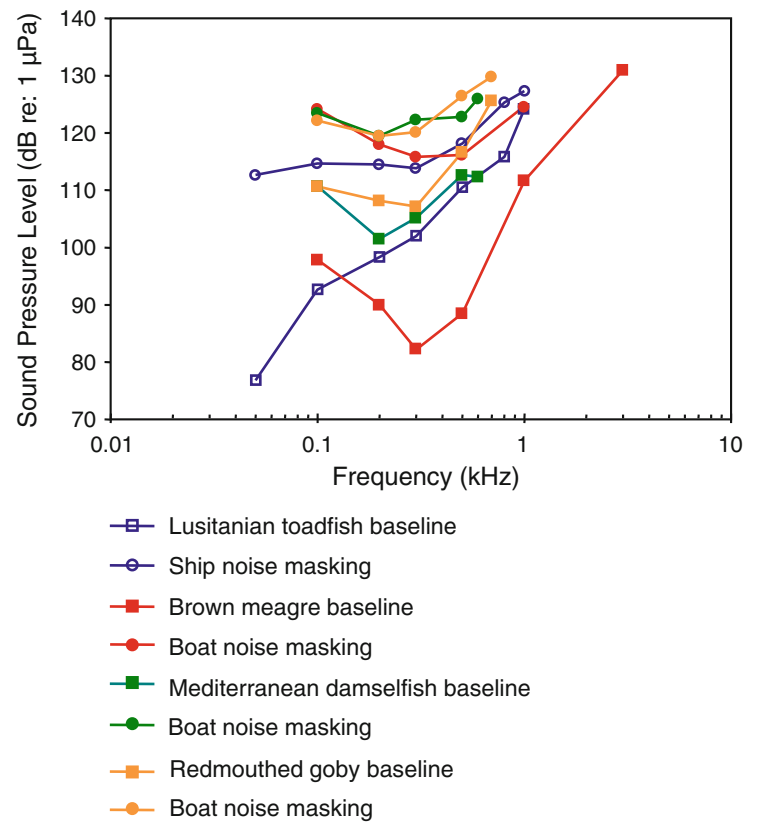

Fig. 63 Hearing thresholds of the Lusitanian toadfish Halobatrachus didactylus, the brown meagre Sciaena umbra, the Mediterranean damselfish Chromis chromis and the redmouthed goby Gobius cruentatus during quiet laboratory conditions (baseline) and in the presence of ship and boat masking noise conditions of their habitat. Ship noise level was $131 \mathrm{~dB}$ for the toadfish and the boat noise level was $132 \mathrm{~dB}$ for the other species. From Vasconcelos et al. (2007) and Codarin et al. (2009)

$(0.068 \mu \mathrm{g} / \mathrm{g})$ increased auditory thresholds up to $9 \mathrm{~dB}$ at low frequencies $(100$ and $500 \mathrm{~Hz})($ Fig. 70).

\section{Comparison of different AEP-protocols}

Auditory thresholds in the goldfish differ between different labs (see "Behavioral and electrophysiological measures of hearing function" section and Fig. 1). Ladich and Wysocki (2009) tried to find out if fish position or loudspeaker choice explains the variability in hearing thresholds in AEP-audiograms of goldfish. They determined hearing thresholds when fish where positioned at different water depths in the experimental tank (immediately below the water surface vs. 5 deeper) as well as when using different speakers (underwater speaker vs. speaker in air, above the water surface). They found that the maximum difference in hearing thresholds in different combinations of speakers and positions was $5.6 \mathrm{~dB}$ (Fig. 71). This rather small difference does not explain differences of more than $20 \mathrm{~dB}$ found at particular frequencies in different

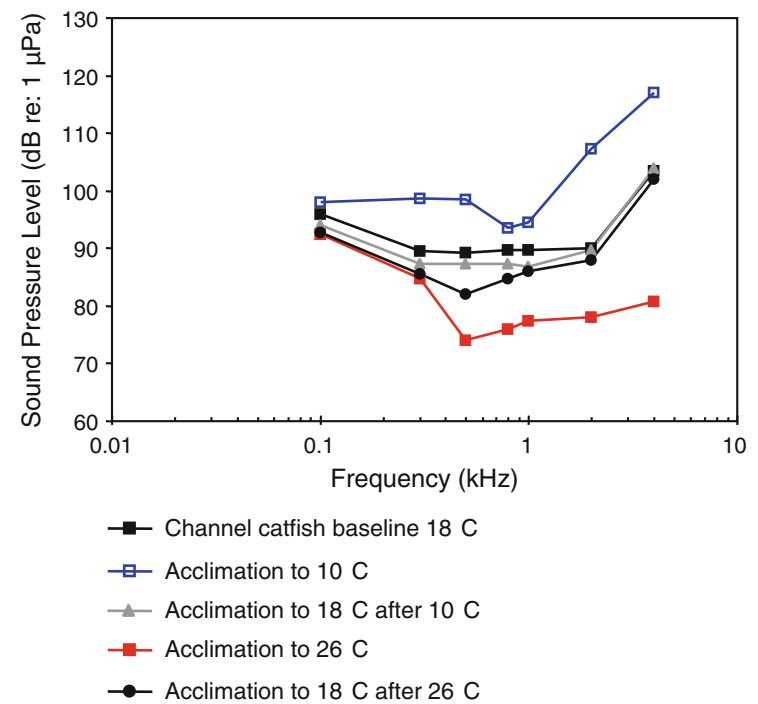

Fig. 64 Hearing thresholds of the channel catfish Ictalurus punctatus at $18{ }^{\circ} \mathrm{C}$ (baseline) and after acclimation to 10,18 and $26^{\circ} \mathrm{C}$ after been acclimated to other temperatures. After Wysocki et al. (2009b)

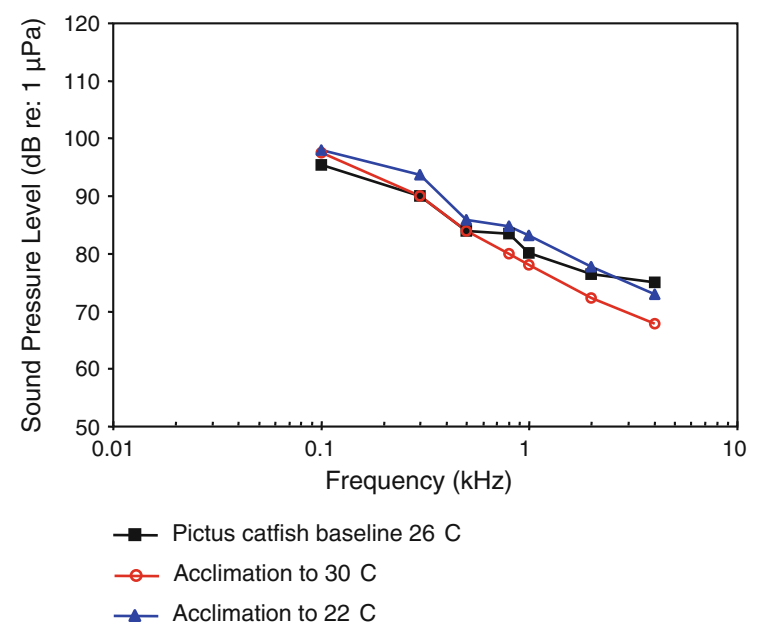

Fig. 65 Hearing thresholds of the pictus cat Pimelodus pictus after acclimation to $26^{\circ} \mathrm{C}$ (baseline), 22 and $30{ }^{\circ} \mathrm{C}$. After Wysocki et al. (2009b)

studies. Based on a survey of the literature, Ladich and Wysocki (2009) concluded that it is rather unlikely that factors such as fish size, temperature, background noise or degree of immobilization are responsible for difference in hearing threshold. The most likely reason (besides potential calibration errors) is the criterion stipulating what is regarded as an auditory threshold in AEP audiometry. Additional factors such as stimuli 
used, different numbers of AEPs averaged, signal-tonoise ratio in the electrophysiological recordings, and genetic differences between fish populations can add to the variation in hearing thresholds published for goldfish.

Cordova and Braun (2007) investigated if immobilization agents affect hearing thresholds. They compared auditory thresholds in goldfish after intramuscular injection of gallamine triethiodide (Flaxedil-a paralytic agent) or in combination with an injection of fentanyl (an anesthetic). Fentanyl (0.1,

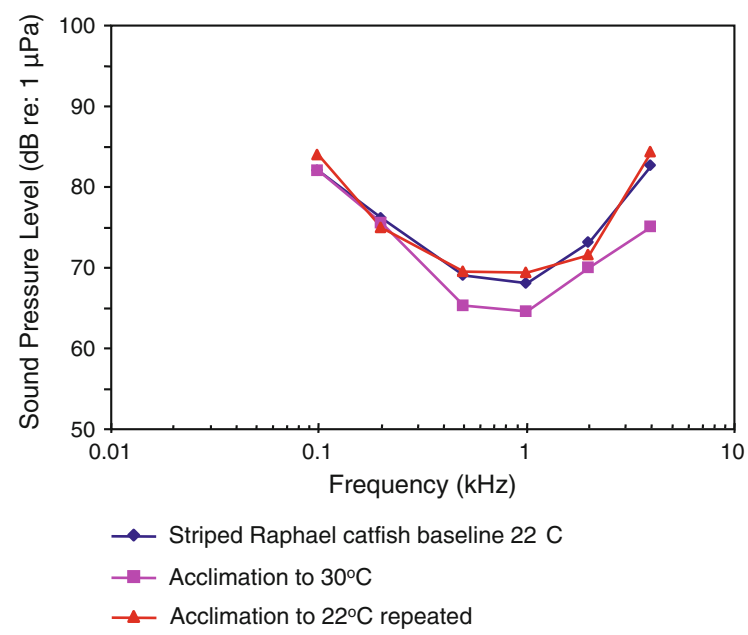

Fig. 66 Hearing thresholds of the striped Raphael catfish Platydoras armatulus after acclimation to $22{ }^{\circ} \mathrm{C}$ (baseline), $30{ }^{\circ} \mathrm{C}$ and $22{ }^{\circ} \mathrm{C}$. After Papes and Ladich (2011)

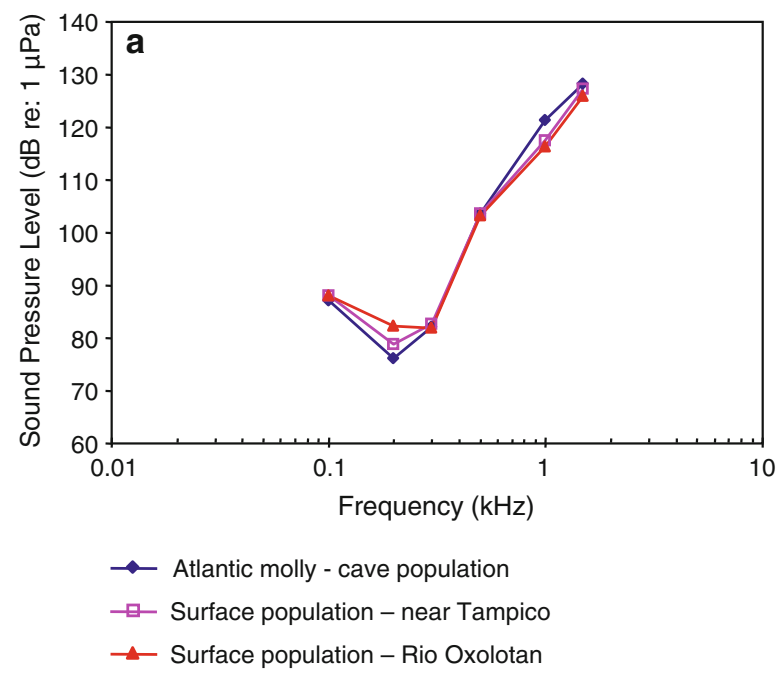

0.5 and $2.5 \mathrm{mg} \mathrm{g}^{-1}$ fish) altered evoked potential waveforms slightly but did not alter estimated threshold sensitivity (Fig. 72).

Xiao and Braun (2008) investigated the effects of residual noise on threshold determination in order to reduce interobserver disagreements during subjective threshold estimations. An objective method of threshold determination was developed based on comparison between AEP amplitude and controlled residual noise.

Effects of dominance and reproductive status

Maruska et al. (2012) found out that the dominance and reproductive status affects hearing in the social cichlid Astatotilapia burtoni. Subordinate males had lower thresholds than dominant males between 600 and $800 \mathrm{~Hz}$ (Fig. 73). In females, gravid individuals had lower thresholds $(5-15 \mathrm{~dB})$ at low frequencies from 100 to $600 \mathrm{~Hz}$ compared to mouth-brooding females.

\section{Applying AEP-techniques to study acoustic communication}

The majority of AEP-studies is based on the determination of hearing thresholds in $\mathrm{dB}$ (either re $1 \mu \mathrm{Pa}$ or $1 \mu \mathrm{m} / \mathrm{s}^{2}$ ) gained under various conditions (see "Behavioral and electrophysiological measures of hearing function to Other factors affecting auditory sensitivity"

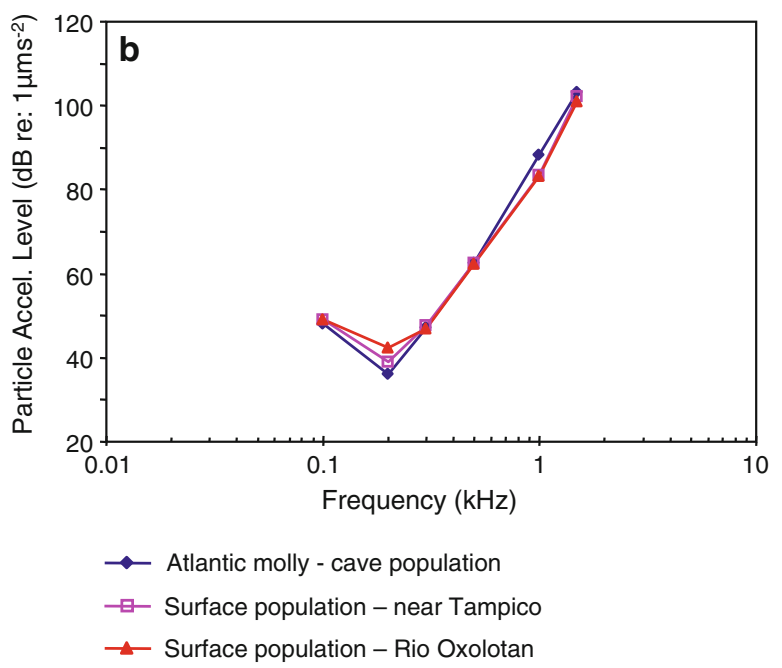

Fig. 67 Hearing thresholds of a cave and two surface populations of the Atlantic molly Poecilia mexicana. a gives thresholds in terms of SPL and $\mathbf{b}$ in terms of PAL. After Schulz-Mirbach et al. (2010) 


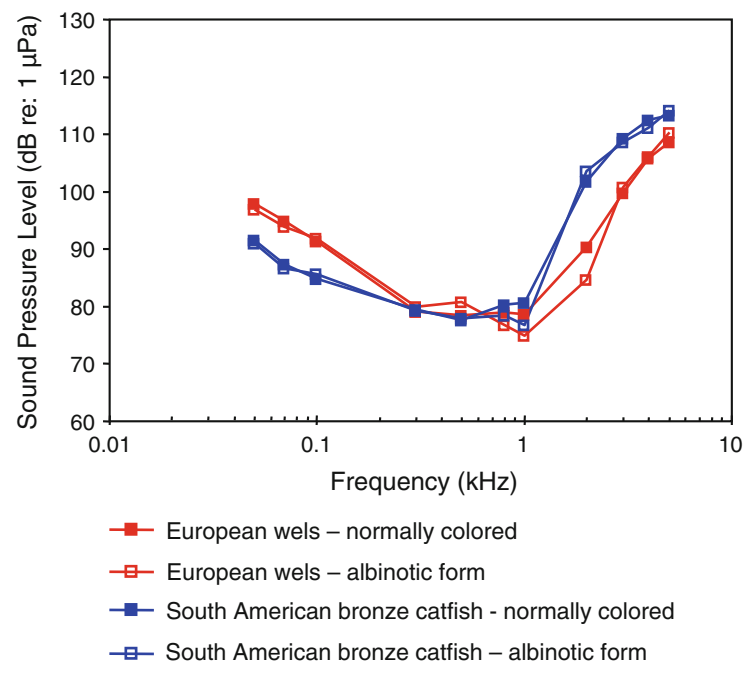

Fig. 68 Hearing thresholds of normally colored and albinotic individuals of the European wels Silurus glanis and the South American bronze catfish Corydoras aeneus. After Lechner and Ladich (2011)

sections). Hearing curves are frequently compared to the spectra of vocalizations to investigate the detectability of conspecific sounds in various contexts such as during ontogenetic development or in the presence of ambient or anthropogenic noise (Wysocki and Ladich 2001; Amoser and Ladich 2005; Vasconcelos et al. 2007; Maruska et al. 2012).

However, the technique is also suitable to study the temporal resolution of the auditory system. Temporal patterns of broad-band pulses within vocalizations are

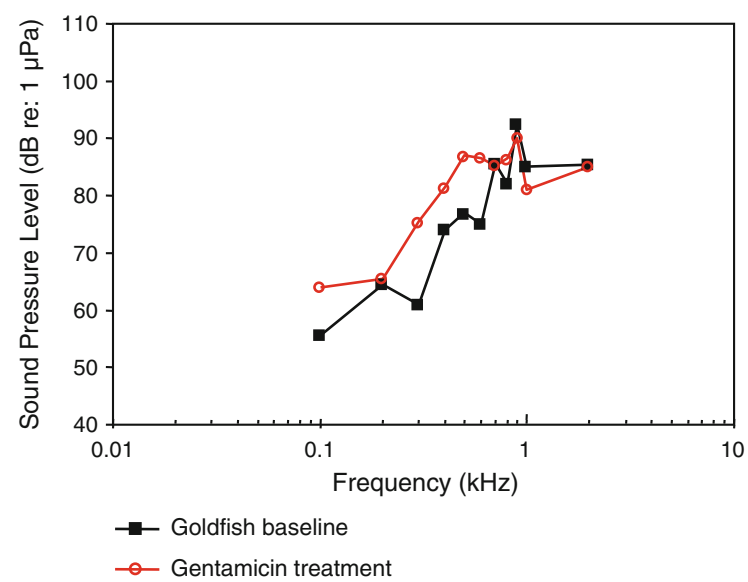

Fig. 69 Hearing thresholds in goldfish without (baseline) and after administration of gentamicin at $100 \mathrm{mg} / \mathrm{ml}$. After Ramcharitar and Brack (2010)

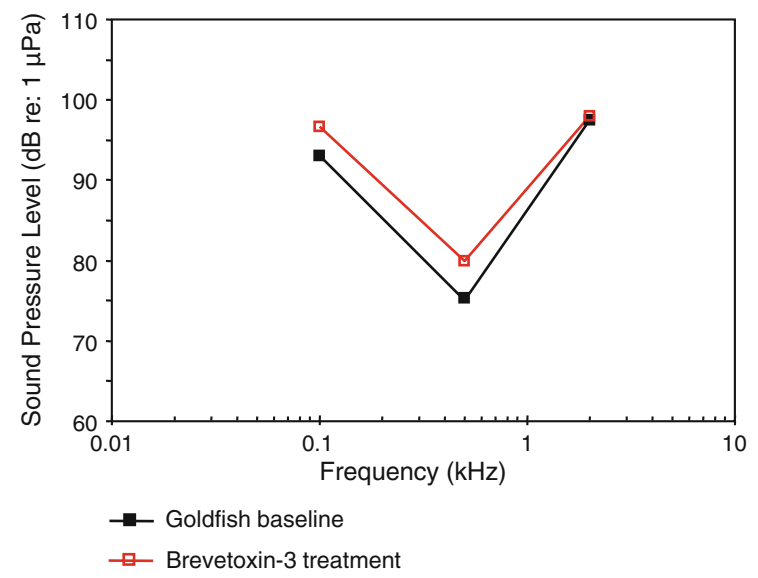

Fig. 70 Hearing thresholds in goldfish without (baseline) and after administration of brevetoxin-3 $(0.068 \mu \mathrm{g} / \mathrm{g})$. After Lu and Tomchik (2002)

thought to be important carriers of information in fishes (e.g., Myrberg et al. 1978). In order to determine whether fishes are able to utilize temporal characteristics of acoustic signals Wysocki and Ladich (2002) determined the time resolution in four species of otophysines and anabantoids by analyzing AEPs gained in response to double-click stimuli with varying click inter-click intervals. The minimum interval resolvable by the auditory system using AEP methods was below $1.5 \mathrm{~ms}$ in each species studied (goldfish-Cyprinidae; striped Raphael catfish-

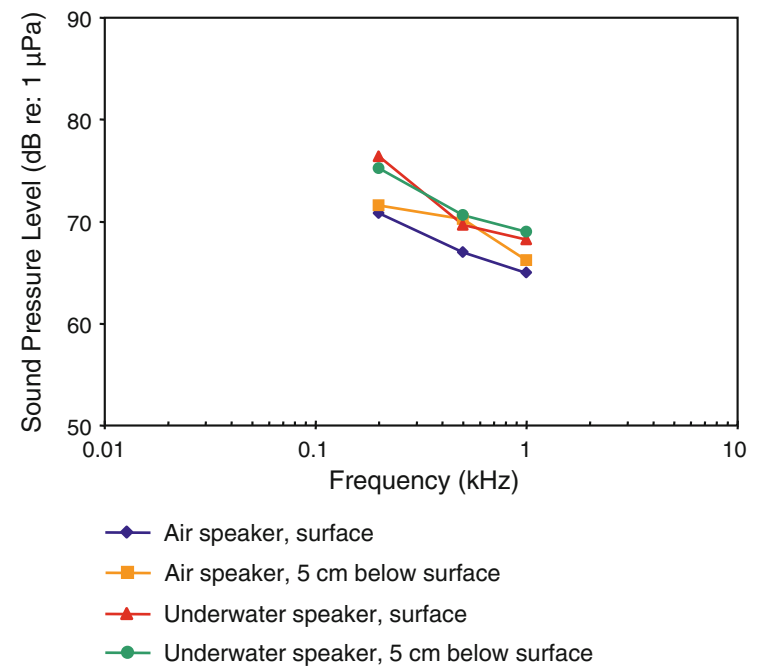

Fig. 71 Hearing thresholds in goldfish at different positions in the sound field (at or $5 \mathrm{~cm}$ below surface) and when using different speakers (air speaker vs. underwater speaker). After Ladich and Wysocki (2009) 


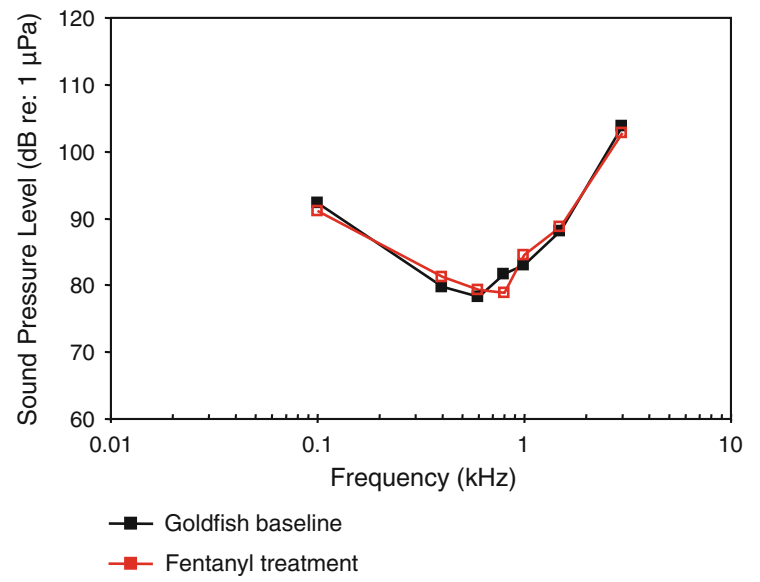

Fig. 72 Hearing thresholds in goldfish after injections of flaxedil (baseline) and after fentanyl treatment. After Cordova and Braun (2007)

Doradidae; croaking gourami, blue gourami-Osphronemidae) indicating the vocal species can process each pulse within intraspecific vocalizations. Wysocki and Ladich (2005b) studied the effects of white noise exposure $(158 \mathrm{~dB})$. Analysis of the response to double clicks showed that the minimum click period resolvable by the auditory system increased significantly from 1.25 to $2.08 \mathrm{~ms}$ immediately after noise exposure.

The AEP protocol was modified by Wysocki and Ladich (2003) to investigate how conspecific sounds are processed by the auditory system. AEPs elicited by conspecific sounds were recorded and analyzed in five species of teleosts. In fishes possessing sound pressure hearing specializations (striped Raphael catfish, pictus cat, orange finned loach, croaking gourami) each pulse within the sounds elicited a separate brainwave that closely followed the temporal structure of the stimulus. Data indicate that, besides temporal patterns, amplitude fluctuations and the frequency content of sounds can be represented in the auditory system to help extract important information for acoustic communication. In a subsequent study Codarin et al. (2009) determined the detectability of vocalizations by measuring the thresholds to conspecific sounds in the brown meagure and the Mediterranean damselfish. Vasconcelos et al. (2011) investigated the representation of conspecific mating and agonistic calls in the auditory system of the Lusitanian toadfish, and analysed auditory responses to vocalizations from heterospecifics such as the sympatric meagre Argyrosomus regius (Sciaenidae)

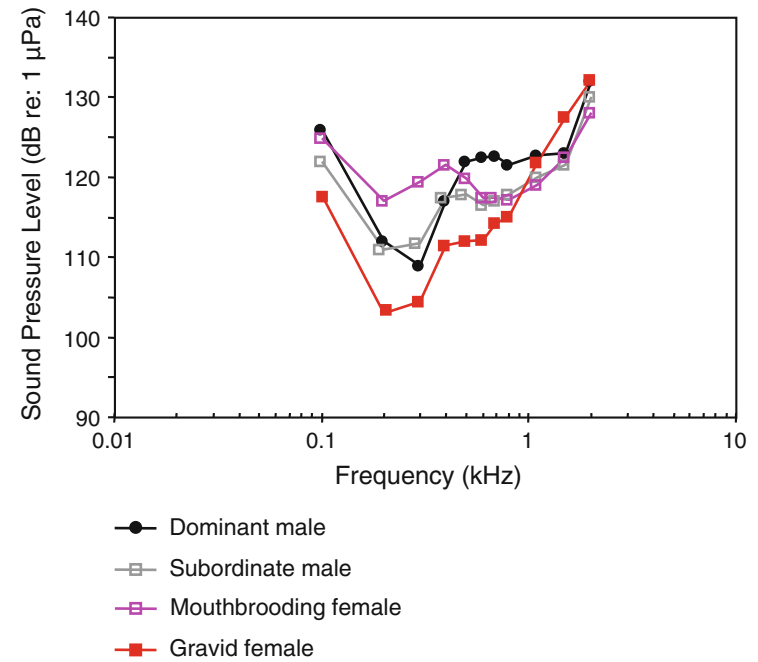

Fig. 73 Hearing thresholds of the cichlid Astatotilapia burtoni depending on the dominance status in males (dominant, subordinate) and the reproductive status in females (gravid, mouth-brooding). After Maruska et al. (2012)

and a potential predator (bottlenose dolphin Tursiops truncatus-family Delphinidae). The authors provide evidence that the auditory system of a vocal fish, lacking accessory hearing structures, is capable of resolving fine features of con- and heterospecific vocalizations.

\section{Summary and conclusions}

In "Systematic description of baseline AEP-audiograms" section through "Applying AEP-techniques to study acoustic communication" we summarize in how many species and in how many different ways AEP techniques has been utilized to study hearing sensitivities in approximately 100 species of fishes. At least seven different methodical approaches have been used-ranging from the determination of baseline hearing sensitivities for various purposes up to the analysis of the AEPs gained in response to vocalizations. There are numerous advantages of the AEP techniques compared to behavioral conditioning techniques (see "Introduction" section). Nevertheless, it is necessary to summarize the advantages and shortcomings of the AEP technique.

One issue is the large variation of AEP audiograms for the same species, in particular the goldfish. This effect, however, is not peculiar to AEP studies since the same or more variation has been observed in 
behavioral experiments. When comparing the median goldfish audiograms from behavioral and AEP approaches we find a clear difference between these two methodical approaches. Based on the physics of the AEP technique we tentatively assume that the tendency seen in the goldfish, namely that the AEP technique gives higher thresholds at lower frequencies and lower thresholds at higher frequencies, reflects a general difference between techniques and can be expected for other species too. Because there is no second species which has been investigated as often as goldfish and because this goldfish trend cannot be seen as clearly in other species, it is impossible to quantify this effect and to derive a factor so that AEP audiograms can be transformed to closely match the behavioral data. Based on the goldfish comparison we assume that the 'AEP effect' is frequency dependent and that AEP curves can not simply be shifted downward to estimate the behavioral data.

In view of the large variation of AEP audiograms for the goldfish, one needs to be very cautious when comparing and interpreting results for individual species gained under different conditions or from different labs. The procedure that we recommend is to carry out all measurements under identical conditions (e.g., acoustical environment, threshold definition, etc.). Beyond that we recommend that every lab/ beginner should measure goldfish for comparative purposes. This will give readers information on how thresholds measured in lab A potentially deviate from those gained in lab B.

When measurements are carried out under the identical conditions the AEP technique is a useful tool to measure and compare different species, different stages of age, and to determine the effects of accessory hearing structures, the effects of exposure to noise and the effects of masking by various noise types, the effects of temperature etc.

One generalization we can make from the data reviewed here is that all species known to possess potential specializations for sound pressure detection (a gas body near or in contact with the ears) have lower sound pressure thresholds at best frequency $(55-83 \mathrm{~dB})$, and respond at higher frequencies $(200 \mathrm{~Hz}-3 \mathrm{kHz}$ at best frequency) than fishes not known to be specialized. The fishes not known to be specialized are more diverse in sensitivity and frequency range, but generally have best thresholds between 78 and $150 \mathrm{~dB}$, and best frequencies of below
100 to $1 \mathrm{kHz}$. All fishes studied by measuring AEP particle acceleration threshold levels have thresholds between 30 and $70 \mathrm{~dB}$ re: $1 \mu \mathrm{m} \mathrm{s}^{-2}$.

This review has identified several species, based on their AEP audiograms, that may have sound pressure sensitivity even though they have no obvious or known morphological specializations for detecting sound pressure. These include the red sea bream, the silver mojarra, the jewel cichlid, and the brown meagre, all perciformes.

All future audiometric studies on fishes, except species shown to be primarily sensitive to sound pressure, should include measurements of particle acceleration level in the test tank or test environment, and audiograms expressed in terms of particle acceleration as well as sound pressure. Ideally, the acoustic impedance (ratio of sound pressure to particle velocity levels) of the test environment should be characterized and compared to the impedance of the species natural habitat in order to evaluate the measured audiogram. Wherever possible, the lab studies should be carried out in tanks with very rigid walls (e.g., $4 \mathrm{~cm}$-thick steel) to raise the impedance to near ideal levels (Halvorsen et al. 2011). Furthermore, more efforts should be made to experimentally determine the extent to which the species of interest is sensitive to both of these acoustic quantities. There are several ways to do this, including gas cavity extirpation (but note the caveat on using this procedure in the study by Yan et al. 2000, in Fig. 31 of "Using AEP-technique to investigate accessory hearing structures" section), and the estimation of thresholds as a function of distance from a sound source. If sound pressure thresholds vary with distance from the source, then it is likely that the animals are particle acceleration sensitive under those conditions, since particle acceleration declines steeply as distance increases near a sound source. If sound pressure thresholds are constant with variations in distance from the source, the animals are most likely pressure sensitive (e.g., Myrberg and Spires 1980). In any case, the measured sensitivity should be evaluated with respect to the actual impedance of the test environment, and its deviation from the natural habitat's impedance. We are aware of the fact that suitable (ideally miniature) particle acceleration sensors for lab or field recordings are not (commercially) available and that fish bioacousticians face here a serious technical problem as compared to bioacousticians working with pressure sensitivity animals 
(crickets, frogs, birds or mammals) where suitable pressure sensitive equipment (e.g., microphones, sound level meters) is available.

Acknowledgments We want to thank Arthur N. Popper for extensively reviewing the manuscript. Support from the Austrian Science Fund (FWF grant 22319 to F.L.).

Open Access This article is distributed under the terms of the Creative Commons Attribution License which permits any use, distribution, and reproduction in any medium, provided the original author(s) and the source are credited.

\section{References}

Amoser S, Ladich F (2003) Diversity in noise-induced temporary hearing loss in otophysine fishes. J Acoust Soc Am 113:2170-2179

Amoser S, Ladich F (2005) Are hearing sensitivities of freshwater fish adapted to the ambient noise in their habitats? J Exp Biol 208:3533-3542

Amoser S, Wysocki LE, Ladich F (2004) Noise emission during the first powerboat race in an Alpine lake and potential impact on fish communities. J Acoust Soc Am 116:3789-3797

Anderson PA, Mann DA (2011) Evoked potential audiogram of the lined seahorse, Hippocampus erectus (Perry), in terms of sound pressure and particle acceleration. Environ Biol Fish 91:251-259

Belanger AJ, Bobeica I, Higgs DM (2010) The effect of stimulus type and background noise on hearing abilities of the round goby Neogobius melanostomus. J Fish Biol 77:1488-1504

Bird NC, Hernandez LP (2007) Morphological variation in the Weberian apparatus of cypriniformes. J Morphol 268:739-757

Braun CB, Grande T (2008) Evolution of peripheral mechanisms for the enhancement of sound reception. In: Webb JF, Popper AN, Fay RR (eds) Fish bioacoustics. Springer, New York, pp 99-144

Bullock TH (1981) Neuroethology deserves more study of evoked responses. Neuroscience 6:1203-1215

Casper BM, Mann DA (2006) Evoked potential audiograms of the nurse shark (Ginglymostoma cirratum) and the yellow stingray (Urobatis jamaicensis). Environ Biol Fish 76:101-108

Casper BM, Mann DA (2007a) The directional hearing abilities of two species of bamboo sharks. J Exp Biol 210:505-511

Casper BM, Mann DA (2007b) Dipole hearing measurements in elasmobranch fishes. J Exp Biol 210:75-81

Casper BM, Mann DA (2009) Field hearing measurements of the Atlantic sharpnose shark Rhizoprionodon terraenovae. J Fish Biol 75:2768-2776

Casper BM, Lobel PS, Yan HY (2003) The hearing sensitivity of the little skate, Raja erinacea: a comparison of two methods. Environ Biol Fish 68:371-379

Chapman CJ, Hawkins A (1973) A field study of hearing in the cod, Gadus morhua L. J Comp Physiol A 85:147-157

Chapman CJ, Johnstone ADF (1974) Some auditory discrimination experiments on marine fish. J Exp Biol 61:521-528
Christensen-Dalsgaard J, Brandt C, Wilson M, Wahlberg M, Madsen PT (2011) Hearing in the African lungfish (Protopterus annectens): pre-adaptation to pressure hearing in tetrapods? Biol Lett 7:139-141

Codarin A, Wysocki LE, Ladich F, Picciulin M (2009) Effects of ambient and boat noise on hearing and communication in three fish species living in a marine protected area (Miramare, Italy). Mar Pollut Bull 58:1880-1887

Cordova MS, Braun CB (2007) The use of anesthesia during evoked potential audiometry in goldfish (Carassius auratus). Brain Res 1153:78-83

Corwin JT (1981) Audition in elasmobranchs. In: Tavolga WN, Popper AN, Fay RR (eds) Hearing and sound communication in fishes. Springer, New York, pp 81-102

Corwin JT, Bullock TH, Schweitzer J (1982) The auditory brainstem response in five vertebrates. Electroencephal Clin Neurophysiol 54:629-641

Edds-Walton P, Fay RR (2009) Physiological evidence for binaural directional computations in the brainstem of the oyster toadfish, Opsanus tau (L.). J Exp Biol 212:1483-1493

Egner SA, Mann DA (2005) Auditory sensitivity of sergeant major damselfish Abudefduf saxatilis from post-settlement juvenile to adult. Mar Ecol Progr Ser 285:213-222

Enger PS (1966) Acoustic threshold in goldfish and its relation to the sound source distance. Comp Biochem Physiol 18:859-868

Fay RR (1969) Auditory sensitivity of the goldfish within the near acoustic field. U.S. Naval Submarine Medical Center, Submarine Base, Groton, Connecticut, Report No. 605, pp 1-11

Fay RR (1974) Masking of tones by noise for the goldfish (Carassius auratus). J Comp Physiol Psychol 87:708-716

Fay RR (1985) Sound intensity processing by the goldfish. Acoust Soc Am 78:1296-1309

Fay RR (1988) Hearing in vertebrates: a psychophysics databook. Hill-Fay Associates, Winnetka, Ill

Fay RR (1995) Psychoacoustical studies of the sense of hearing in goldfish using conditioned respiratory suppression. In: Klump GM, Dooling RJ, Fay RR, Stebbins WC (eds) Methods in comparative psychoacoustics. Birkhäuser, Basel, pp 249-261

Fay RR, Coombs SL (1983) Neural mechanisms in sound detection and temporal summation. Hear Res 10:69-92

Fay RR, MacKinnon JR (1969) A simplified technique for conditioning respiratory mouth movements in fish. Behav Res Meth Instr 1:123-124

Fay RR, Popper AN (1974) Acoustic stimulation of the ear of the goldfish, (Carassius auratus). J Exp Biol 61:243-260

Fay RR, Popper AN (1975) Modes of stimulation of the teleost ear. J Exp Biol 62:379-387

Fay RR, Ream TJ (1986) Acoustic response and tuning in saccular nerve fibers of the goldfish (Carassius auratus). J Acoust Soc Am 79:1883-1895

Fay RR, Edds-Walton PL (1997) Directional response properties of saccular afferents of the toadfish, Opsanus tau. Hearing Res 111:1-21

Fish JF, Offutt GC (1972) Hearing threshold from toadfish, Opsanus tau, measured in the laboratory and field. J Acoust Soc Am 4:1318-1321

Frisch Kv (1938) The sense of hearing in fish. Nature 141:8-11 
Frisch Kv, Dijkgraaf S (1935) Can fish perceive sound direction? Z vergl Physiol 22:641-655

Frisch Kv, Stetter H (1932) Untersuchungen über den Sitz des Gehörsinnes bei der Elritze. Z vergl Physiol 17:687-801

Furukawa T, Ishii Y (1967) Neurophysiological studies on hearing in goldfish. J Neurophysiol 30:1377-1403

Green DM, Swets JA (1966) Signal detection theory and psychophysics. Wiley, New York

Gutscher M, Wysocki LE, Ladich F (2011) Effects of aquarium and pond noise on hearing sensitivity in an otophysine fish. Bioacoustics 20:117-136

Halvorsen MB, Wysocki LE, Stehr CM, Baldwin DH, Chicoine DR, Scholz NL, Popper AN (2009) Barging effects on sensory systems of chinook salmon smolts. Trans Amer Fisher Soc 138:777-789

Halvorsen MB, Carlson TJ, Casper BM, Woodley CM, Popper AN (2011) Predicting and mitigating hydroacoustic impacts on fish from pile installations. NCHRP research results digest. National Academy of Sciences, Washington, Project, pp 25-28

Halvorsen MB, Zeddies DG, Ellison WT, Chicoine DR, Popper AN (2012) Effects of mid-frequency active sonar on hearing in fish. J Acoust Soc Am 131:599-607

Hawkins AD (1981) The hearing abilities of fish. In: Tavolga WN, Popper AN, Fay RR (eds) Hearing and sound communication in fishes. Springer, New York, pp 109-133

Hawkins AD, Johnstone ADF (1978) The hearing of the Atlantic Salmon, Salmon salar. J Fish Biol 13:655-673

Higgs DM, Souza MJ, Wilkins HR, Presson JC, Popper AN (2001) Age- and size related changes in the inner ear and hearing ability of the adult zebrafish (Danio rerio). J Assoc Res Otolaryngol 3:174-184

Higgs DM, Rollo AK, Souza MJ, Popper AN (2003) Development of form and function in peripheral auditory structures of the zebrafish (Danio rerio). J Acoust Soc Am 113:1145-1154

Higgs DM, Plachta DTT, Rollo AK, Singheiser M, Hastings MC, Popper AN (2004) Development of ultrasound detection in American shad (Alosa sapidissima). J Exp Biol 207:155-163

Holt DE, Johnston CE (2011) Hearing sensitivity in two black bass species using the auditory brainstem response approach. Environ Biol Fishes 91:121-126

Horodysky AZ, Brill RW, Fine ML, Musick JA, Latour RJ (2008) Acoustic pressure and particle thresholds in six sciaenid fishes. J Exp Biol 211:1504-1511

Jacobs DW, Tavolga WN (1967) Acoustic intensity limens in the goldfish. Anim Behav 15:324-335

Jerko H, Turunen-Rise J, Enger PS, Sand O (1989) Hearing in the eel (Anguilla anguilla). J Comp Physiol A 165:455-459

Kenyon TN (1996) Ontogenetic changes in the auditory sensitivity of damselfishes (Pomacentridae). J Comp Physiol A 179:553-561

Kenyon TN, Ladich F, Yan HY (1998) A comparative study of hearing ability in fishes: the auditory brainstem response approach. J Comp Physiol A 182:307-318

Kleerekoper H, Roggenkamp PA (1959) An experimental study on the effect of the swimbladder on hearing sensitivity in Ameiurus nebulosus (Lesueur). Can J Zool 37:1-8

Köhler D (1973) A behavioral audiogram of juvenile carp. Experientia 29:125-127
Kojima T, Ito H, Komada T, Taniuchi T, Akamatsu T (2005) Measurements of auditory sensitivity in common carp Cyprinus carpio by the auditory brainstem response technique and cardiac conditioning method. Fisher Sci 71:95-100

Kojima T, Suga T, Kusano A, Shimizu S, Matsumoto H, Aoki S, Takai N, Taniuchi T (2010) Acoustic pressure sensitivities and effects of partical motion in red sea bream Pagrus major. Fisher Sci 76:13-20

Kratochvil H, Ladich F (2000) Auditory role of lateral trunk channels in cobitid fishes. J Comp Physiol A 186:279-289

Ladich F (1999) Did auditory sensitivity and vocalization evolve independently in otophysan fishes? Brain Behav Evol 53:288-304

Ladich F, Popper AN (2004) Parallel evolution in fish hearing organs. In: Manley G, Fay RR, Popper AN (eds) Evolution of the vertebrate auditory system. Springer, New York, pp 95-127

Ladich F, Wysocki LE (2003) How does tripus extirpation affect auditory sensitivity in goldfish? Hear Res 182:119-129

Ladich F, Wysocki LE (2009) Does speaker presentation effect auditory evoked potential threshold in goldfish? Comp Biochem Physiol A 154:341-346

Ladich F, Yan HY (1998) Correlation between auditory sensitivity and vocalization in anabantoid fishes. J Comp Physiol A 182:737-746

Laming PR, Morrow G (1981) Contribution of the swimbladder to audition in the roach, (Rutilus rutilus). Comp Biochem Physiol 69:537-541

Lechner W, Ladich F (2008) Size matters: diversity in swim bladders and Weberian ossicles affects hearing in catfishes. J Exp Biol 211:1681-1689

Lechner W, Ladich F (2011) How do albino fish hear? J Zool 283:186-192

Lechner W, Wysocki LE, Ladich F (2010) Ontogenetic development of auditory sensitivity and sound production in the squeaker catfish Synodontis schoutedeni. BMC Biol 8:10

Lechner W, Heiss E, Schwaha T, Glösmann M, Ladich F (2011) Ontogenetic development of Weberian ossicles and hearing abilities in the African bullhead catfish. PLoS ONE 6(4):e18511

Lovell JM, Findlay MM, Moate RM, Nedwell JR, Pegg MA (2005) The inner ear morphology and hearing abilities of the paddlefish (Polyodon spathula) and the lake sturgeon (Acipenser fulvescens). Comp Biochem Physiol A 142:286-296

Lovell JM, Findlay MM, Nedwell JR, Pegg MA (2006) The hearing abilities of silver carp (Hypophthalmichthys molitrix) and bighead carp (Aristichthys nobilis). Comp Biochem Physiol A 143:286-291

Lu Z, Tomchik SM (2002) Effects of a red-tide toxin on fish hearing. J Comp Physiol A 188:807-813

Lugli M, Yan HY, Fine ML (2003) Acoustic communication in two freshwater gobies: the relationship between ambient noise, hearing thresholds and sound spectrum. J Comp Physiol A 189:309-320

Mann DA, Lu Z, Popper AN (1997) A clupeid fish can detect ultrasound. Nat Lond 389:341

Mann DA, Lu Z, Hastings M, Popper AN (1998) Detection of ultrasonic tones and simulated dolphin echolocation clicks by a teleost fish, the American shad (Alosa sapidissima). J Acoust Soc Am 104:562-568 
Mann DA, Higgs DM, Tavolga WN, Souza MJ, Popper AN (2001) Ultrasound detection by clupeiform fishes. J Acoust Soc Am 109:3048-3054

Mann DA, Popper AN, Wilson B (2005) Pacific herring hearing does not include ultrasound. Biol Lett 1:158-161

Mann DA, Cott PA, Hanna BW, Popper AN (2007) Hearing in eight species of northern Canadian freshwater fishes. J Fish Biol 70:109-120

Mann DA, Wilson CD, Song J, Popper AN (2009) Hearing sensitivity of the walleye pollock. Trans Am Fish Soc 138:1000-1008

Maruska KP, Boyle KS, Dewan LR, Tricas TG (2007) Sound production and spectral hearing sensitivity in the Hawaiian sergeant damselfish, Abudefduf abdominalis. J Exp Biol 210:3990-4000

Maruska KP, Ung US, Fernald RD (2012) The African cichlid fish Astatotilapia burtoni uses acoustic communication for reproduction: sound production, hearing, and behavioral significance. PLoS ONE 7(5):e37612

Myrberg AA (1964) An analysis of the preferential care of eggs and young by adult cichlid fishes. Z Tierpsychol 21:53-98

Myrberg AA, Ha SJ, Walewski S, Branburry JC (1972) Effectiveness of acoustic signals in attracting epipelagic sharks to an underwater sound source. B Mar Sci 22:926-949

Myrberg AA, Spanier E, Ha SJ (1978) Temporal patterning in acoustical communication. In: Reese ES, Lighter FJ (eds) Contrasts in Behaviour. Wiley, New York, pp 137-179

Myrberg AA, Spires JY (1980) Hearing in damselfishes: an analysis of signal detection among closely related species. J Comp Physiol 140:135-144

Nedwell JR, Turnpenny AWH, Lovell JM, Edwards B (2006) An investigation into the effects of underwater piling noise on salmonids. J Acoust Soc Am 120:2550-2554

Nelson JS (2006) Fishes of the World. Wiley, Hoboken, NJ

Offutt GC (1968) Auditory response in the goldfish. J Aud Res 8:391-400

Oxman DS, Barnett-Johnson R, Smith ME, Coffin A, Miller DL, Josephson R, Popper AN (2007) The effect of vaterite deposition on sound reception, otolith morphology, and inner ear sensory epithelia in hatchery-reared chinook salmon (Oncorhynchus tshawytscha). Can J Fish Aquat Sci 64:1469-1478

Papes S, Ladich F (2011) Effects of temperature on sound production and auditory abilities in the striped Raphael catfish Platydoras armatulus (Family Doradidae). PLoS ONE 6:e26479

Parker GH (1903) The sense of hearing in fishes. Am Nat 37:185-204

Parmentier E, Colleye O, Mann D (2009) Hearing ability in three clownfish species. J Exp Biol 212:2023-2026

Parmentier E, Mann K, Mann D (2011) Hearing and morphological specializations of the mojarra (Eucinostomus argenteus). J Exp Biol 214:2697-2701

Poggendorf D (1952) Die absolute Hörschwelle des Zwergwelses (Amiurus nebulosus) und Beiträge zur Physik des Weberschen Apparates der Ostariophysen. Z vergl Physiol 34:222-257

Popper AN (1970) Auditory capacities of the Mexican blind cave fish (Astyanax jordani) and its eyed ancestor (Astyanax mexicanus). Anim Behav 18:552-562
Popper AN (1971) The effects of size on auditory capacities of the goldfish. J Audit Res 11:239-247

Popper AN (1972a) Auditory threshold in the goldfish (Carassius auratus) as a function of signal duration. J Acoust Soc Am 52:596-602

Popper AN (1972b) Pure-tone auditory thresholds for the carp, Cyprinus carpio. J Acoust Soc Am 52:1714-1717

Popper AN, Fay RR (1973) Sound detection and processing by teleost fishes: a critical review. J Acoust Soc Am 53: 1515-1529

Popper AN, Fay RR (1993) Sound detection and processing by fish: cirtical review and major research questions. Brain Behav Evolut 41:14-38

Popper AN, Fay RR (2011) Rethinking sound detection by fishes. Hear Res 273:25-36

Popper AN, Hawkins A (2012) The effects of noise on aquatic life. Springer, New York

Popper AN, Smith ME, Cott PA, Hanna BW, MacGillivray AO, Austin ME, Mann DA (2005) Effects of exposure to seismic airgun use on hearing of three fish species. J Acoust Soc Am 117:3958-3971

Popper AN, Halvorsen HB, Kane A, Miller DL, Smith ME, Song J, Stein P, Wysocki LE (2007) The effects of highintensity, low-frequency active sonar on rainbow trout. J Acoust Soc Am 122:623-635

Ramcharitar JU, Brack CL (2010) Physiological dimensions of ototoxic responses in a model fish species. J Clin Neurosci 17:103-106

Ramcharitar JU, Popper AN (2004) Masked auditory thresholds in sciaenid fishes: a comparative study. J Acoust Soc Am 116:1687-1691

Ramcharitar JU, Selckmann GM (2010) Differential ablation of sensory receptors underlies ototoxin-induced shifts in auditory thresholds of the goldfish (Carassius auratus). J Appl Toxicol 30:536-541

Ramcharitar J, Higgs DM, Popper AN (2001) Sciaenid inner ears: a study in diversity. Brain Behav Evolut 58:152-162

Ramcharitar JU, Deng X, Ketten D, Popper AN (2004) Form and function in the unique inner erar of the teleost: silver perch (Bairdiella chrysoura). J Comp Neurol 475:531-539

Ramcharitar JU, Higgs DM, Popper AN (2006) Audition in sciaenid fishes with different swim bladder-inner ear configurations. J Acoust Soc Am 119:439-443

Ripley JL, Lobel PS, Yan HY (2002) Correlation of sound production with hearing sensitivity in lake Malawi cichlid Tramitichromis intermedius. Bioacoustics 12:238-240

Sand O (1974) Recordings of saccular microphonic potentials in the perch. Comp Biochem Physiol 47:387-390

Sand O, Enger PS (1973) Evidence for an auditory function of the swimbladder in the cod. J Exp Biol 59:405-414

Schneider H (1941) Die Bedeutung der Atemhöhle der Labyrinthfische für ihr Hörvermögen. $\mathrm{Z}$ vergl Physiol 29: 172-194

Scholik AR, Yan HY (2001) Effects of underwater noise on auditory sensitivity of a cyprinid fish. Hear Res 152:17-24

Scholik AR, Yan HY (2002a) The effects of noise on the auditory sensitivity of the bluegill sunfish, Lepomis macrochirus. Comp Biochem Physiol 133:43-52

Scholik AR, Yan HY (2002b) Effects of boat engine noise on the auditory sensitivity of the fathead minnow, Pimephales promelas. Environ Biol Fish. 63:203-209 
Scholz K, Ladich F (2006) Sound production, hearing and possible interception under ambient noise conditions in the topmouth minnow Pseudorasbora parva. J Fish Biol 69:892-906

Schulz-Mirbach T, Ladich F, Riesch R, Plath M (2010) Otolith morphology and hearing abilities in cave- and surfacedwelling ecotypes of the Atlantic molly, Poecilia mexicana (Teleostei: Poeciliidae). Hear Res 267:137-148

Schulz-Mirbach T, Metscher B, Ladich F (2012) Relationship between swim bladder morphology and hearing abilities-a case study on Asian and African cichlids. PLoS ONE 7:e42292

Silman S, Silverman CA (1991) Auditory diagnosis: principles and applications. Chapter 1: stimuli commonly employed in audiologic tests. Academic Press, San Diego

Smith ME, Kane AS, Popper AN (2004a) Noise-induced stress response and hearing loss in goldfish (Carassius auratus). J Exp Biol 207:427-435

Smith ME, Kane AS, Popper AN (2004b) Acoustical stress and hearing sensitivity in fishes: does the linear threshold shift hypothesis hold water? J Exp Biol 207:3591-3602

Smith ME, Coffin AB, Miller DL, Popper AN (2006) Anatomical and functional recovery of the goldfish (Carassius auratus) ear following noise exposure. J Exp Biol 209:4193-4202

Smith ME, Schuck JB, Gilley RR, Rogers BD (2011) Structural and functional effects of acoustic exposure in goldfish: evidence of tonotopy in the teleost saccule. BMC Neurosci. doi:10.1186/1471-2202-12-19

Starr A, Amlie RN, Martin WH, Saunders S (1977) Development of auditory function in newborn infants revealed by auditory brainstem potentials. Pediatrics 60:831-839

Tavolga WN (1974) Signal/noise ratio and the critical band in fishes. J Acoust Soc Am 55:1323-1333

Tavolga WN, Wodinsky J (1963) Auditory capacities in fishes. Pure tone thresholds in nine species of marine teleosts. Bull Am Mus Nat Hist 126:177-240

Vasconcelos RO, Ladich F (2008) Development of vocalization, auditory sensitivity and acoustic communication in the Lusitanian toadfish Halobatrachus didactylus. J Exp Biol 11:502-509

Vasconcelos RO, Amorim MCP, Ladich F (2007) Effects of ship noise on the detectability of communicaion signals in the Lusitanian toadfish. J Exp Biol 210:2104-2112

Vasconcelos RO, Fonseca PJ, Amorim MCP, Ladich F (2011) Representation of complex vocalizations in the Lusitanian toadfish auditory system: evidence of fine temporal, frequency and amplitude discrimination. Proc Roy Soc Lond B Biol Sci 278:826-834

Weber EH (1820) De Aure et Auditu Hominis et Animalium. Pars I. De Aure Animalium Aquatilium. Gerhard Fleischer, Leipzig

Weiss BA (1966) Auditory sensitivity in the goldfish. J Aud Res 6:321-335

Weiss BA (1967) Sonic sensitivity in the goldfish (Carassius auratus). In: Cahn P (ed) Lateral line detectors. Indiana University Press, Bloomington, pp 249-264
Wilson M, Montie EW, Mann KA, Mann DA (2009) Ultrasound detection in the Gulf menhaden requires gas-filled bullae and an intact lateral line. J Exp Biol 212:3422-3427

Wolff DL (1967) Das Hörvermögen des Flußbarsches (Perca fluviatilis L.). Biol Zent bl 86:449-460

Wright KJ, Higgs DM, Cato DH, Leis JM (2010) Auditory sensitivity in settlement-stage larvae of coral reef fishes. Coral Reefs 29:235-243

Wysocki LE, Ladich F (2001) The ontogenetic development of auditory sensitivity, vocalization and acoustic communication in the labyrinth fish Trichopsis vittata. J Comp Physiol A 187:177-187

Wysocki LE, Ladich F (2002) Can fishes resolve temporal characteristics of sounds? New insights using auditory brainstem responses. Hear Res 169:36-46

Wysocki LE, Ladich F (2003) The representation of conspecific sounds in the auditory brainstem of teleost fishes. J Exp Biol 206:2229-2240

Wysocki LE, Ladich F (2005a) Hearing in fishes under noise conditions. J Assoc Res Otolaryngol 6:28-36

Wysocki LE, Ladich F (2005b) Effects of noise exposure on click detection and the temporal resolution ability of the goldfish auditory system. Hear Res 201:27-36

Wysocki LE, Davidson JW, Smith ME, Frankel AS, Ellison WT, Mazik PM, Popper AN, Bebak J (2007) Effect of aquaculture production on hearing, growth, and disease resistance of rainbow trout Oncorhynchus mykiss. Aquaculture 272:687-697

Wysocki LE, Codarin A, Ladich F, Picciulin M (2009a) Sound pressure and particle acceleration audiograms in three marine fish species from the Adriatic Sea. J Acoust Soc Am 126:2100-2107

Wysocki LE, Montey K, Popper AN (2009b) The influence of ambient temperature and thermal acclimation on hearing in an eurythermal and a stenothermal otopyhsan fish. J Exp Biol 212:3091-3099

Xiao J, Braun CB (2008) Objective threshold estimation and measurement of the residual background noise in auditory evoked potentials in goldfish. J Acoust Soc Am 124:3053-3063

Yan HY (1998) Auditory role of the suprabranchial chamber in gourami fish. J Comp Physiol A 183:325-333

Yan HY, Curtsinger WS (2000) The otic gasbladder as an ancillary structure in a mormyrid fish. J Comp Physiol A 186:595-602

Yan HY, Popper AN (1991) An automated positive reward method for measuring acoustic sensitivity in fish. Behav Res Meth Instr Comp 23:351-356

Yan HY, Popper AN (1992) Auditory sensitivity of the cichlid fish Astronotus ocellatus (Cuvier). J Comp Physiol A 171:105-109

Yan HY, Fine ML, Horn NS, Colon WE (2000) Variability in the role of the gasbladder in fish audition. J Comp Physiol A $186: 435-445$ 